\author{
Guido Gómez Peña
}

\title{
Análise de Eventos em Redes de Distribuição por meio das Transformadas Wavelet e S
}

Dissertação de Mestrado apresentada à Escola de Engenharia de São Carlos, da Universidade de São Paulo, como requisito para obtenção do título de Mestre em Ciências, Programa de Engenharia Elétrica.

Área de Concentração: Sistemas Dinâmicos.

Orientador: Prof. Dr. Ricardo Quadros Machado

\author{
São Carlos
}

2012

Trata-se da versão corrigida da dissertação. A versão original se encontra disponível na EESC que aloja o Programa de Pós-Graduação de Engenharia Elétrica. 
Autorizo a reprodução e divulgação total ou parcial deste trabalho, por qualquer meio convencional ou eletrônico, para fins de estudo e pesquisa, desde que citada a fonte.

Ficha catalográfica preparada pela Seção de Tratamento da Informação do Serviço de Biblioteca - EESC/USP

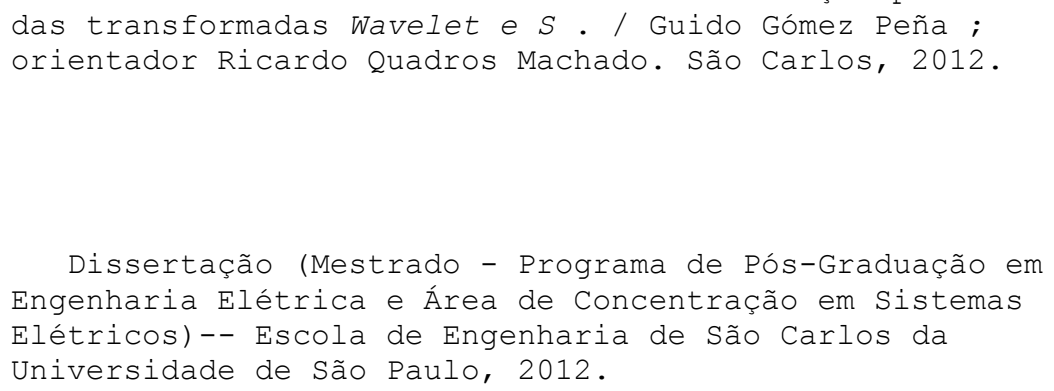




\section{FOLHA DE JULGAMENTO}

Candidato: Engenheiro GUIDO GOMEZ PENA.

Título da dissertação: "Análise de eventos em redes de distribuição por meio das transformadas Wavelet e $S^{\prime \prime}$.

Data da defesa: 02/04/2012

\section{Comissão Julgadora:}

Prof. Dr. Ricardo Quadros Machado (Orientador)

(Escola de Engenharia de São Carlos/EESC)

Prof. Dr. Enes Gonçalves Marra

(Universidade Federal de Goiás/UFG)

Prof ${ }^{\mathrm{a}}$. Titular Vilma Alves de Oliveira

(Escola de Engenharia de São Carlos/EESC)
Resultado:

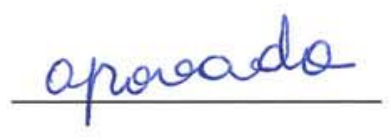

aproriado

aprovado

Coordenador do Programa de Pós-Graduação em Engenharia Elétrica: Prof. Titular Denis Vinicius Coury

Presidente da Comissão de Pós-Graduação:

Prof. Associado Paulo Cesar Lima Segantine 



\section{Agradecimentos}

A Deus.

A minha mãe, por todo o seu amor, porque todas as coisas boas que habitam em mim, vêm dela.

A meu pai, pelo seu apoio incondicional, por me ensinar que mesmo sob a mais dura couraça, haverá "fraquezas" de incalculável grandeza.

A minhas irmãs, Lili (q.e.p.d) por abrir os meus olhos e me mostrar que o local certo do lar é o coração, e a Marce por me mostrar que o lugar do coração é o lar. As duas por sua amizade e por serem guia, exemplo e companhia.

A Kate, por ser minha amiga, meu amor, minha motivação, meu presente.

A meus avôs Álvaro e Julio, e meu tio Rodrigo por serem inspiração e modelo de vida.

Ao Prof. Dr. Ricardo Quadros, pela oportunidade, o interesse e apoio neste trabalho, e, sobretudo pela amizade.

Aos amigos em Brasil, Eugenia Dager, Lianet Sepúlveda, Sara Mansour, Carol Rodrigues, Lie Yamanaka, Amilcar Gonçalves, Giovani Pozzebon, Marcelo Suetake, Renato Monaro, Marcel Cezare, Nilton Moçambique, Julian Villamarín e Jaime Mosquera. Em Colômbia, Isa Vela, Jhon Morales, Enrique Jaramillo, Juan Pablo e Santiago Andrade, vocês são grandes. Muito obrigado por tudo.

Aos professores, Vilma Alves, Enes Marras e Mario Oleskovicz pelas contribuições ao trabalho.

A secretaria da Pós - graduação em engenharia elétrica, especialmente a Jussara pelo trato, seu carisma e por tentar sempre achar uma solução rápida e eficaz.

A Cnp-q pela ajuda financeira. 



\section{Resumo}

PEÑA, G.G (2012). Análise de Eventos em Redes de Distribuição por meio das Transformadas Wavelet e S. Dissertação (Mestrado) - Escola de Engenharia de São Carlos, Universidade de São Paulo, 2012.

O presente trabalho apresenta uma comparação de duas técnicas para a análise tempo - frequência em análise de Qualidade de Energia Elétrica para sinais de tensão que contenham distúrbios individuais ou simultâneos. Dessa forma, o objetivo, desta dissertação, é encontrar uma ferramenta que forneça as características e parâmetros para a localização, identificação e classificação de tais distúrbios. 0 estudo consiste na análise do desempenho da Transformada Wavelet Discreta e da Transformada-S, principalmente, quando os sinais são analisados na presença de múltiplos distúrbios. Ambas as transformadas fornecem informação importante nos domínios do tempo e da frequência. No entanto, essas ferramentas não tem sido amplamente exploradas para análise de múltiplos distúrbios. Neste contexto, ambas as transformadas são testadas para conhecer seus desempenhos e suas capacidades de identificação e localização de eventos de qualidade de energia elétrica. Para finalizar, é projetado um sistema classificador baseado em arvore de decisão capaz de reconhecer quinze tipos de distúrbios diferentes.

Palavras chave - - Qualidade de Energia Elétrica, Transformada-S, Transformada Wavelet. 



\begin{abstract}
PEÑA,G.G (2012). Event Analysis in Distribution Networks using Wavelet and S Transform. Dissertação (Mestrado) - Escola de Engenharia de São Carlos, Universidade de São Paulo, 2012.

\section{Abstract}

This work presents a comparison of two methods for time-frequency analysis applied in Power Quality signals containing single or multiple disturbances. In this way, the aim of this work is to apply tools that supply the parameters and characteristics to identify, locate and classify Power Quality disturbances. For that, the proposed method analyzes the performance of the Wavelet and S transforms, mainly when the signals are with more than one disturbance type. Both mathematical tools supply important information on the time and frequency domain. However, these tools have not been thoroughly used to analyze multiple events locate Power Quality events. In this contest, both transforms are tested in order to assess their performance to identify and locate electrical power quality events. According to a decision tree classifier, fifteen types of single and combined power disturbances are well recognized.
\end{abstract}

Key words - - Power Quality, wavelet transform, S transform 



\section{Lista de Figuras}

Figura 3.1 Transitório oscilatório causado por chaveamento de banco de capacitores. .38

Figura 3.2. Valor RMS da tensão para múltiplos afundamentos. ................................39

Figura 3.3. Exemplo de elevação de tensão ...................................................................40

Figura 3.4. Exemplo de harmônicos. …………........................................................43

Figura 3.5. Exemplo de notching causado por conversor trifásico ...........................44

Figura 3.6. Flutuação de tensão causada pela operação de forno de arco................45

Figura 4.1 Dilatação e translação da wavelet ................................................................. 50

Figura 4.2 Resolução da transformada wavelet..........................................................51

Figura 4.3. Árvore de decomposição da TWD...............................................................57

Figura 5.1. Composição de um sinal de QEE. (a) senoide puro, (b) sinal harmônico, (c) sinal com transitório oscilatório, e (d) sinal resultante......................................................65

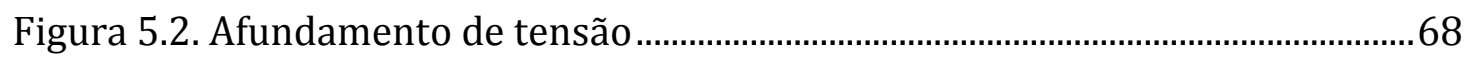

Figura 5.3. Transformada S aplicada em afundamento de tensão...............................69

Figura 5.4. Transformada wavelet discreta aplicada em afundamento de tensão. .70

Figura 5.5. Transitório oscilatório............................................................................. 70

Figura 5.6. Transformada S aplicada em um sinal com transitório oscilatório......71

Figura 5.7. Transformada wavelet discreta de transitório oscilatório. .......................72

Figura 5.8. Sinal com harmônicos: $3^{\mathrm{a}}$ e 9a

Figura 5.9. Transformada S aplicada em um sinal com conteúdo harmônico. .......73

Figura 5.10. Transformada wavelet discreta aplicada em sinal com harmônicos.74

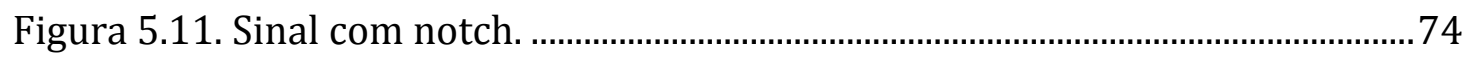

Figura 5.12. Transformada S aplicada em um sinal com notch. ..................................75 
Figura 5.13. Transformada wavelet discreta aplicada em um sinal com notch..... 76

Figura 5.14. Sinal com afundamento de tensão e transitório oscilatório. 76

Figura 5.15. Transformada S aplicada em um sinal com afundamento e transitório oscilatório.

Figura 5.16. Transformada wavelet discreta aplicada em um sinal com afundamento de tensão e transitório oscilatório. 78

Figura 5.17. Sinal com afundamento de tensão e notch. 78

Figura 5.18.Transformada S aplicada em um sinal com afundamento de tensão e notch 79

Figura 5.19. Transformada wavelet discreta aplicada em um sinal com afundamento de tensão e notch. 80

Figura 5.20. Sinal com conteúdo harmônico e elevação de tensão. 80

Figura 5.21. Transformada S aplicada em um sinal com harmônicos e elevação de tensão 81

Figura 5.22. Transformada wavelet aplicada em sinal com harmônicos e elevação de tensão 82

Figura 5.23. Sinal com elevação de tensão e transitório oscilatório. 82

Figura 5.24. Transformada S aplicada em um sinal com elevação de tensao e transitório oscilatório. .83

Figura 5.25. Transformada wavelet aplicada em um sinal com elevação de tensão e transitório oscilatório. 84

Figura 5.26. Fluxograma do sistema classificador. 89 


\section{Lista de Tabelas}

Tabela 3.1. Categorias e características dos distúrbios em sistemas de potência.36

Tabela 5.1. Distúrbios de qualidade de energia considerados. 64

Tabela 5.2. Equações paramétricas de distúrbios de QEE...........................................66

Tabela 5.3. Faixas de frequências de cada nível decomposto pela TWD. .................67

Tabela 5.4. Classificação de distúrbios. ........................................................................91 



\section{Índice}

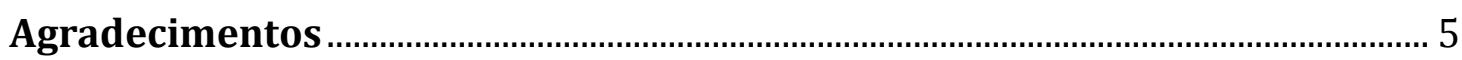

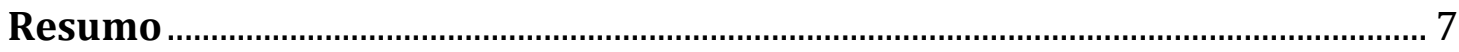

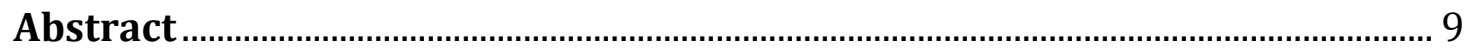

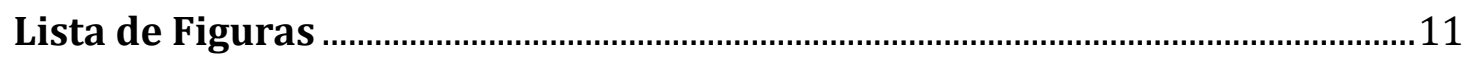

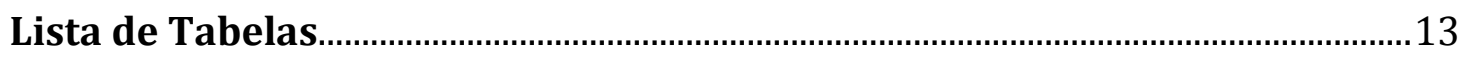

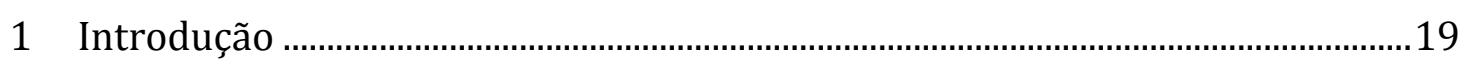

1.1 Estrutura e organização da dissertação ……………………………………...23

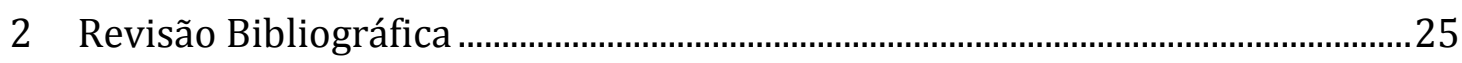

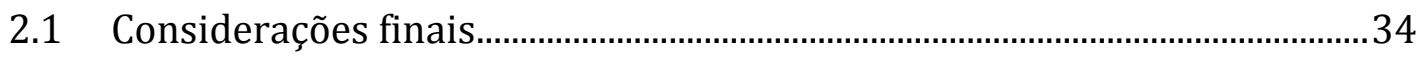

3 Qualidade de Energia Elétrica ........................................................................................35

3.1 Transitórios .......................................................................................................37

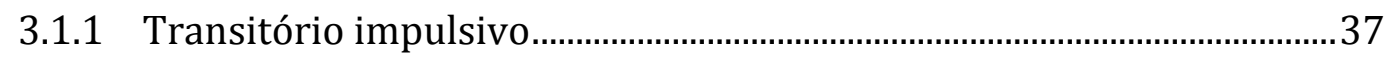

3.1.2 Transitório oscilatório ………………………………………………….....

3.2 Variação de tensão de curta duração..................................................................38

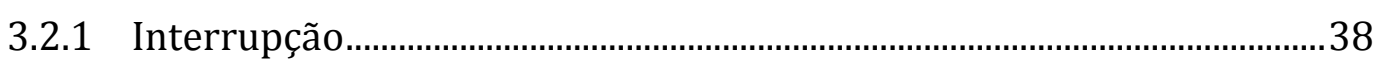

3.2.2 Afundamento …………………………………………………………….....

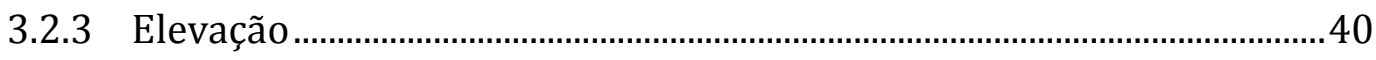

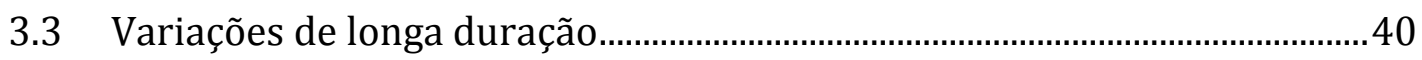

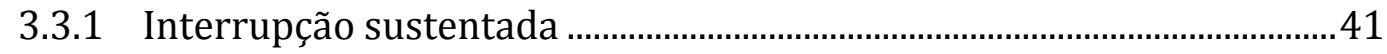




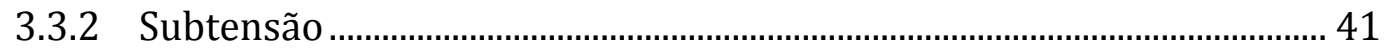

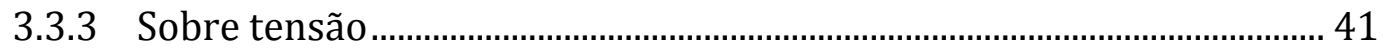

3.4 Desequilíbrio de Tensão ...................................................................................... 41

3.5 Distorção da forma de onda ............................................................................... 42

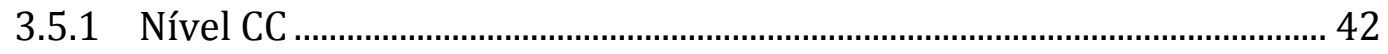

3.5.2 Harmônicos......................................................................................................... 42

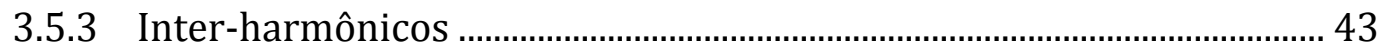

3.5.4 Notching .............................................................................................................. 43

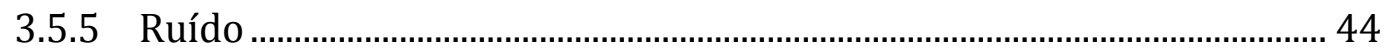

3.6 Flutuação de tensão ............................................................................................... 44

3.7 Variação da frequência do sistema ..................................................................... 45

3.8 Considerações finais........................................................................................... 46

4 Análise Tempo Frequência .............................................................................................. 47

4.1 Transformada wavelet ............................................................................................ 48

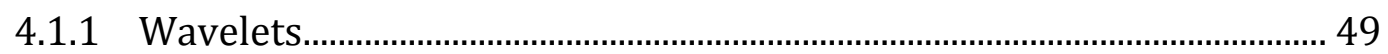

4.1.2 Transformada wavelet contínua (TWC).................................................... 50

4.1.3 Transformada wavelet discreta (TWD) .................................................. 52

4.2 Transformada S ................................................................................................... 57

4.2.1 Vista da transformada-S a partir da transformada de Fourier de tempo curto 58

4.2.2 Vista da transformada-S a partir da transformada wavelet contínua 60

4.2.3 Transformada-S discreta (TSD) …………………………………………....... 61

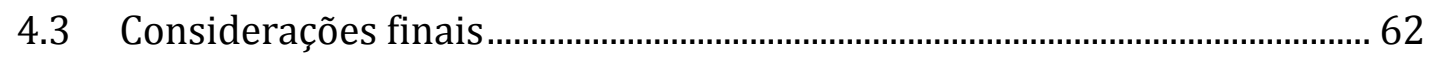

5 Análise de Distúrbios ................................................................................................. 63

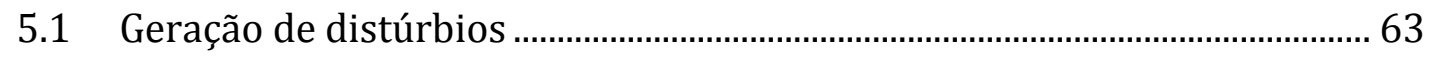

5.2 Transformada S e Wavelet - Análise gráfica em tempo e frequência.......... 66 


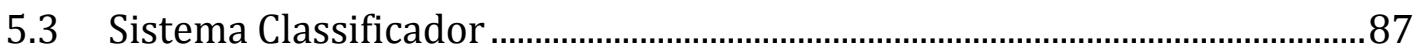

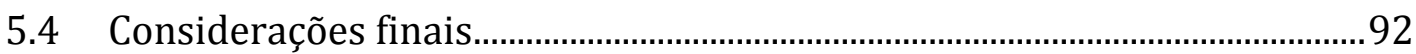

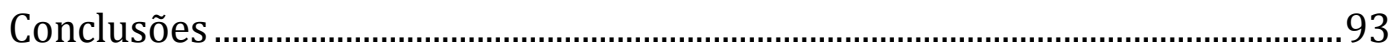

Referências Bibliográficas .................................................................................. 95 



\section{Capítulo 1}

\section{Introdução}

A Qualidade de Energia Elétrica (QEE) está relacionada a uma ampla variedade de fenômenos eletromagnéticos que caracterizam a tensão, corrente e frequência em um determinado instante e em uma localização especifica no sistema elétrico de potência (IEEE Std-1159, 2009). Além disso, esses fenômenos podem causar deterioração, falhas ou má operação tanto de equipamentos eletro-eletrônicos quanto de dispositivos de proteção (DUGAN et al., 2002).

Geralmente o termo QEE é sinônimo de qualidade de tensão, isto se deve ao fato de que os sistemas de geração estão projetados para operar em tensão senoidal e com uma frequência e amplitude específica e sem nenhum controle sobre as correntes fornecidas aos consumidores. No entanto, existe uma interação entre corrente e tensão, dado que uma variação considerável de corrente pode causar deformações na onda da tensão afetando sua qualidade. Dentro destes eventos é possível citar os seguintes:

1. Correntes resultantes de curto-circuito produzem afundamentos ou quedas de tensão; 
2. Correntes elevadas, como as produzidas por descargas atmosféricas, podem gerar impulsos na forma de onda da tensão, além de causarem rompimento no isolamento elétrico entre os condutores;

3. Correntes com distorções harmônicas resultantes da operação de cargas não lineares distorcem as tensões em virtude da impedância do sistema no acoplamento comum (PAC).

Com a finalidade de estabelecer uma padronização dos diferentes eventos indesejáveis que podem alterar o estado de regime permanente da tensão ou da corrente, a IEEE determina: "Práticas Recomendadas Sobre o Monitoramento de QEE" IEEE Standard 1159 (1995), um delineamento das definições e procedimentos, que permitem observar, de modo detalhado, os conceitos e as abordagens referentes à QEE. Nesta norma, podem-se encontrar uma classificação dos vários tipos de eventos tais como notches, harmônicos, transitórios, interrupções, elevações, afundamentos e flutuações de tensão etc. Por sua vez, no Brasil, estipularam-se padrões relacionados à QEE que podem ser encontrados no modulo 8 de ANEEL (2009), que além de fornecer a terminologia, parâmetros e valores de referencia relativos a tensão em regime permanente, visa a estabelecer os procedimentos relativos a QEE abordando a qualidade do produto e do serviço.

Destaca-se que a ocorrência de qualquer distúrbio pode tornar o sistema susceptível a um novo distúrbio, que pode acontecer de forma seqüencial ou simultânea.

Atualmente, a QEE tem-se tornado um tema de muito interesse tanto para concessionárias, quanto para a indústria e consumidores devido a diversos fatores: equipamentos e sistemas de controle sensíveis a variâncias de tensão ou corrente, sistemas de potencia projetados para serem mais eficientes aumentando os níveis de harmônicos e o aumento de dispositivos interligados na rede, assim como o aumento no nível de conscientização dos consumidores no tema de qualidade no fornecimento (DUGAN et al., 2002), e é este último que faz com que a energia elétrica seja vista como um produto, de modo tal que como produto deve cumprir com um certo critério de qualidade (BROSLN, 2007).

Diante disso, nos últimos anos a necessidade de reduzir os problemas relacionados à QEE, tem levado ao desenvolvimento e aplicação de diversas metodologias que permitam de forma confiável a identificação e o reconhecimento 
automático dos diferentes distúrbios. Dentre os apontamentos encontrados, pode-se observar o uso de metodologias que envolvem ou compreendem duas áreas, uma encarregada de abstrair informações importantes que definem um problema em particular e a segunda, de processar esta informação para definir, de forma automática, a classe ou tipo de distúrbio ao qual pertencem (GRANADOS et al., 2011).

No ato de encontrar informações importantes dentre os sinais sob análise, diferentes abordagens tem sido empregados para QEE. Isto, devido a que na análise de sinais é usual representá-los em função do tempo ou no domínio da frequência, sendo que em ambos possuem as mesmas informações em relação ao sinal analisado, entretanto respondem a abordagens diferentes e complementares (CHUI, 1992).

A técnica mais usada na análise de frequência é a Transformada de Fourier que permite conhecer os componentes em frequência de um sinal, no entanto, apresenta duas desvantagens, a primeira surge devido ao fato de que as informações temporais são espalhadas dentro do espectro de frequência perdendo informação de transitórios e/ou localizações específicas dentro do sinal, já a segunda, deriva da anterior, sendo que apresenta limitações para análise de sinais não estacionárias. Não obstante, para solucionar o problema são utilizadas as janelas temporais que permitem obter uma representação da variação espectral ao longo do tempo. A idéia do uso de janelas é conhecida como transformada de Fourier de tempo curto (STFT, do inglês Short Time Fourier Transform) que permite o estudo de sinais variantes no tempo. Contudo, para sinais que apresentam variações rápidas é difícil estabelecer uma janela de dimensão apropriada que evite a perda de informação. Pelo que foi mencionado anteriormente, é preciso procurar técnicas que se comportem mais adequadamente na extração de informações nos domínios do tempo e frequência (VETTERLI e HERLEY, 1992).

A análise em tempo e frequência fornece um método adequado para o tratamento de sinais não estacionários. Por meio desta técnica é possível mapear sinais num espaço de duas dimensões, tempo e frequência, proporcionando uma visão melhorada das características temporais e espectrais do sinal. Deste modo, é possível diferenciar componentes locais, transitórios ou esporádicos que só podem ser obtidos mediante métodos espectrais (ADDISON et al., 2009).

Atualmente, existem diferentes métodos para análise tempo frequência como a transformada Wavelet e a transformada $\mathrm{S}$, além de métodos quadráticos como as 
distribuições de Wigner -Ville e Cho William, etc. No entanto, os métodos quadráticos apresentam dados inexistentes resultantes da natureza quadrática das transformadas que são conhecidos como termos cruzados, podendo obscurecer características reais de interesse (ADDISON et al., 2009).

0 objetivo principal, do uso da análise tempo frequência, é obter uma melhor representação dos eventos presentes no sinal para a subseqüente classificação automática. Para conseguir uma classificação confiável, diversas técnicas têm sido empregadas com a finalidade de determinar as características que definem cada um dos eventos. Na análise de distúrbios de QEE, dentre os classificadores encontrados na literatura e que se destacam podem-se citar: as redes neurais artificiais, a lógica fuzzy, support vector machine e as arvores de decisão. Estes classificadores, mesmo sendo robustos, dependem dos dados fornecidos pela etapa anterior, que corresponde à extração de características particulares, para assim conseguir um desempenho satisfatório.

Como será descrito no capitulo seguinte, na revisão bibliográfica, encontrou-se grande quantidade de trabalhos que fazem uso das transformadas wavelet ou $\mathrm{S}$ em combinação com um sistema classificador, como mencionado acima, no entanto a maioria destes trabalhos estão focados na análise e classificação de distúrbios isolados, tratados de forma independente, deixando uma área quase inexplorada, quando diferentes distúrbios acontecem de forma seqüencial ou simultânea, fato que motiva e converte-se no foco deste trabalho.

Neste contexto, este trabalho apresentará uma metodologia de análise de múltiplos sinais de QEE com presença de distúrbios individuais, seqüenciais ou simultâneos, através da análise tempo frequência baseada na Transformada Wavelet e na Transformada S. Para isto, é gerado um banco de dados que contém quinze tipos ou combinações de distúrbios, baseado em sinais sintéticos obtidos através de equações paramétricas. Como primeiro passo são avaliadas as duas transformadas em relação à quantidade de características fornecidas e a sua capacidade de separar distúrbios contidos num mesmo sinal. Uma vez é definida a transformada que forneça melhores características procede-se a definir um sistema classificador simples que determine para cada caso apresentado, a saída esperada. 


\subsection{Estrutura e organização da dissertação}

O capitulo seguinte faz referencia a revisão bibliográfica, mostrando trabalhos importantes que darão base na consecução deste trabalho. No capítulo 3, serão apresentados os conceitos relacionados aos principais distúrbios de qualidade de energia elétrica. 0 capítulo 4 apresenta a fundamentação teórica da Transformada Wavelet e da Transformada-S, ferramentas fundamentais e foco no desenvolvimento do trabalho. 0 capitulo 5 mostra como são obtidos os sinais com distúrbios, o desempenho da Transformadas Wavelet e S na extração de características dos distúrbios e por ultimo é apresentado o sistema classificador. Finalmente, no capítulo 6, são apresentadas as conclusões e seqüência deste trabalho. 



\section{Capítulo 2}

\section{Revisão Bibliográfica}

Este capítulo apresenta alguns dos trabalhos importantes sobre a temática desenvolvida nesta dissertação, abordando as diferentes técnicas e metodologias utilizadas por pesquisadores ao redor do mundo, mostrando-se em destaque trabalhos que utilizam ferramentas para analise em tempo-frequência, com o intuito de criar uma visão global da análise de QEE.

Como primeira instância serão abordados trabalhos focados na metodologia que usa a transformada wavelet bem como, a transformada S. Além disso, deve-se considerar que cada um dos artigos escolhidos mostram algum tipo de sistema de classificação, isto permitirá observar o trabalho conjunto das técnicas e o desempenho obtido.

Na atualidade, a transformada wavelet é a ferramenta mais popular utilizada para obtenção de características no domínio do tempo e da frequência (JENSEN e LA COURHARBO, 2001). Na análise de eventos de QEE foi introduzida por Ribeiro (1994) na análise de sinais não estacionarias em sistemas de potencia, e dois anos depois como método de análise de transitórios por Robertson (1996) e Santoso (1996), explorando a capacidade de decompor um sinal mediante o uso da análise de multiresolução (AMR), em versões suavizadas, aproximações, e versões detalhadas, que permitem visualizar 
componentes tanto em baixas como em altas frequências. Além disso, destaca-se a necessidade de projetar um sistema capaz de classificar automaticamente os distúrbios presentes no sistema elétrico.

Por outro lado, Dash (2003), introduz a transformada-S como método de analise tempo - frequência na análise de distúrbios de QEE, considerando o fato que a transformada S é uma extensão das idéias da transformada wavelet e que além de apresentar uma excelente resolução tempo - frequência, fornece informação valiosa da fase do sinal.

Desta forma, múltiplos trabalhos abordam a análise de sinais com distúrbios utilizando tanto a transformada wavelet como a transformada $S$, devido à capacidade de fornecer informações das componentes em tempo e frequência de forma simultânea.

Uma vez estabelecida uma ferramenta para extração de características próprias de um sinal, neste caso as transformadas wavelet e $S$, procede-se a procura de um sistema capaz de receber estas características e decifrar, dentre as suas composições, semelhanças que possam ser agrupadas em classes conhecidos como classificadores. Os classificadores mais usados em QEE são as redes neurais artificiais, a lógica fuzzy e o support vector machine, no entanto alguns outros como arvores de decisão, modelos ocultos de Markov, algoritmos genéticos e classificadores bayesianos são também utilizados. Alguns artigos que apresentam a combinação das técnicas de análise e classificação citadas acima e que são de interesse para o desenvolvimento do trabalho são expostos seguir.

Em Santoso et al. (2000a; b) exploraram a utilização de redes neurais artificiais, como classificadores automáticos de distúrbios combinado com a transformada wavelet estudada em trabalhos anteriores. Na primeira parte, é mostrada a fundamentação teórica necessária na construção do classificador neural tipo LVQ (Learning Vector Quantization). Na segunda parte, do trabalho, são aplicados os conceitos estabelecidos na primeira parte, para classificação de eventos como chaveamento de capacitores (rápidos e lentos), senoide pura, transitórios impulsivos, afundamento de tensão e interrupções momentâneas. Cabe ressaltar que os sinais que pertencem as primeiras quatro categorias são analisados e classificados no domínio wavelet (tempo frequência) e os sinais das duas categorias restantes são classificados no domínio do 
tempo. Os resultados obtidos mostram uma eficiência de 92,3\% para o primeiro grupo e $98,51 \%$ para o segundo.

Abdel-Galil et al. (2005) apresentam uma nova abordagem para classificação de distúrbios de QEE mediante o uso de Modelos ocultos de Markov (HMM do inglês hidden Markov Models). 0 método é projetado para a classificação de transitórios oscilatórios, sinal senoidal puro, afundamento e elevação de tensão, harmônicos e flutuação de tensão. Este método esta dividido em três etapas: o uso da transformada wavelet (TW) ou transformada de Fourier (TF) na extração de características que garantam atributos diferenciáveis entre cada tipo de evento; um sistema de codificação dos atributos baseado em quantização vetorial (VQ, do inglês vector quantization); e os HMM como sistema classificador. As seis classes de eventos são geradas através de simulações tanto no Matlab como em EMTDC/PSCAD, levando em conta que no segundo software são inseridos diferentes níveis de ruído nos sinais. As transformadas wavelet e Fourier são testadas em separado, com a finalidade de definir qual destas apresenta um melhor desempenho dentro do método planejado. Para os sinais gerados na plataforma Matlab, a TW apresenta um melhor desempenho atingindo um 98\% de eficiência sobre a TF que alcançou um 97,83\%; enquanto para os sinais gerados em EMTDC/PSCAD, a TF consegue atingir um $96 \%$ sobre o $95,17 \%$ da TW.

Alem da comparação entre as duas transformadas, os autores realizam uma comparação com classificadores baseados em redes neurais artificiais (RNA). Os critérios avaliados são: taxa de acerto, treinamento, teste, velocidade de processamento e escalabilidade, estabelecendo um melhor desempenho de HMM em relação às RNA's.

Janik e Lobos (2006) propõem um método de classificação de distúrbios utilizando support vector machine (SVM) e realiza, de forma paralela, uma comparação com o desempenho obtido por uma RNA configurada em função de base radial (RBF, do inglês radial basis function). Como entradas para os classificadores é proposta a extração de características mediante a transformada wavelet, fazendo uso da família daubechies 6. É importante ressaltar que os distúrbios considerados são: elevação, afundamento e flutuação de tensão, harmônicos e transitórios oscilatórios, os quais são modelados mediante equações paramétricas. Os resultados obtidos indicam um melhor desempenho do classificador SVM com uma media de acerto de 98,75\% contra 84,58\% obtido com o uso da RBF, mostrando também que o classificador SVM apresenta um 
melhor desempenho quando sinais com presença de ruído são analisados. Além da classificação anterior, os autores, para o caso exclusivo de afundamentos de tensão, inserem a idéia do uso de um fasor de espaço (space phasor) que aplicado quando as três fases do sistema estão sob análise permite uma melhor diferenciação dos padrões encontrados na análise em uma só fase e diminui o esforço computacional.

Reaz et al. (2007) aborda o uso da TW em conjunto com um classificador que incorpora RNA's e lógica Fuzzy, desenvolvido na plataforma VHDL (Very High Speed Integrated Circuits Description Language), fazendo com que seja obtida uma taxa de acerto de 98,19\% na classificação dos diferentes distúrbios. Os distúrbios analisados incluem transitórios, interrupção, afundamento, elevação e flutuação de tensão. 0 processo de classificação começa com a extração de características particulares de cada distúrbio aplicando a TW discreta, usando a família Daubechies-4, sendo cada sinal decomposto em cinco níveis de resolução. Como a RNA é adotada uma rede neural otimizada univariável (URONN, do inglês univariate randomly optimized neural network). A URONN é escolhida porque é uma rede robusta, necessita de uma menor quantidade de cálculos e mediante uma busca randômica dos pesos consegue minimizar o erro de forma rápida. No entanto, a saída da rede pode conter algumas imprecisões, para o qual, os autores inserem uma última etapa baseada em lógica fuzzy que por meio do uso de regras pretende corrigir decisões erradas feitas pela RNA e assim, garantir maior acerto na classificação.

Oleskovicz et al. (2009) apresentam um sistema capaz de identificar, localizar e classificar diferentes distúrbios de QEE fazendo uso da TW e RNAs. Os distúrbios a serem analisados são: senoide pura, transitório oscilatório, ruído, afundamento, elevação e interrupção de tensão, gerados no software ATP (Alternative Transient Program). Este sistema denominado pelos autores como sistema hibrido esta composto por duas etapas ou estágios. A primeira etapa, projetada para identificar e localizar temporalmente qualquer anormalidade presente no sistema recebe informação advinda de uma janela de análise de comprimento correspondente a um ciclo do sinal $(60 \mathrm{~Hz})$, que por sua vez é deslocada um quarto de ciclo para cada nova entrada ao sistema. Para este conjunto de dados fornecidos é aplicada a TW utilizando a família symlet de quatro coeficientes (sym-4). Cada primeiro detalhe da TW é comparado com um limiar preestabelecido que define a existência de distúrbios. Enquanto o sistema não identificar 
anomalias, este continua a analisar o sinal, caso contrário, ativa a segunda etapa do sistema. Uma vez que a segunda etapa esteja ativada, a janela com a informação do distúrbio é decomposta em sete níveis de resolução mediante TW. Nesta etapa a wavelet, a ser utilizada pertence à família Haar. A seguir, é aplicado o teorema de Parseval com a finalidade de calcular a energia de cada nível. Os sete níveis são distribuídos em três grupos segundo a faixa de frequência à qual pertencem: baixa, media ou alta. Para cada um dos três grupos encontra-se o valor médio que serão as entradas do classificador, formado por cinco RNAs cada uma responsável pela classificação de um distúrbio em particular. Foram adotadas duas arquiteturas de RNA: perceptrón multicamada (PMC) e função de base radial (RBF). As RNAs são treinadas individualmente, testadas e finalmente são comparadas às duas arquiteturas adotadas. 0 sistema para a arquitetura PMC apresenta uma taxa global de acerto de 91,03\% em tanto com a RBF obteve $87,07 \%$. Para finalizar, os autores com o intuito de validar o sistema proposto analisam múltiplos casos reais de afundamentos e transitórios oscilatórios do sistema elétrico brasileiro, obtendo melhores resultados com a arquitetura RBF.

Panigrahi e Pandi (2009) apresentam um método de classificação automática de distúrbios de QEE utilizando a transformada wavelet packet (WPT, do inglês, Wavelet Packet Transform) e um classificador FkNN (fuzzy k-nearest neighbour), baseado no algoritmo do vezinho mais próximo, mais conhecido por as suas siglas em inglês kNN $(k$ nearest neighbour) que incorpora funções de pertinência fuzzy. No artigo são analisados diferentes tipos de distúrbios como notching, spikes, harmônicos, transitórios oscilatórios, afundamento, elevação, interrupção e flutuação de tensão, além de analisar alguns distúrbios quando acontecem de forma simultânea, neste caso, afundamento e elevação de tensão com presença de harmônicos, formando um total de dez distúrbios a serem analisados. Os sinais para a análise são obtidos utilizando modelos paramétricos dos distúrbios de QEE. O método inicia todo o processo extraindo informações do quarto nível de resolução decomposto pela WPT fazendo uso do software Matlab. 0 quarto nível está composto por um total de dezesseis aproximações e detalhes, dividindo a frequência do sinal em um número igual de faixas. Deve-se esclarecer que a WPT é uma generalização da TW que decompõe tanto as aproximações como também os detalhes de cada nível do sinal, permitindo obter um maior número de faixas de frequência do sinal 
em análise. As informações contidas nas aproximações e detalhes do quarto nível são utilizadas para encontrar as seguintes seis características estadísticas: energia, desvio padrão, média, kurtosis, skewness e entropia de shannon. Portanto, uma vez calculadas todas as características estatísticas para as faixas de frequência pertencentes ao quarto nível, tem-se um vetor de características de comprimento noventa e seis ( $6 \times 16$ ), que serão as entradas ao classificador. O classificador escolhido corresponde ao FkNN que, segundo os autores, fornece soluções ótimas em problemas de classificação, dando maior garantia de que a classificação seja correta. No entanto, os autores advertem que o uso de muitas entradas ao classificador aumenta consideravelmente o tempo de processamento e por isso que projetam um algoritmo genético (AG) com a finalidade de encontrar dentre todas as características a mais representativa para cada faixa de frequência, que permitam uma taxa de acerto alta, sem uso excessivo de informação e em um tempo de processamento adequado. Os resultados são apresentados de modo que é possível observar a taxa de acerto quando algumas ou todas as características estatísticas são utilizadas, como também quando o AG escolhe as características mais significativas. A eficiência do uso do AG proporciona uma média de 96,27\% de acerto, sendo superior às outras. Para finalizar, os autores geram dados práticos com uma bancada de laboratório conseguindo uma taxa de acerto de 96,33\%, demonstrando assim a eficácia do método desenvolvido.

Masoum et al (2010) propõem um método baseado na combinação da TWD e uma rede wavelet para reconhecimento e classificação de distúrbios de QEE. São estabelecidos quatro passos ou etapas: eliminação de ruído, detecção do distúrbio, extração de características e treinamento/teste da rede wavelet. A eliminação do ruído é realizada pela TWD (sym -4) eliminando os coeficientes abaixo do limiar advindo da combinação do método do estimador de risco imparcial de Stain e limiarização universal, permitindo a eliminação do ruído sem perda de energia do sinal uma vez este seja reconstruído. A detecção do distúrbio é feita mediante o uso de um "critério de identificação" baseado na definição generalizada da distorção harmônica total aplicada no domínio wavelet. Quando o critério de identificação é maior do que um, indica que há presença de distúrbio e procede-se a extrair as suas características relevantes, caso contrario as amostras são descartadas e continua-se com um novo conjunto de dados. 0 uso da análise de componentes principais fornece uma combinação ótima de oito 
vetores característicos que retêm as informações mais importantes do sinal original, sendo estes as entradas ao classificador. 0 classificador, como dito anteriormente, é uma rede wavelet cuja diferença de outras, é o uso de wavelets como funções de ativação, facilitando o processo de treinamento com uma melhor generalização, em conseqüência, melhor desempenho comparada com RNAs tradicionais. 0 método é projetado para identificar e classificar dezesseis distúrbios de QEE, sendo que oito são distúrbios individuais e os restantes uma combinação de dois deles (ex. afundamento mais transitório oscilatório). Os resultados obtidos apresentam uma media de 98,18\% de acerto mostrando a eficácia do método proposto. Um ponto importe a realçar na busca da wavelet a utilizar é o teste de 40 diferentes famílias mostrando que a sym-4 é mais precisa superando as outras famílias testadas.

Chilukuri e Dash (2004) propõem um sistema de reconhecimento de padrões para eventos de QEE. Determinado por duas etapas o sistemas envolve o uso da transformada S (TS) para obter vetores característicos de cada distúrbio sob análise na primeira etapa, e a seguir um sistema classificador fuzzy recolhe informações de amplitude e do desvio padrão calculado sobre os resultados fornecidos pela TS, de forma que mediante regras lingüísticas organiza ou distribui os sinais em sua determinada classe alcançando uma media de acerto de 98\%. Os distúrbios utilizados no estudo são: elevação, afundamento e interrupção de tensão, notching, spikes, harmônicos e transitórios oscilatórios. Além disso, os autores introduzem nos sinais três diferentes graus de ruído, sendo estes de 40, 30 e 20 decibéis (dB) obtendo taxas de acerto de $99,28 \%, 96,50 \%$ e $75 \%$ respectivamente.

Fengzhan e Rengang (2007) fazendo uso das vantagens da TS propõem um método para detectar e classificar dez tipos de distúrbios de QEE de forma simples e sem necessidade de um classificador robusto. As características particulares de cada distúrbio são abstraídas da aplicação da TS, dado que a resposta gerada pela transformada é uma matriz cujo conteúdo fornece valores tanto de frequência, amplitude e localização no tempo. Deste modo, são analisadas quatro formas de onda ou curvas: (1) curva de amplitude máxima, que mostra os componentes em frequência e a sua amplitude máxima; (2) curva de desvio padrão, mostra a frequência versus o desvio padrão da TS em cada frequência; (3) curva da frequência fundamental, mostra variações na amplitude na frequência fundamental, sendo que seu valor para um sinal 
sem distúrbio deve ser constante; (4) curva de amplitude média, mostra a frequência versus a média da ST para cada frequência. Baseando se nas curvas anteriormente mencionadas, são estabelecidas regras capazes de classificar distúrbios. Os distúrbios considerados no estudo foram interrupção, afundamento e elevação de tensão, Spike, notch, ruído, transitórios, harmônicos além de afundamento e elevação com conteúdo harmônico. Com o intuito de mostrar a efetividade do método proposto, os autores inserem níveis de ruído de 40, 30 e 20 decibéis conseguindo uma taxa de acerto de $99,7 \%, 98,5 \%$ e $93,8 \%$ respectivamente.

Gargoom et al. (2008) apresentam uma técnica para o monitoramento de eventos de QEE baseado na análise multiresolução da ST e o teorema de Parseval. Da TS são extraídos os vetores das frequências instantâneas, seguido pelo calculo da energia de cada uma delas usando o teorema de Parseval, isto permite distinguir e diferenciar distintos tipos de distúrbios, elevação, afundamento e interrupção de tensão, transitórios e harmônicos. Os eventos de QEE são gerados fazendo uso de equações paramétricas. 0 uso do vetor das energias das frequências instantâneas permite diferenciar em três zonas a atuação dos diferentes distúrbios, é assim como na zona 1 podem se encontrar interrupções, afundamentos e elevações de tensão, na zona 2 agrupam se sinais com conteúdo harmônico, e já na zona 3 transitórios oscilatórios. No entanto, os autores determinam que não só é importante classificar distúrbios como também determinar as características que o definem. Assim para cada uma das zonas são calculados parâmetros que alem de diferenciar melhor os distúrbios, permitem conhecer valores como magnitude, duração, distorção harmônica total (THD) e frequência de oscilação, todas estas extraídas do analise de energias proposto. Com a finalidade de demonstrar a funcionalidade desta técnica, diferentes eventos de QEE são gerados utilizando a plataforma SimPowerSystem Blockset de Simulink conseguindo classificar e caracterizar apropriadamente os eventos testados.

Bhende et al. (2008) projetam um sistema classificador de distúrbios de QEE baseado na TS e redes neurais artificiais modulares. Para o desenvolvimento do trabalho são considerados onze tipos de distúrbios sendo senóide pura, flutuação, afundamento, elevação e interrupção de tensão, harmônicos, notch, spike, transitórios e por último, afundamento e elevação com conteúdo harmônico. 0 calculo da TS proporciona parâmetros de magnitude, localização temporal (tempo), frequência e fase do sinal. 
Fazendo uso destes parâmetros, são estabelecidas quatro variáveis que definirão as diferencias entre os distúrbios: a variável 1 e 2 correspondem ao desvio padrão e energia das magnitudes máximas da TS respectivamente; a variável 3 é o desvio padrão do contorno das frequências e a variável 4 é o desvio padrão do contorno da fase. 0 sistema classificador esta projetado em vários módulos, cada módulo contém uma RNA capaz de reconhecer um distúrbio especifico, estas RNAs estão configuradas como perceptrón multicamada com função de ativação tangente hiperbólica. Com o intuito de mostrar o desempenho do classificador composto por varias RNAs, realiza-se uma comparação com um classificador composto de uma RNA que recebe as mesmas informações, esta comparação determina que o uso de RNAs específicas fornecem um melhor desempenho, menor tempo de execução, menor numero de neurônios na camada escondida e maior estabilidade no caso de reduzir o número de entradas. Como dado final, é importante mencionar que o sistema proposto tem uma taxa de acerto de $95,5 \%$.

Behera et al. (2009) apresentam uma abordagem para mineração de dados de QEE utilizando a TS baseado em um sistema fuzzy especialista (FES, do inglês Fuzzy Expert System). Inicialmente os sinais com distúrbios são pré-processados através da TS extraindo características estatísticas que são usadas como entradas ao sistema classificador FES. As características são extraídas por serem úteis na detecção, classificação e quantificação de parâmetros relevantes dos sinais. São selecionadas cinco características determinadas assim: (1) diferença da soma dos valores máximo e mínimo do sinal com distúrbio contra os valores máximo e mínimo de sinal sem distúrbio; (2) desvio padrão das magnitudes versus o tempo obtido da TS; (3) energia da ST; (4) distorção harmônica total e (5) frequência estimada da maior amplitude obtida na TS. Depois de conhecer as faixas e/ou limites das características para cada um dos doze distúrbios, se estabelecem o conjunto de regras que o FES irá utilizar na classificação. Cada saída do FES deve corresponder a uma classe de distúrbio, no obstante, pequenas variações nos valores de saída podem confundir o sistema em quanto à correspondência do evento a sua classe. Com a finalidade de evitar erros na toma de decisões, é adotada a técnica de partículas adaptativas swarm (PSO, do inglês Particle Swarm Optimization) inserida na caracterização das funções de pertinência do FES. O uso do PSO faz do 
classificador mais confiável e preciso na classificação. 0 método desenvolvido mostra uma taxa de acerto alta, atingindo os 99,8\% de acerto na classificação.

\subsection{Considerações finais}

Neste capitulo foi apresentada uma revisão dos trabalhos que abordam a utilização de técnicas relacionadas à detecção e classificação de distúrbios de QEE. É observado que tanto o uso da transformada wavelet como a transformada $\mathrm{S}$ em combinação com um sistema classificador apropriado obtém taxas de acerto adequadas. No entanto, pode-se observar que a maioria dos sistemas desenvolvidos visa à análise de distúrbios isolados, enquanto aqueles que tratam a ocorrência de múltiplos eventos simultâneos além de serem poucos, precisam de técnicas mais elaboradas, que permitam uma maior separação das características próprias de cada evento. 


\section{Capitulo 3}

\section{Qualidade de Energia Elétrica}

Este capítulo faz uma descrição dos conceitos básicos dos diferentes tipos de distúrbios que são encontrados em redes de energia elétrica.

Segundo a IEEE Std. 1159 (2009) e Dugan (2002) os distúrbios podem ser parametrizados por seu conteúdo espectral, duração e amplitude típica além de serem categorizados segundo seu comportamento em sete grupos ou classes: transitórios, variações de curta e longa duração, distorções na forma de onda, desequilíbrios e flutuações de tensão e variações na frequência.

Para uma maior facilidade na visualização, todos os distúrbios com suas respectivas características estão resumidos na Tabela 3.1. e serão descritos em detalhe ao longo do capítulo. Cabe ressaltar que as características aqui citadas são de grande importância no processo de identificação de cada um dos distúrbios. 
Tabela 3.1. Categorias e características dos distúrbios em sistemas de potência (DUGAN et al., 2002)

Categoria

Conteúdo

Espectral Típico

Duração Típica

Magnitude Tensão Típica

\section{Transitórios}

\begin{tabular}{llccc}
\hline \multirow{3}{*}{ Impulsivo } & Nanosegundo & $5 \mathrm{~ns}$ pico & $<50 \mathrm{~ns}$ & \\
& Microsegundo & $1 \mu \mathrm{s}$ pico & $50 \mathrm{~ns}-1 \mathrm{~ms}$ & \\
\cline { 2 - 5 } Oscilatório & Milisegundo & $0,1 \mathrm{~ms}$ pico & $>1 \mathrm{~ms}$ & $0-4 \mathrm{pu}$ \\
& Freq. Baixa & $<5 \mathrm{kHz}$ & $0,3-50 \mathrm{~ms}$ & $0-8 \mathrm{pu}$ \\
& Freq. Média & $5-500 \mathrm{kHz}$ & $20 \mu \mathrm{s}$ & $0-4 \mathrm{pu}$ \\
\hline
\end{tabular}

Variações de Curta Duração

\begin{tabular}{llcc}
\hline \multirow{3}{*}{ Instantânea } & Interrupção & $0,5-30$ ciclos & $<0,1 \mathrm{pu}$. \\
& Afundamento & $0,5-30$ ciclos & $0,1-0,9 \mathrm{pu}$. \\
& Elevação & $0,5-30$ ciclos & $1,1-1,8 \mathrm{pu}$. \\
\cline { 2 - 4 } Momentânea & Interrupção & 30 ciclos $-3 \mathrm{~s}$ & $<0,1 \mathrm{pu}$. \\
& Afundamento & 30 ciclos $-3 \mathrm{~s}$ & $0,1-0,9 \mathrm{pu}$. \\
& Elevação & 30 ciclos $-3 \mathrm{~s}$ & $1,1-1,4 \mathrm{pu}$. \\
\cline { 2 - 4 } Temporária & Interupção & $3 \mathrm{~s}-1 \mathrm{~min}$ & $<0,1 \mathrm{pu}$. \\
& Afundamento & $3 \mathrm{~s}-1 \mathrm{~min}$ & $0,1-0,9 \mathrm{pu}$. \\
& Elevação & $3 \mathrm{~s}-1 \mathrm{~min}$ & $1,1-1,2 \mathrm{pu}$. \\
\hline
\end{tabular}

Variações de Longa Duração

\begin{tabular}{lcc}
\hline Interrupção Sustentada & $>1 \mathrm{~min}$ & $0,0 \mathrm{pu}$. \\
Subtensão & $>1 \mathrm{~min}$ & $0,8-0,9 \mathrm{pu}$. \\
Sobretensão & $>1 \mathrm{~min}$ & $1,1-1,2 \mathrm{pu}$. \\
\hline
\end{tabular}

Desequilíbrio de Tensão

Regime Permanente

$0,5-2 \%$

Distorção da Forma de Onda

\begin{tabular}{lclc}
\hline Nível CC & & Regime Permanente & $0-0,1 \%$ \\
Harmônicos & $0-100$ harmônica & Regime Permanente & $0-20 \%$ \\
Inter harmônicos & $0-6 \mathrm{kHz}$ & $\begin{array}{l}\text { Regime Permanente } \\
\text { Notching }\end{array}$ & $\begin{array}{l}\text { Regime Permanente } \\
\text { Ruído }\end{array}$ \\
\hline & Toda banda & Regime Permanente & $0-1 \%$ \\
Flutuação de Tensão & $<25 \mathrm{~Hz}$ & Intermitente & $0,1-7 \%$ \\
\hline
\end{tabular}

Variação da Freq. do Sistema

$>10 \mathrm{~s}$

Nota: $\mathrm{s}=$ segundos, $\mathrm{ns}=$ nanosegundos,$\mu \mathrm{s}=$ microsegundos, $\mathrm{ms}=$ milisegundos, $\mathrm{kHz}=$ kilohertz, $\mathrm{MHz}=$ megahertz, $\min =$ minuto, $\mathrm{pu}=$ per unidade. 


\subsection{Transitórios}

O termo transitório é usado para caracterizar fenômenos oriundos de alterações súbitas nas condições operacionais de um sistema de energia elétrica. Geralmente, a duração de um transitório é muito pequena, mas de grande importância, uma vez que os equipamentos presentes no sistema elétrico serão submetidos a grandes solicitações de tensão e/ou corrente. (DUGAN et al., 2002)

Existem dois tipos de transitórios: os impulsivos, causados por descargas atmosféricas, e os oscilatórios, causados por chaveamentos.

\subsubsection{Transitório impulsivo}

Um transitório impulsivo é uma alteração repentina nas condições do regime permanente da tensão, corrente ou ambas, caracterizando-se por apresentar impulsos unidirecionais em polaridade (positivo ou negativo) e com frequência bastante diferente da frequência fundamental do sistema elétrico. Normalmente os transitórios oscilatórios são caracterizados pelo tempo de subida e descida, o que leva a uma subclassificação em nanosegundos, microsegundos e milissegundos (DUGAN et al., 2002).

\subsubsection{Transitório oscilatório}

Um transitório oscilatório é uma alteração repentina nas condições de regime permanente da tensão, corrente ou sobre ambas, com valores instantâneos alternando em polaridade e que apresenta decaimento ao longo do tempo podendo ser descrito por seu conteúdo espectral, duração e amplitude. A Figura 3.1 mostra um caso de transitório oscilatório.

Os transitórios oscilatórios, de acordo com o conteúdo espectral, podem ser divididos em três classes: baixa, média e alta frequência. Estas faixas de frequências são escolhidas para coincidirem com fenômenos já conhecidos. Assim, transitórios oscilatórios de frequência alta, são o resultado de uma resposta local do sistema elétrico quando um transitório impulsivo acontece.

Os transitórios oscilatórios de frequência média são causados por energização de capacitores ou chaveamento de disjuntores, além disso, podem ser produzidos como resposta a transitórios impulsivos. Por último, os transitórios oscilatórios de baixa frequência que são encontrados em sistemas de subtransmissão e distribuição, são 
causados por diversos eventos, dentre os quais se destaca a energização de capacitores. (IEEE Std. 1159, 2009)

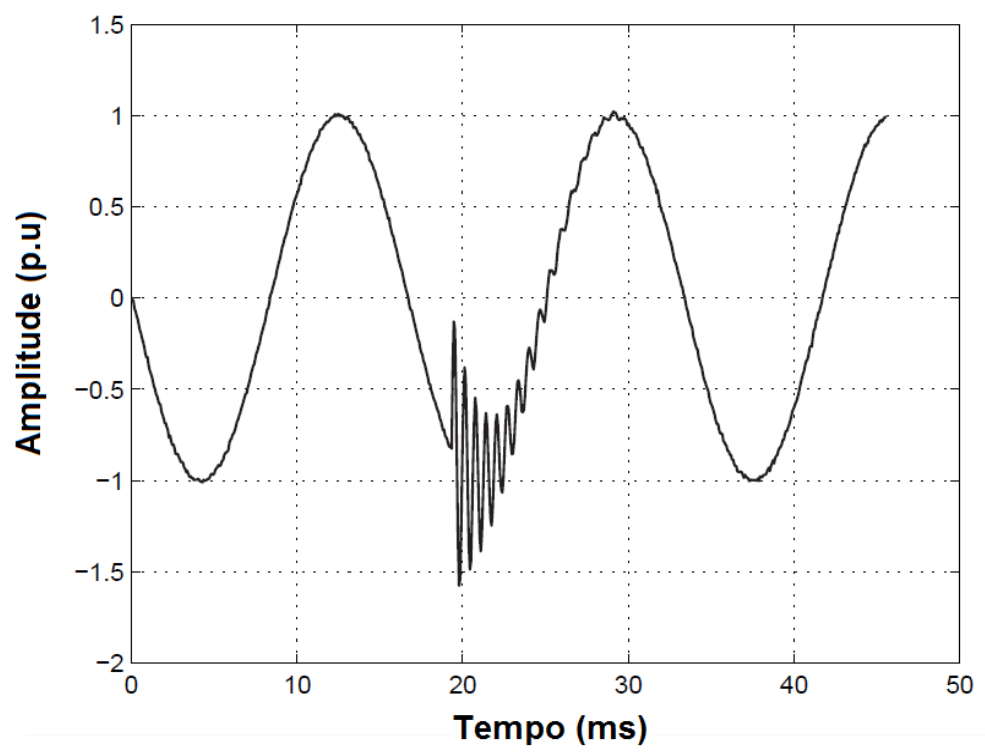

Figura 3.1 Transitório oscilatório causado por chaveamento de banco de capacitores.

\subsection{Variação de tensão de curta duração}

As variações de curta duração são classificadas em instantâneas, momentâneas ou temporárias dependendo da duração como definido na Tabela 3.1. Normalmente são causadas por condições de falta, energização de grandes cargas que precisam de correntes altas de partida ou conexões com contatos inadequados. Dependendo da localização da falta e das condições do sistema, pode causar afundamentos, elevações ou uma perda total da tensão $(1159,2009)$.

\subsubsection{Interrupção}

Como definido em IEEE Std. 1159 (2009) uma interrupção de curta duração acontece quando a tensão ou corrente decresce a menos de 0,1 p.u por um período de tempo não excedente a 1 minuto. Interrupções são resultantes de faltas no sistema elétrico de potência, falhas de equipamentos ou funcionamento inadequado dos sistemas de controle. 
A duração de uma interrupção, devido a uma falta no sistema é determinada pelo tempo de operação dos dispositivos de proteção. Sistemas de religamento limitam a interrupção causada por uma falta não-permanente a menos de 30 ciclos de duração da forma de onda da tensão. Um atraso no religamento, dos dispositivos de proteção, pode causar uma interrupção momentânea ou temporária. Algumas interrupções podem ser precedidas por afundamentos de tensão quando estas interrupções são devidas a falhas no sistema principal.

\subsubsection{Afundamento}

Um afundamento é a redução da amplitude da componente fundamental da tensão ou corrente entre 0,1 e 0,9 p.u. (Figura 3.2) e com duração entre 0,5 ciclos da forma de onda da tensão e 1 minuto. Os eventos podem ser classificados em três categorias dependendo de sua duração: instantâneas, momentâneas e temporárias, as quais coincidem com as três categorias de variações de curta duração (interrupção, afundamento, elevação). Estes tempos de permanência sobre o sistema correspondem aos tempos de operação que são típicos dos dispositivos de proteção das concessionárias e das normas técnicas internacionais (DUGAN et al., 2002).

Afundamentos estão associados à faltas no sistema, mas podem ser causados por energização de grandes cargas ou partida de grandes motores.

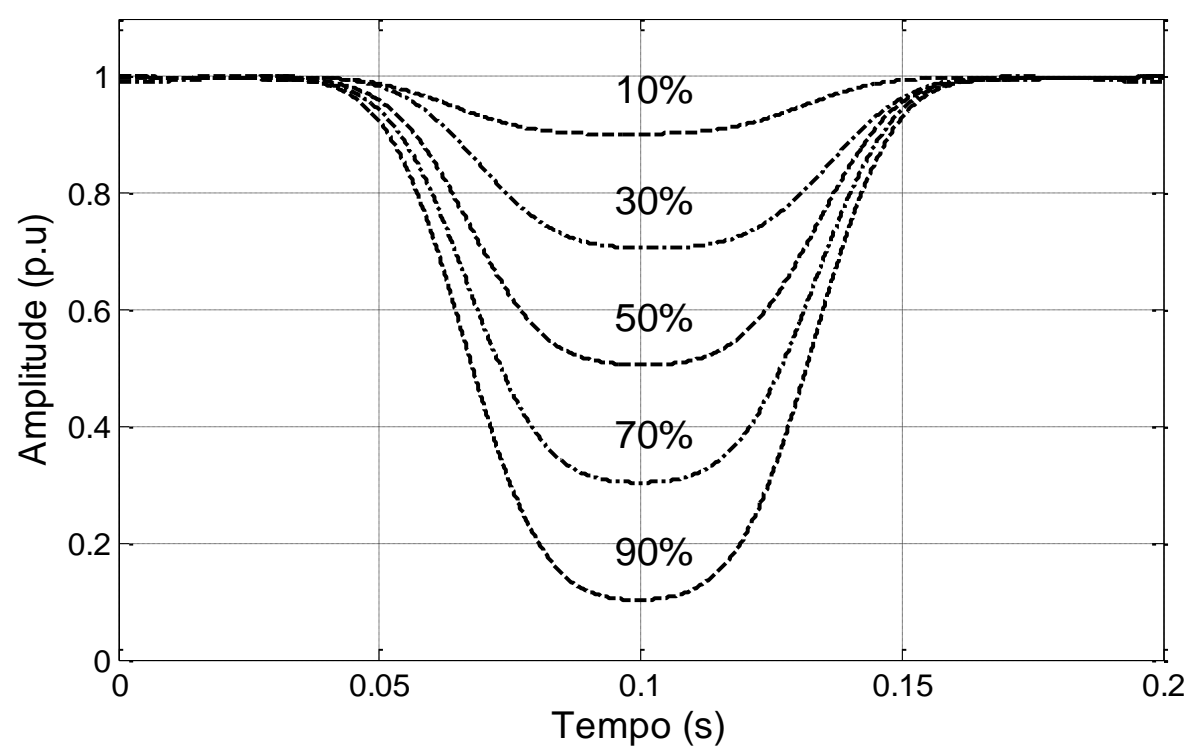

Figura 3.2. Valor RMS da tensão para múltiplos afundamentos. 


\subsubsection{Elevação}

Elevação é o aumento da amplitude da componente fundamental da tensão ou corrente entre 1,1 e 1,8 p.u, com duração entre 0,5 ciclos e 1 minuto. Da mesma forma que os afundamentos de tensão, as elevações estão associadas as condições de faltas no sistema, contudo não são tão comuns como os afundamentos.

Elevações podem ocorrer devido a uma falta fase-terra que eleva a tensão nas fases sem falta, além de poderem ser causada por desligamento de uma grande carga ou chaveamento de um grande banco de capacitores. As elevações são caracterizadas por sua magnitude (valor rms) e duração, assim como nos casos anteriores estão divididas em instantânea, momentânea e temporária. (DUGAN et al., 2002). A seguir a Figura 3.3 mostra um caso de elevação de tensão:

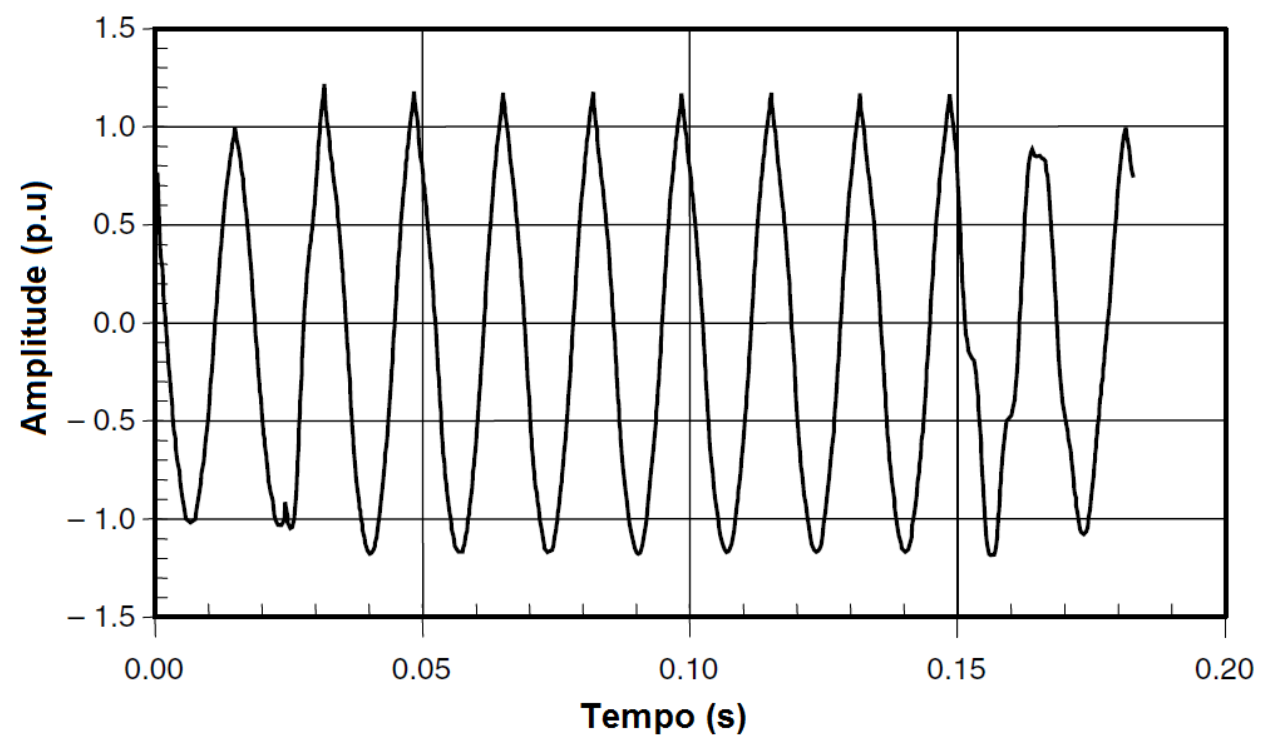

Figura 3.3. Exemplo de elevação de tensão(DUGAN et al., 2002).

\subsection{Variações de longa duração}

Variações de longa duração compreendem desvios no valor eficaz da tensão ou na frequência do sistema por um período maior de 1 minuto. São classificadas em sobretensão, subtensão e interrupção sustentada. Sobretensão e subtensão geralmente são decorrentes de variações de cargas e operações de chaveamento no sistema. 


\subsubsection{Interrupção sustentada}

Quando o fornecimento de tensão permanece nulo por um período de tempo que excede 1 minuto, a variação de tensão de longa duração é considerada como uma interrupção sustentada. As interrupções de tensão com duração superior a 1 minuto são consideradas permanentes e requerem intervenção humana para reparar o sistema e restabelecer o fornecimento normal de energia (DUGAN et al., 2002).

As interrupções sustentadas podem ocorrer de forma inesperada ou de forma planejada. A maioria delas ocorre inesperadamente e as principais causas são: falhas nos disjuntores, queima de fusíveis, falha de componentes de circuito alimentador, etc. As interrupções planejadas são feitas geralmente para executar transferência de carga ou manutenção na rede, ou seja, serviços como: troca de cabos e postes, mudança do tap do transformador, alteração dos ajustes de equipamentos de proteção e outros.

\subsubsection{Subtensão}

Uma subtensão é caracterizada por um decréscimo no valor eficaz da tensão a valores menores a 0,9 p.u, considerando-se a frequência do sistema com período de duração maior do que 1 minuto. As subtensões resultam de conexão de grandes cargas ou desligamento de bancos de capacitores que são utilizados para regular a tensão a valores próximos dos limites de tolerância.

\subsubsection{Sobre tensão}

Uma sobretensão é caracterizada por um incremento no valor eficaz da tensão acima de 1,1 p.u por um período de duração superior a 1 minuto. Sobretensões resultam do desligamento de grandes cargas ou energização de bancos de capacitores e o uso inadequado de taps em transformadores. Além disso, pode se mencionar a possibilidade de ocorrência quando o sistema é muito fraco na regulação da tensão ou os controles de tensão são inadequados (DUGAN et al., 2002).

\subsection{Desequilíbrio de Tensão}

Desequilíbrio de tensão é medido como a razão entre a componente de seqüência negativa ou zero, e a componente de seqüência positiva da tensão. Seqüências negativas de tensão são resultado de cargas desbalanceadas que causam correntes de seqüência negativas. 0 desequilíbrio pode ser estimado como o máximo desvio da média da tensão 
ou corrente das três fases dividido pela média das tensões ou correntes das fases e é expresso em porcentagem As principais fontes de desequilíbrios de tensão são alocações mal dimensionadas de cargas monofásicas nos circuitos de alimentação trifásicos.

\subsection{Distorção da forma de onda}

A distorção da forma de onda está definida como um desvio, em regime permanente, da forma de onda senoidal na frequência fundamental do sistema e pode ser caracterizada pelo conteúdo espectral do desvio. (DUGAN et al., 2002)

Há cinco tipos principais de distorções na forma de onda:

$>$ Nível de Corrente Continua (CC);

$>$ Harmônicos;

$>$ Inter-harmônicos;

$>$ Notching;

$>$ Ruído.

\subsubsection{Nível CC}

A presença de uma tensão CC em um sistema de energia é denominada nível CC e pode ocorrer como resultado de um distúrbio ou devido à operação de retificadores de meia onda. O nível CC em redes CA pode levar a saturação de transformadores, resultando em sobreaquecimento e diminuição da vida útil do equipamento. Além disso, pode causar corrosão eletrolítica de eletrodos do aterramento e outros conectores. Valores típicos da magnitude destes fenômenos se encontram abaixo de 0,001 p.u.

\subsubsection{Harmônicos}

Harmônicas são tensões ou correntes senoidais contendo frequências múltiplas inteiras da frequência fundamental do sistema elétrico. Os harmônicos distorcem a forma de onda da tensão ou a corrente e ocorrem devido a características não-lineares de equipamentos e cargas conectados ao sistema elétrico (rede de distribuição ou transmissão), tais como retificadores e inversores. Assim, a distorção na forma de onda produzida pelos harmônicos é de forma continua ou pelo menos durante alguns segundos como mostrado na Figura 3.4, e está associada diretamente com a operação continua da carga (IEEE Std. 1159, 2009; IEEE Std. 519, 1992). 


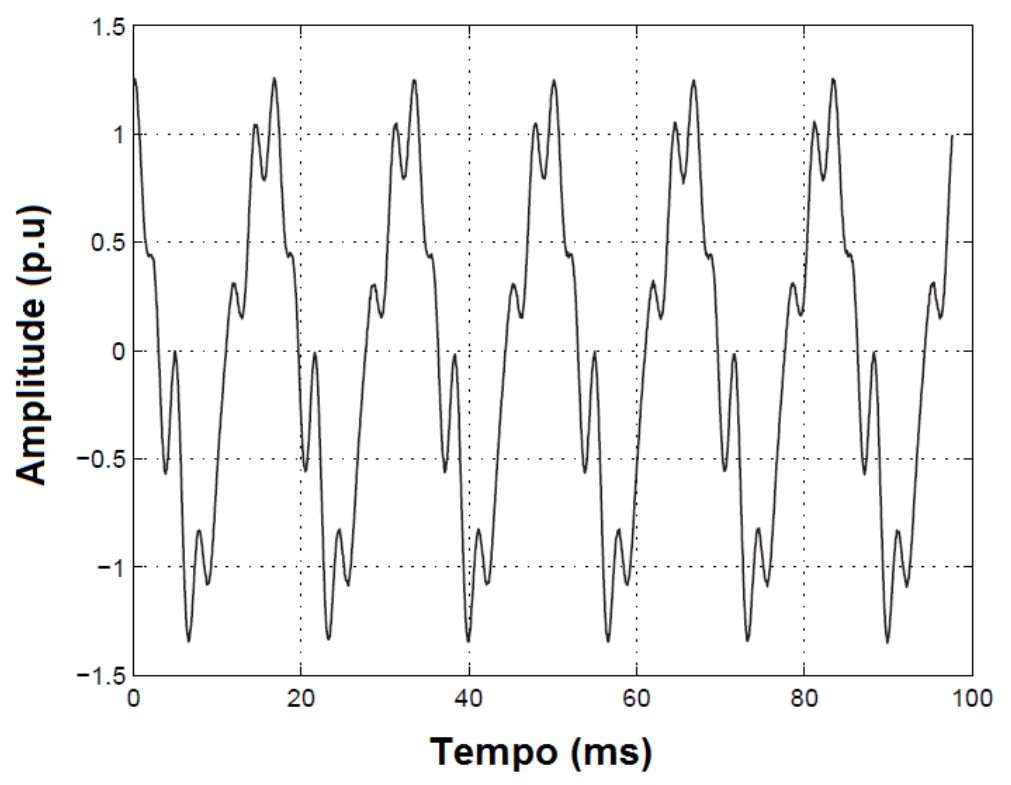

Figura 3.4. Exemplo de harmônicos.

\subsubsection{Inter-harmônicos}

Inter-harmônicos são formas de onda de tensão ou corrente que apresentam componentes de frequência que não são múltiplos inteiros da frequência fundamental do sistema elétrico. Estes podem aparecer como frequências discretas ou como um espectro de banda larga e podem ser encontrados em redes de todas as classes de tensões. As principais fontes de inter-harmônicos são conversores estáticos de frequência, cicloconversores, fornos de indução e dispositivos de arco.

\subsubsection{Notching}

Notching são distúrbios periódicos de tensão causados pela operação normal de dispositivos de eletrônica de potência quando a corrente é comutada de uma fase para outra. No entanto, o notching é tratado como um caso especial que pode chegar a ser caracterizado entre transitório e distorção harmônica devido a os componentes de frequência e a periodicidade de ocorrência. Contudo, os componentes de frequencia associados ao notching podem ser bastante elevados e dificilmente caracterizados por equipamentos usados para a análise de harmônicos (IEEE Std. 1159, 2009). Conversores trifásicos que produzem corrente contínua são as mais importantes fontes de notching, um exemplo deste caso é visto na Figura 3.5. 


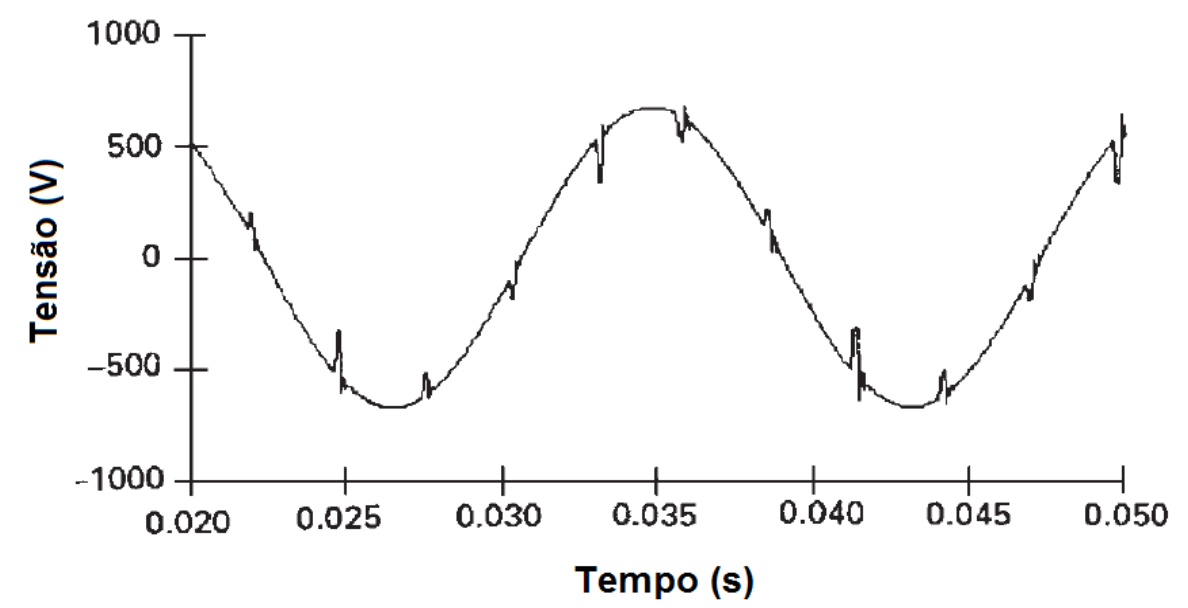

Figura 3.5. Exemplo de notching causado por conversor trifásico $(1159,2009)$.

\subsubsection{Ruído}

O Ruído é definido como um sinal elétrico indesejado, contendo uma ampla faixa espectral com frequências menores que $200 \mathrm{kHz}$ superpostas sobre a tensão ou corrente de fase do sistema elétrico ou nos condutores do neutro. 0 ruído em sistemas de potência pode ser causado por dispositivos de eletrônica de potência, circuitos de controle, equipamento de arco, cargas com retificadores de estado sólido ou fontes chaveadas. (DUGAN et al., 2002)

Basicamente o ruído consiste em qualquer distorção indesejada do sinal elétrico que não pode ser classificado como uma distorção harmônica ou como um transitório. Portanto, o ruído pode gerar distúrbios em dispositivos eletrônicos como microprocessadores e controladores programáveis. Uma forma de mitigar o problema de ruído é a utilização de filtros, transformadores de isolação ou equipamentos condicionadores de linha.

\subsection{Flutuação de tensão}

Flutuações de tensão correspondem a variações sistemáticas ou aleatórias do valor eficaz da tensão que não excedem a faixa de 0,9 a 1,1 p.u.

Qualquer carga que presente variações cíclicas, especialmente nos componentes reativos, podem causar flutuações de tensão. Cargas que exibem variações contínuas e rápidas na magnitude da corrente de carga podem causar variações na tensão que são erroneamente referidas como flicker. 0 termo flicker é derivado do impacto da flutuação 
de tensão nas lâmpadas, tal que são perceptivos ao olho humano. Tecnicamente, flutuação de tensão é um fenômeno eletromagnético enquanto flicker é o resultado indesejável da flutuação de tensão em algumas cargas. Geralmente aparecem como uma modulação da frequência fundamental do sistema de energia (similar à modulação de amplitude de um sinal de rádio AM) (IEEE Std. 1159, 2009).

Os fornos a arco são as causas mais comuns das flutuações de tensão nos sistemas de transmissão e distribuição (Figura 3.6). Nesses fornos, as amplitudes das oscilações dependem do estado de fusão do material, bem como do nível de curto-circuito da instalação. As flutuações também são originadas por equipamentos como máquinas de solda, laminadores, elevadores de minas, ferrovias, bem como a partida direta de grandes motores, causando diversos efeitos no sistema de energia.

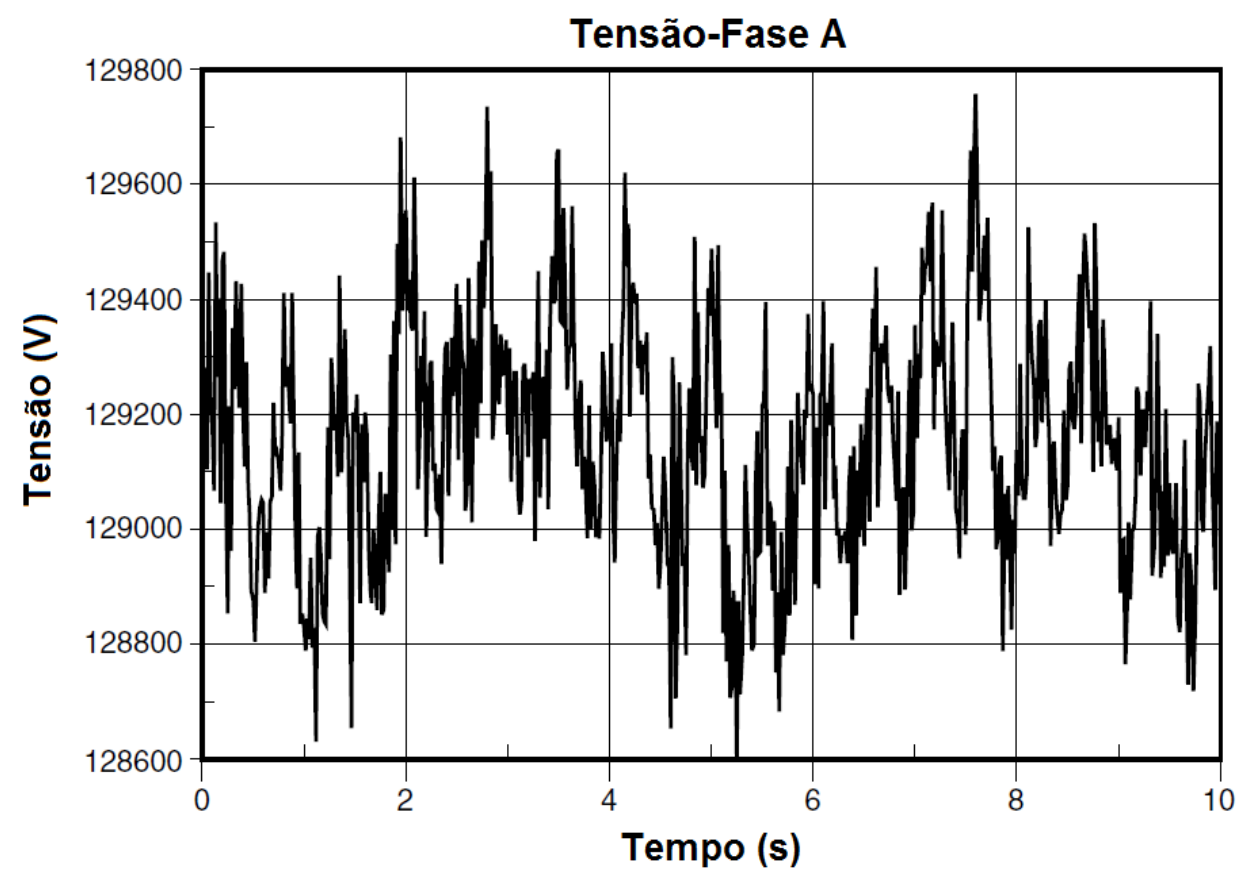

Figura 3.6. Flutuação de tensão causada pela operação de forno de arco(DUGAN et al., 2002).

\subsection{Variação da frequência do sistema}

Variação da frequência do sistema está definida como o desvio na frequência fundamental do sistema de seu valor nominal (50 ou $60 \mathrm{~Hz}$ ). A frequência nos sistemas de potência está diretamente relacionada com a velocidade de rotação dos geradores do sistema e depende do equilíbrio entre as cargas e a capacidade de geração. 0 valor de deslocamento da frequência e sua duração dependem das características da carga e da 
resposta de controle do sistema gerador nas mudanças da carga. No entanto, variações de frequência fora dos limites estabelecidos para a operação normal permitida podem ser causadas por falhas das cargas conectadas ao sistema de transmissão, como por exemplo, a desconexão de um grande bloco de cargas ou um grande sistema de geração se desconectando da rede (DUGAN et al., 2002).

\subsection{Considerações finais}

Este capítulo oferece uma descrição teórica dos diversos fenômenos que afetam a qualidade de energia elétrica. Conforme com o apresentado, é possível observar as diferentes características e parâmetros que definem cada um dos distúrbios, visando a esclarecer os conceptos que permitam obter uma visão melhor e, por conseguinte, fazer uma melhor análise da qualidade de energia no decorrer do trabalho. 


\section{Capítulo 4}

\section{Análise Tempo Frequência}

$\mathrm{Na}$ análise de sinais é usual representá-las em função do tempo ou no domínio da frequência, sendo que em ambos os casos, contemplam as mesmas informações presentes no sinal que está sendo analisado, mas respondendo a abordagens diferentes e complementares.

Ao se processar sinais é comum encontrar fenômenos oscilantes localizados no tempo, como também, ondas duradouras com amplitudes quase estacionárias, que mostram padrões de frequência variável no tempo(CHUI, 1992). Assim é como surge à noção dos fenômenos localizados no tempo e na frequência, em outras palavras, eventos que para sua descrição precisam da informação conjunta de ambos os domínios.

Os métodos para análise de sinais no tempo e na frequência oferecem informação simultânea tanto no domínio do tempo quanto na frequência, permitindo elucidar componentes locais, transitórios ou intermitentes, que só podem ser obtidos mediante métodos espectrais(ADDISON et al., 2009). 


\subsection{Transformada wavelet}

A transformada wavelet (TW) tem emergido como uma ferramenta versátil capaz de decompor sinais no domínio do tempo e da frequência simultaneamente, apresentando informação útil e contendo inúmeras aplicações em diversas áreas do conhecimento(JENSEN e LA COUR-HARBO, 2001).

Muitas das idéias que deram como resultado a teoria wavelet e a transformada wavelet foram estabelecidas e exploradas nos anos 80, começando quando Grossman e Morlet idealizaram um método para analisar sinais sísmicos baseados numa analogia com a transformada de Fourier de tempo curto (STFT, do inglês Short Time Fourier Transform), substituindo a função janela por uma função $(\psi)$ bem localizada no tempo e na frequência e substituindo a translação em frequência por escalonamentos, obtendo, assim, melhores resultados em sinais transitórios que os obtidos com a análise de Fourier.

Em 1985, Meyer descobriu que adotando valores discretos nos parâmetros de dilatação e translação era possível obter bases ortonormais, e assim, em 1987, junto com Mallat estabeleceram a fundamentação matemática chamando-a de análise multiresolução, que combina idéias de análise de Fourier, processamento de sinais (bancos de filtros) e ciências da computação (algoritmos piramidais), o que gerou a base das wavelets.

No ano 1988, Daubechies utilizou a conexão com a teoria de filtros para construir uma família de wavelets com suporte compacto. Nos anos seguintes a teoria wavelet passou por um rápido desenvolvimento sendo aplicada em diferentes áreas do conhecimento tomando a atenção de muitos pesquisadores (JENSEN e LA COUR-HARBO, 2001).

Basicamente, existem duas classes da transformada wavelet que têm sido amplamente utilizadas, a transformada wavelet contínua (TWC), sendo uma transformada integral para propósitos matemáticos e a transformada wavelet discreta (TWD), projetada para se ter uma reconstrução perfeita dos sinais, alta velocidade de processamento e suprimir dados desnecessários. Baseada nesta última, foi desenvolvida a transformada wavelet packet, que utilizando o mesmo principio de análise 
multiresolução, faz uma decomposição mais detalhada do sinal, dividindo-o em um maior número de aproximações e detalhes.

\subsubsection{Wavelets}

Da mesma forma que Fourier analisou sinais usando senóides complexas de dimensão infinita como funções base para extração de informação no domínio da frequência e com o intuito de minimizar as restrições no domínio do tempo geradas pelas funções base quando aplicadas na STFT, a teoria wavelet adota novas funções base denominadas wavelets (VETTERLI e HERLEY, 1992).

As wavelets são funções obtidas de uma função padrão conhecida como wavelet mãe $(\psi)$ com a finalidade fundamental de transformar o sinal sob análise através de dilatações ou contrações e translações, em outro tipo de representação tempo-escala que apresenta a informação contida no sinal de uma forma mais útil. As wavelets estão definidas por:

$$
\psi_{a, b}(t)=\frac{1}{\sqrt{a}} \psi\left(\frac{t-b}{a}\right) \quad a \in \mathfrak{R}^{+}, b \in \mathfrak{R}
$$

Sendo $a$, o parâmetro de dilatação que estabelece o grau de compressão ou escala e $b$, o parâmetro de translação que determina a localização da wavelet no eixo do tempo. Assim, para valores grandes de $a$, a função wavelet é uma versão dilatada da wavelet mãe que fornece maior resolução no tempo. Portanto, corresponde às baixas frequências. Aliás, para um valor reduzido de $a$, a função wavelet é uma versão contraída da wavelet mãe com menor suporte no domínio do tempo e corresponde às altas frequências. É assim como as wavelets se adaptam na largura do tempo para a análise das frequências (DEBANATH, 2002).

No entanto, uma função para ser classificada como wavelet deve satisfazer algumas características ou critérios matemáticos que fazem delas superiores as senóides complexas usadas por Fourier (ADDISON, 2002).

1. A wavelet deve ter energia finita

$$
E=\int_{-\infty}^{\infty}|\psi(t)|^{2} d t<\infty
$$

2. Se $\hat{\psi}(f)$ é a transformada de Fourier de $\psi(t)$, isto é. 


$$
\hat{\psi}(f)=\int_{-\infty}^{\infty} \psi(t) e^{-i(2 \pi f) t} d t
$$

Então a seguinte condição deve ser satisfeita:

$$
C_{g}=\int_{0}^{\infty} \frac{|\hat{\psi}(f)|^{2}}{f} d f<\infty
$$

Isto implica que a wavelet não possui componentes na frequência zero $\hat{\psi}(0)=0$, portanto, sua média é zero. A equação (4.4), é conhecida como condição de admissibilidade, onde $C_{g}$ é a constante de admissibilidade e seu valor depende da wavelet a se utilizar.

3. Para wavelets complexas, a transformada de Fourier deve ser real e, além disso, deve atenuar as frequências negativas.

Assim, a wavelet base pode assumir diversas formas, cada uma com características próprias, tornando-a mais adequada a um determinado número de situações. A Figura 4.1 mostra a dilatação e translação de uma função wavelet mexican hat.
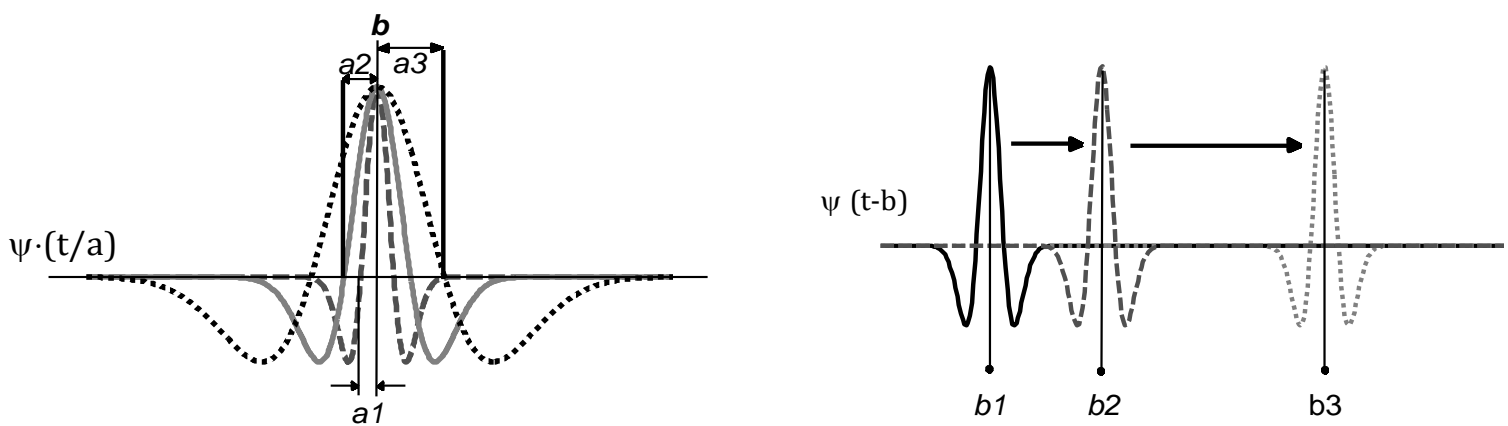

Figura 4.1 Dilatação e translação da wavelet (ADDISON, 2002).

\subsubsection{Transformada wavelet contínua (TWC)}

A TWC pode ser estabelecida como o produto interno entre um sinal $x(t)$ e versões escaladas e deslocadas da função wavelet e pode ser definida por (ADDISON, 2002):

$$
T(a, b)=\int_{-\infty}^{\infty} x(t) \psi_{(a, b)}^{*}(t) d t
$$


$\psi^{*}$ indica o conjugado complexo da função wavelet que foi definida na equação (4.1). Desta forma, a TWC também pode ser escrita como:

$$
T(a, b)=\frac{1}{\sqrt{a}} \int_{-\infty}^{\infty} x(t) \psi^{*}\left(\frac{t-b}{a}\right) d t
$$

E determinada em função da frequência como:

$$
T(a, b)=\sqrt{a} \int_{-\infty}^{\infty} \hat{x}(f) \hat{\psi}^{*}(a f) e^{i(2 \pi f) b} d f
$$

Assim, o mapeamento no domínio tempo - frequência feito pela TWC mostra uma nova alternativa a STFT, dividindo a informação em uma estrutura diferente como mostrado na Figura 4.2.

Se para qualquer wavelet $\psi(t)$ bem localizada em um intervalo centrado em $t_{0}$, de comprimento $\Delta t$, e $\hat{\psi}(f)$ localizada em uma faixa $0<f_{1} \leq|f| \leq f_{2}$ de largura $\Delta f$. Então, as wavelets $\psi_{a, b}(t)$ estão localizadas no intervalo centrado em $a t_{0}+b$, de comprimento $a \Delta t$ e em uma faixa $0<f_{1} / a \leq|f| \leq f_{2} / a$ com largura $\Delta f / a$. Com isso, é possível visualizar que a resolução no tempo é inversamente proporcional a resolução em frequência, mantendo constante a relação $\Delta t \Delta f$ (CHUI, 1992)

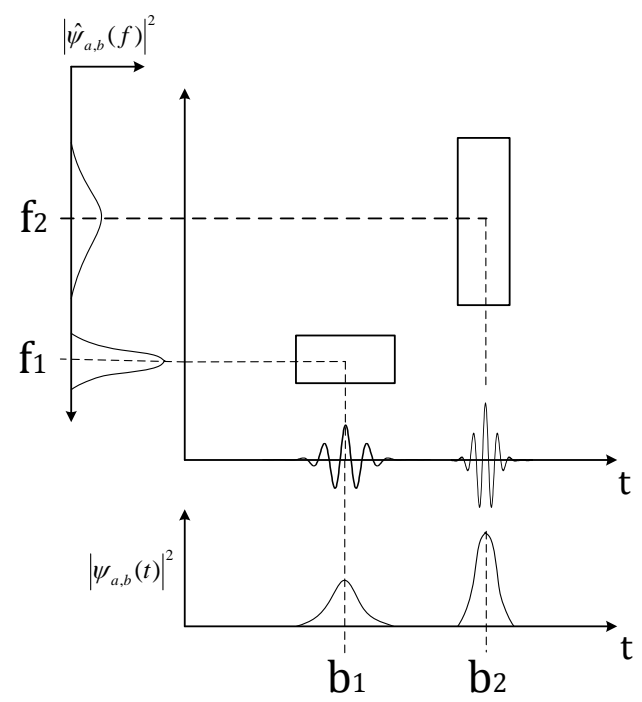

Figura 4.2 Resolução da transformada wavelet (ADDISON, 2002). 


\subsubsection{Transformada wavelet discreta (TWD)}

Como definido em (4.1), a wavelet contínua é obtida através dos parâmetros de dilatação $a$ e deslocamento $b$. Com a finalidade de diminuir a quantidade de dados resultantes e fazer da transformada wavelet uma ferramenta aplicável a sistemas computacionais, estabelece-se uma discretização logarítmica para a escala $a$ vinculada ao tamanho entre os passos adotados para as localizações de $b$. Para vincular $b \operatorname{com} a$, deve-se deslocar através de passos discretos para cada posição de $b$, os quais são proporcionais a escala $a$. Portanto, a wavelet discreta obtém a forma seguinte (ADDISON, 2002):

$$
\psi_{m, n}(t)=\frac{1}{\sqrt{a_{0}^{m}}} \psi\left(\frac{t-n b_{0} a_{0}^{m}}{a_{0}^{m}}\right) \quad a_{0}>1 ; b_{0}>0
$$

Sendo $m$ e $n$ os parâmetros inteiros que controlam a dilatação e translação respectivamente; $a_{0}$ e $b_{0}$ são o passo de dilatação e o parâmetro de translação que possuem valores constantes. Com a finalidade de se obter uma discretização simples e mais eficiente atribuem-se valores fixos, assim: $a_{0}=2$ e $b_{0}=1$. Esta escala logarítmica com potência de dois, para estabelecer os parâmetros de dilatação e translação, é conhecida como rede diádica e permite a construção de wavelets de base ortonormal. Substituindo estes valores em (4.8), têm-se:

$$
\psi_{m, n}(t)=\frac{1}{\sqrt{2^{m}}}\left(\frac{t-n 2^{m}}{2^{m}}\right)
$$

De uma forma mais compacta:

$$
\psi_{m, n}(t)=2^{-m / 2} \psi\left(2^{-m} t-n\right)
$$

Agora, usando a rede diádica das equações anteriores, a TWD de um sinal contínuo $x(t)$ é descrita por:

$$
T_{m, n}=2^{-m / 2} \int_{-\infty}^{\infty} x(t) \psi\left(2^{-m} t-n\right) d t
$$

$\mathrm{Ou}$ 


$$
T_{m, n}=\int_{-\infty}^{\infty} x(t) \psi_{m, n}(t) d t
$$

Assim, $T_{m, n}$ são os coeficientes wavelet (ou detalhes) de uma escala $m$ e uma localização $n$.

As wavelets diádicas ortonormais estão associadas a funções escala e sua equação de dilatação. A função escala é chamada também de wavelet pai e está relacionada com a suavidade do sinal e possui a mesma forma que a wavelet conforme se mostra em (4.13).

$$
\phi_{m, n}(t)=2^{-m / 2} \phi\left(2^{-m} t-n\right)
$$

A convolução da função escala com o sinal $x(t)$ produz os coeficientes de aproximação, dados por:

$$
S_{m, n}=\int_{-\infty}^{\infty} x(t) \phi_{m, n}(t) d t
$$

Portanto, o sinal original $x(t)$ pode ser representado pela combinação dos seus coeficientes de aproximação $S_{m, n}$ (em uma escala arbitrária $m_{0}$ ) com os seus coeficientes de detalhe $T_{m, n}$, como segue:

$$
x(t)=\sum_{n=-\infty}^{\infty} S_{m_{0}, n} \phi_{m_{0}, n}(t)+\sum_{m=-\infty}^{m_{0}} \sum_{n=-\infty}^{\infty} T_{m, n} \psi_{m, n}(t)
$$

A equação anterior em função da aproximação e detalhes pode ser escrita como segue:

$$
x(t)=x_{m_{0}}(t)+\sum_{m=-\infty}^{m_{0}} d_{m}(t)
$$

Dada a equação (4.16), é possível observar que aderindo os detalhes de uma escala arbitraria $(m)$ à aproximação nessa mesma escala, pode-se obter a aproximação da escala anterior $(m-1)$, (4.17). O processo de obtenção de sucessivas escalas é conhecido como Análises Multiresolução (AMR).

$$
x_{m-1}=x_{m}(t)+d_{m}(t)
$$


Na prática quando um sinal $x(t)$ discretizado em $N$ pontos é analisado, deve-se estabelecer que o comprimento do vetor seja uma potência de 2 , dado por $N=2^{M}$, o que permite que o número de níveis a se obter através do AMR seja $0<m<M$. Deste modo, (4.15) para um sinal discreto é dada por:

$$
x(t)=S_{M, n} \phi_{M, n}(t)+\sum_{m=1}^{M} \sum_{n=0}^{2^{M-m}-1} T_{m, n} \psi_{m, n}(t)
$$

Conforme mencionado anteriormente, se a função escala mostra uma versão suavizada e a função wavelet uma versão dos detalhes do sinal original, pode-se afirmar que o processo AMR corresponde a uma sucessiva filtragem do sinal através de filtros passa-baixas e passa-altas. Estes filtros estão relacionados às funções escala e wavelet como será mostrado a seguir (ADDISON, 2002).

A equação escala que descreve a função escala em termos de versões contraídas e deslocadas dela mesma esta definida como:

$$
\phi(t)=\sum_{k} c_{k} \phi(2 t-k)
$$

Sendo $\phi(2 t-k)$ a versão contraída de $\phi(t)$, deslocada em um passo $k$ inteiro ao longo do eixo do tempo e multiplicado pelo coeficiente de escala associado $c_{k}$. Isto indica que a função escala em uma escala determinada pode ser construída pelo número de equações escala, da escala anterior. Os coeficientes de escala devem satisfazer a seguinte expressão:

$$
\sum_{k} c_{k}=2
$$

Adicionalmente com a finalidade de criar um sistema ortogonal requere-se que:

$$
\sum_{k} c_{k} c_{k}+2 k^{\prime}= \begin{cases}2 & \text { se } k^{\prime}=0 \\ 0 & \text { caso contrario }\end{cases}
$$

O que demonstra que a soma dos quadrados dos coeficientes de escala é igual a dois. Estes mesmos coeficientes são usados em sentido inverso com sinais alternados para definir a equação wavelet associada. Deste modo, para um número finito de coeficientes $\left(N_{k}\right)$ têm-se: 


$$
\psi(t)=\sum_{k}(-1)^{k} c_{N_{k}-1-k} \phi(2 t-k)
$$

Geralmente os coeficientes reconfigurados usados para a função wavelet, são escritos de forma compacta assim:

$$
b_{k}=(-1)^{k} C_{N_{k}-1-k}
$$

Deve-se estabelecer que a soma dos coeficientes $b_{k}$ é zero. Substituindo (4.23) em (4.22) a equação wavelet fica da seguinte forma:

$$
\psi(t)=\sum_{k=0}^{N_{k}-1} b_{k} \phi(2 t-k)
$$

Os vetores que contém cada um dos valores de $c_{k} e b_{k}$ obtidos pelas funções scala e wavelet compõem os filtros passa-baixa e passa-alta, respectivamente. 0 conhecimento prévio destes coeficientes permite maior rapidez na execução do AMR, como será visto mais adiante, convertendo o processo de calculo das aproximações e detalhes em um processo de convolução do sinal com ditos filtros.

0 projeto dos filtros obedece às características estabelecidas para as wavelets, como também características dadas pelo projetista. Na literatura podem ser encontradas diferentes famílias de filtros, como as famílias de daubechies, coiflet, symlets entre outras. Cada família contém características definidas pelos seus criadores e projetadas com alguma finalidade especifica, encontrando algumas características particulares como o número de coeficientes do filtro e número de momentos nulos. 0 conjunto de famílias wavelets, que utilizam só os coeficientes wavelet e de escala, definidos anteriormente como filtros, são conhecidas como bancos de filtros. Para observar como são obtidos, a seguir, será mostrado o caso para a wavelet Daubechies 4 (Db4).

A wavelet Daubechies (ADDISON, 2002) requer que as suas wavelets possuam suporte compacto e um grau de suavidade. A suavidade está associada a uma condição de momento que pode ser expresso em termos dos coeficientes de escala, assim:

$$
\sum_{k=0}^{N_{k}-1}(-1)^{k} c_{k} k^{m}=0
$$

Para $m=0,1,2, \ldots, N_{k} / 2-1$. Possuindo $N_{k} / 2$ momentos nulos. 
Baseados em (4.19) e (4.22) pode-se saber que as equações escala e wavelet para quatro coeficientes são:

$$
\begin{aligned}
& \phi(t)=c_{0} \phi(2 t)+c_{1} \phi(2 t-1)+c_{2} \phi(2 t-2)+c_{3} \phi(2 t-3) \\
& \psi(t)=c_{3} \phi(2 t)+c_{2} \phi(2 t-1)+c_{1} \phi(2 t-2)+c_{0} \phi(2 t-3)
\end{aligned}
$$

Nas equações (4.26) e (4.27) é possível encontrar o valor dos coeficientes para a $\mathrm{Db} 4:$

Utilizando (4.20) e (4.21) têm-se que:

$$
\begin{aligned}
& c_{0}+c_{1}+c_{2}+c_{3}=2 \\
& c_{0}^{2}+c_{1}^{2}+c_{2}^{2}+c_{3}^{2}=2
\end{aligned}
$$

E utilizando (4.25), para $m=1$,

$$
-1 c_{1}+2 c_{2}-3 c_{3}=0
$$

Os valores dos coeficientes que satisfazem as equações anteriores e que pertencem a equação escala são:

$$
c_{0}=\frac{1+\sqrt{3}}{4} \quad c_{1}=\frac{3+\sqrt{3}}{4} \quad c_{2}=\frac{3-\sqrt{3}}{4} \quad c_{3}=\frac{1-\sqrt{3}}{4}
$$

Da mesma forma para a equação wavelet, segundo (4.23) são:

$$
b_{0}=\frac{1-\sqrt{3}}{4} \quad b_{1}=\frac{3-\sqrt{3}}{4} \quad b_{2}=\frac{3+\sqrt{3}}{4} \quad b_{3}=\frac{1+\sqrt{3}}{4}
$$

Uma vez obtidos os filtros a decomposição de um sinal discreto em sua aproximação e detalhe esta dado por:

$$
\begin{aligned}
& S_{m+1, n}=\frac{1}{\sqrt{2}} \sum_{k=0}^{N_{k}-1} c_{k} S_{m, 2 n+k}=\frac{1}{\sqrt{2}}\left[c_{0} S_{m, 2 n}+c_{1} S_{m, 2 n+1}+c_{2} S_{m, 2 n+2}+c_{3} S_{m, 2 n+3}\right] \\
& T_{m+1, n}=\frac{1}{\sqrt{2}} \sum_{k=0}^{N_{k}-1} b_{k} S_{m, 2 n+k}=\frac{1}{\sqrt{2}}\left[b_{0} S_{m, 2 n}+b_{1} S_{m, 2 n+1}+b_{2} S_{m, 2 n+2}+b_{3} S_{m, 2 n+3}\right]
\end{aligned}
$$

A utilização dos filtros para obtenção da TWD fornecera uma decomposição que dependerá da família wavelet e das características com que foi construído, sendo isto um parâmetro chave na aplicação da TWD. A Figura 3.4 ilustra a decomposição em 
vários níveis de um sinal utilizando a TWD. 0 sinal de entrada é filtrado sucessivamente pelos filtros passa-baixas $(c)$ e passa-altas $(b)$, cada decomposição gera uma aproximação e um detalhe os quais possuem uma diminuição da metade do nível anterior. A decomposição em sucessivos níveis permite visualizar, da melhor forma o conceito de AMR. O sinal resultante é dado pela concatenação da aproximação do último nível com as aproximações começando do nível inferior até o primeiro nível.

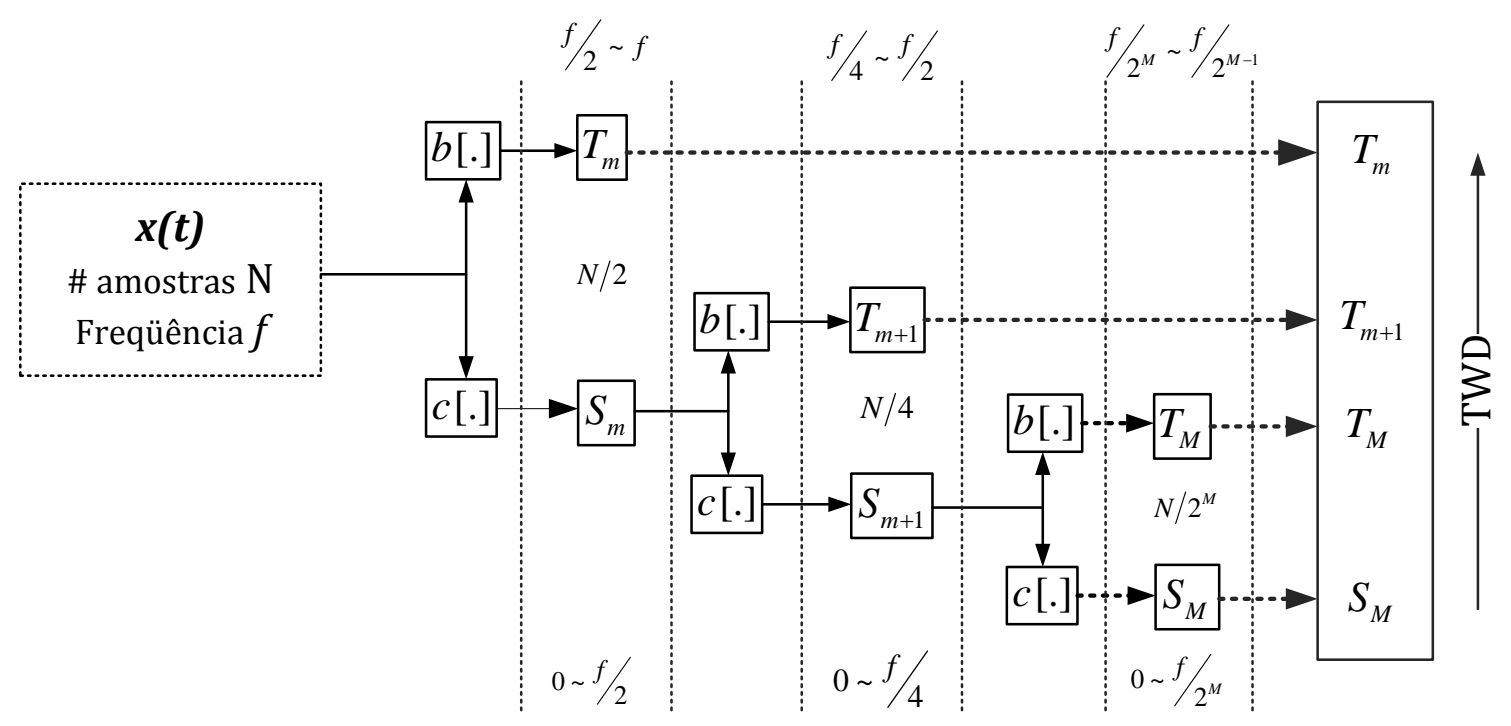

Figura 4.3. Árvore de decomposição da TWD.

\subsection{Transformada S}

A transformada S (TS) nasce como uma ferramenta para a análise tempofrequência de sinais geofísicos, desenvolvida por R.G Stockwell e publicada em 1996 como uma extensão das idéias da TWC que apresenta resolução dependente da frequência mantendo uma estreita relação com o espectro de Fourier. Em outras palavras, a TS produz uma representação tempo-frequência de séries temporais, que combina de forma única a resolução dependente da frequência com localização simultânea do espectro real e imaginário.

Segundo Ventosa et al. (2008), a TS pode-ser vista como o passo intermédio entre a STFT e a TWC, que possibilita o uso da frequência como uma variável assim como também o uso da estratégia da multiresolução das wavelets. Portanto, existem dois métodos para visualizar a TS, a primeira como um caso especial da STFT e a segunda, 
como uma correção de fase da TWC. Stockwell (1999) determina as relações da ST sobre a STFT e TWC, que para uma melhor compreensão serão mostradas a seguir.

\subsubsection{Vista da transformada-S a partir da transformada de Fourier de tempo curto}

O espectro de Fourier $X(f)$ de um sinal temporal $x(t)$ é dado por:

$$
X(f)=\int_{-\infty}^{\infty} x(t) e^{-2 \pi f t} d t
$$

E a sua inversa definida por:

$$
x(t)=\int_{-\infty}^{\infty} X(f) e^{i 2 \pi f t} d f
$$

O espectro $X(f)$ pode ser referenciado como o espectro da média do tempo. Se o sinal $x(t)$ é janelado por uma função janela $w(t)$, então o espectro resultante será:

$$
X(f)=\int_{-\infty}^{\infty} x(t) w(t) e^{-i 2 \pi f t} d t
$$

A TS adota como função janela uma Gaussiana normalizada por ser mais compacta no tempo e na frequência.

$$
w(t)=\frac{1}{\sigma \sqrt{2 \pi}} e^{-\frac{t^{2}}{2 \sigma^{2}}}
$$

Aderindo à função Gaussiana propriedades de dilatação (ou largura de janela) $\sigma$ e deslocamento $\tau$, a TS é definida como:

$$
S(\tau, f, \sigma)=\int_{-\infty}^{\infty} x(t) \frac{1}{\sigma \sqrt{2 \pi}} e^{\frac{(t-\tau)}{2 \sigma^{2}}} e^{-i 2 \pi f t} d t
$$

No entanto, determinar a função em base a três variáveis, torna-a inadequada como ferramenta de análise. Assim, restringindo a largura da janela e fazendo-a proporcional ao inverso da frequência.

$$
\sigma(f)=\frac{1}{|f|}
$$

É possível estabelecer a TS como mostra a equação (4.39) 


$$
S(\tau, f)=\frac{|f|}{\sqrt{2 \pi}} \int_{-\infty}^{\infty} x(t) e^{\frac{(t-\tau)^{2} f^{2}}{2}} e^{-i 2 \pi f t} d t
$$

A avaliação em um $\tau$, fixando a frequência $f_{1}$, definido como $S\left(\tau, f_{1}\right)$ recebe o nome de voice. A avaliação da frequência em um $\tau$ fixo, $S\left(\tau_{1}, f\right)$ é chamado de local ou espectro local (STOCKWELL, 1999).

É possível observar que a frequência de voice zero da ST é igual a zero, o que não fornece informação, portanto $S(\tau, 0)$ define-se independente do tempo e assume o valor da média do sinal temporal $x(t)$

$$
S(\tau, 0)=\lim _{T \rightarrow \infty} \frac{1}{T} \int_{-T / 2}^{T / 2} x(t) d t
$$

A TS pode ser escrita como a convolução de duas funções sobre a variável $t$

$$
S(\tau, f)=\int_{-\infty}^{\infty} p(t, f) w(t-\tau, f) d t
$$

$\mathrm{ou}$

$$
S(\tau, f)=p(t, f) * w(\tau, f)
$$

onde

$$
p(\tau, f)=x(\tau) e^{-i 2 \pi f \tau}
$$

$\mathrm{e}$

$$
w(\tau, f)=\frac{|f|}{\sqrt{2 \pi}} e^{-\frac{\tau^{2} f^{2}}{2}}
$$

Agora, se $B(\alpha, f)$ é a transformada de Fourier da TS $S(\tau, f)$. Aplicando o teorema da convolução, a convolução no domínio do tempo $(\tau)$ converte-se na multiplicação no domínio da frequência(f), assim:

$$
B(\alpha, f)=P(\alpha, f) W(\alpha, f)
$$

em que $P(\alpha, f)$ e $W(\alpha, f)$ as transformadas de Fourier de $p(\tau, f)$ e $w(\tau, f)$ respectivamente. Então: 


$$
B(\alpha, f)=X(\alpha+f) e^{-\frac{2 \pi^{2} \alpha^{2}}{f^{2}}}
$$

onde $X(\alpha+f)$ é a transformada de Fourier de (4.43), e o exponencial é a transformada de Fourier da função Gaussiana (4.44). Deste modo, a TS é a transformada de Fourier inversa de (4.46) definida por(STOCKWELL et al., 1996), assim:

$$
S(\tau, f)=\int_{-\infty}^{\infty} X(\alpha+f) e^{-\frac{2 \pi^{2} \alpha^{2}}{f^{2}}} e^{i 2 \pi \alpha \tau} d \alpha
$$

A função exponencial na equação anterior é a janela dependente da frequência chamada voice Gaussina e cumpre a função de um filtro passa-baixas pra cada voice.

\subsubsection{Transformada-S a partir da transformada wavelet contínua}

Como mostrado na seção 3.2.2, a TWC pode ser estabelecida como o produto interno entre um sinal $x(t)$ e versões escalonadas e deslocadas da função wavelet:

$$
T(\tau, d)=\int_{-\infty}^{\infty} x(t) \psi(t-\tau, d) d t
$$

A TS de uma função $x(t)$ pode ser definida como uma TWC que utiliza uma especifica wavelet mãe multiplicada por um fator de fase assim:

$$
S(\tau, f)=T(\tau, d) e^{i 2 \pi f \tau}
$$

Sendo a wavelet mãe está definida por:

$$
\psi(t, f)=\frac{|f|}{\sqrt{2 \pi}} e^{-\frac{t^{2} f^{2}}{2}} e^{-i 2 \pi f t}
$$

Note que o parâmetro $d$ é o inverso da frequência $f$.

A wavelet em (4.50) não possui média zero, portanto não satisfaz a condição de admissibilidade definida para as wavelets. Isto faz com que a ST não seja um tipo de TWC (VENTOSA et al., 2008).

O fator de fase em (4.49), em si, é um corretor de fase para a já definida WT. De forma que separa a wavelet mãe em duas partes, a função Gaussiana que gera um envelope de variação lenta para as localizações temporais e a função exponencial $e^{-i 2 \pi f t}$ que seleciona as frequências que estão sendo localizadas. A Gaussiana é transladada enquanto à função exponencial permanece estática. Fixando a função exponencial, a ST 
localiza os componentes reais e imaginários do espectro de forma independente, localizando tanto a fase do espectro como sua amplitude.

\subsubsection{Transformada-S discreta (TSD)}

Baseando-se na equação (4.47) é possível calcular a TSD tomando vantagem da eficiência da transformada rápida de Fourier (FFT) e do teorema de convolução.

Seja $x[k T], k=0,1, \ldots, N-1$ um sinal discreto amostrado em um intervalo de tempo T. A transformada discreta de Fourier esta dada por:

$$
X\left[\frac{n}{N T}\right]=\frac{1}{N} \sum_{k=0}^{N-1} x[k T] e^{-\frac{i 2 \pi n k}{N}}
$$

onde $n=0,1, \ldots N-1$. No caso discreto a TS é a projeção do vetor definido pela serie temporal $x[k T]$ em um conjunto gerador de vetores. Estes vetores não são ortogonais $\mathrm{e}$ os elementos da TS não são independentes. Cada vetor base é dividido em $N$ vetores, que serão multiplicados elemento a elemento com os $N$ vetores correspondentes ao deslocamento da Gaussiana, de tal forma que a soma desses vetores da como resultado o vetor base original.

Retomando (4.47), fazendo $f \rightarrow n / N T$ e $\tau \rightarrow j T$ para um sinal $x[k T]$ a TSD esta dada por:

$$
S\left[j T, \frac{n}{N T}\right]=\sum_{m=0}^{N-1} X\left[\frac{m+n}{N T}\right] e^{-\frac{2 \pi^{2} m^{2}}{n^{2}}} e^{\frac{i 2 \pi m j}{N}}
$$

Sendo para $\mathrm{n}=0$ igual á constante definida como:

$$
S[j T, 0]=\frac{1}{N} \sum_{m=0}^{N-1} x\left(\frac{m}{N T}\right)
$$

onde $j, m, n=0,1, . ., N-1$. O fato de estabelecer uma constante na frequência zero assegura que a inversa seja exata para qualquer sinal em geral.

Para finalizar, é necessário declarar que a saída fornecida pela TS é uma matriz complexa onde cada linha contém os componentes em frequência nos diferentes tempos amostrados e as colunas representam o espectro local nesse tempo em particular. As frequências são normalizadas com relação à máxima frequência permitida (Nyquist) e correspondem segundo a equação seguinte: 


$$
f_{n}=n \frac{f_{0}}{f_{s}}, \quad n=1,2,3, \ldots
$$

onde, $f_{0} \rightarrow$ Frequência fundamental

$$
f_{s} \rightarrow \text { Frequência de amostragem }
$$

Para o calculo de TS é recomendado seguir os seguintes passos (STOCKWELL, 1999):

1. Calcular a Transformada de Fourier do sinal original $x(k)$ com $N$ pontos para obter o espectro $X[m]$, usando a transformada rápida de Fourier;

2. Calcular a janela gaussiana $W[m, n]$ para a frequência requerida $n$;

3. Converta o espectro $X[m]$ para $X[(m+n)]$ para a frequência requerida $n$;

4. Multiplique $X[(m+n)]$ por $W[m, n]$, obtendo $B[n, m]$;

5. Aplica-se a transformada de Fourier inversa para $B[n, m]$, obtendo a primeira fila de $S[n, j]$ correspondente a frequência $n$.

6. Repita os passos 3,4 e 5 até encontrar todas as filas de $S[n, j]$ que correspondem a todas as freqüências $n$ definidas.

\subsection{Considerações finais}

No decorrer deste capítulo foi apresentada a fundamentação teórica sobre as transformadas S e wavelet. É visto que a analise tempo - frequência provê mais informação que os métodos tradicionais permitindo extrair informação de ambos os domínios, ressaltando a aplicabilidade para sinais não estacionários com presencia de mudanças bruscas em seu comportamento. 


\section{Capítulo 5}

\section{Análise de Distúrbios}

Neste capitulo é apresentada a metodologia adotada para a análise e classificação dos diferentes distúrbios de qualidade de energia elétrica. Como primeiro passo, será apresentado o modelo para geração dos sinais com distúrbios de acordo com as características definidas no capítulo 3, de modo que seja possível garantir um banco de dados pertinente para o estudo. Uma vez definido o banco de dados, são apresentadas as transformadas S e wavelet como ferramentas na extração de características dominantes de cada um dos sinais, para finalmente, serem usadas na etapa de classificação. Cabe dizer que para o desenvolvimento do trabalho foi utilizada o ambiente computacional Matlab sem o uso dos toolboxes.

\subsection{Geração de distúrbios}

Como mostrado na Tabela 3.1 (pag. 36), características como magnitude, duração e espectro de frequência definem cada distúrbio de qualidade de energia. Estas características serão o ponto de partida na geração do banco de dados através de equações ou modelos paramétricos. 0 uso de modelos paramétricos fornece a grande 
vantagem de gerar um amplo numero de sinais mediante a variação controlada dos seus parâmetros (PANIGRAHI e PANDI, 2009).

Os eventos considerados no presente trabalho pertencem a seis classes diferentes, além de combinações destas, para obter sinais compostos, assim, tem-se um total de quinze tipos diferentes de distúrbios mostrados a continuação na Tabela 5.1.

Tabela 5.1. Distúrbios de qualidade de energia considerados.

\begin{tabular}{|c|c|}
\hline Interrupção & Afundamento + harmônicos \\
\hline Afundamento & Elevação + transitório oscilatório \\
\hline Elevação de tensão & Elevação + notch \\
\hline Transitórios oscilatórios & Elevação + harmônicos \\
\hline Harmônicos & Harmônicos + notch \\
\hline Notch & Transitório oscilatório + notch \\
\hline Afundamento + transitório oscilatório & Transitório oscilatório + harmônico \\
\hline Afundamento + notch & \\
\hline
\end{tabular}

Além das características particulares de cada um dos eventos, são considerados parâmetros globais na geração dos sinais. Cada um destes apresenta uma duração de 12 ciclos com uma taxa de amostragem de $7680 \mathrm{~Hz}$, correspondendo a um total de 128 amostras por ciclo, e projetado, considerando uma frequência fundamental de $60 \mathrm{~Hz}$.

Segundo Duque et al. (2005) um sinal $x(t)$ correspondente a QEE pode ser modelado como a soma de diferentes tipos de fenômenos, sendo expressados como:

$$
x(t)=f(t)+h(t)+\operatorname{tr}(t)+\ldots
$$

sendo que $f(t), h(t), \operatorname{tr}(t)$, fazem referencia à fundamental, harmônicos e transitórios, respectivamente. Assim, um sinal que contêm múltiplos eventos pode ser calculado ou dividido em partes, de modo que cada uma destas representa um evento especifico. Para uma melhor compreensão e levando em conta os distúrbios mencionados na equação, a Figura 5.1 mostra em (a) um sinal senoidal puro, em (b) um sinal de frequência $300 \mathrm{~Hz}$ correspondendo ao $5^{\underline{a}}$ harmônico, e em (c) um transitório 
oscilatório, assim, aplicando (5.1) tem-se como resultado um sinal composto de múltiplos distúrbios como mostrado em (d). Segundo o anterior, este processo é aplicado na geração de todos os sinais listados na Tabela 5.1, obtendo uma grande quantidade de fenômenos elétricos próprios de QEE. As equações paramétricas que definem cada um dos distúrbios individuais são mostradas na Tabela 5.2. Observando esta tabela $\alpha$ representa o parâmetro de variação da amplitude do evento tanto para interrupção, afundamento, elevação quanto para os diferentes componentes harmônicos, representados de acordo com a sua componente ( $3^{\underline{a}}, 5^{\underline{a}}$, $7^{\underline{a}}$ e $9^{\underline{a}}$ harmônico). A função passo unitário $u(t)$ permite o deslocamento do distúrbio ao longo do sinal. Durante a geração de sinais com distúrbios baseados nas equações paramétricas, a variação no valor de $\alpha$ e da posição $u(t)$ permite obter um grande numero de sinais de diferente magnitude em diferentes pontos e com diferentes durações $\left(t_{2}-t_{1}\right)$ de forma controlada.

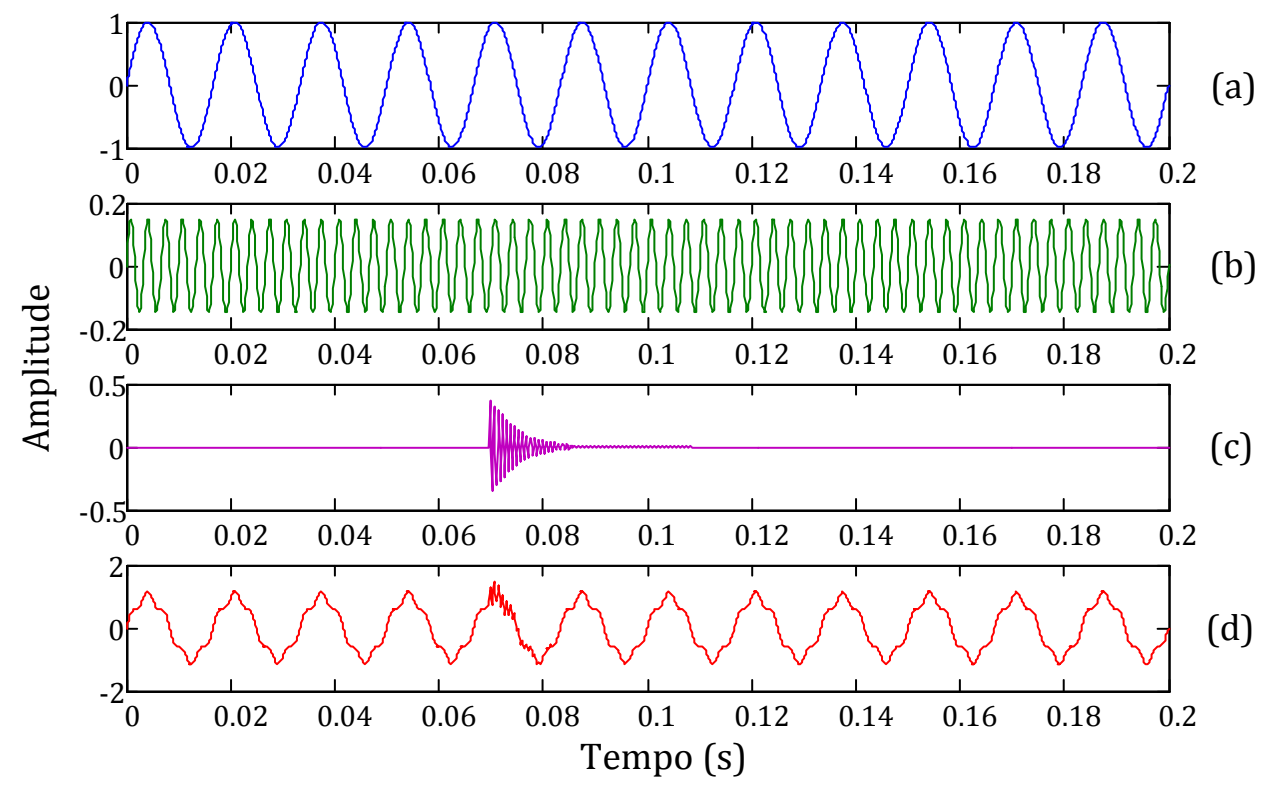

Figura 5.1. Composição de um sinal de QEE. (a) senoide puro, (b) sinal harmônico, (c) sinal com transitório oscilatório, e (d) sinal resultante.

Os transitórios oscilatórios ao igual que o notch, são modelados como uma senoide de magnitude $\alpha$ amortecida por uma constante $\gamma$ que proporciona uma duração entre 5 e 50 milissegundos para frequências $\left(f_{T}\right)$ entre 500 a $3000 \mathrm{~Hz}$ em transitórios e aproximadamente 1milissegundo para notches com frequências entre 2000 e $3000 \mathrm{~Hz}$. 
Cabe anotar que o valor de $\alpha$ no notch apresenta um valor negativo pelo fato de ser uma variação em direção ao zero, segundo as características vistas no capítulo 3 (pag. 43).

Tabela 5.2. Equações paramétricas de distúrbios de QEE.

\begin{tabular}{|c|c|c|}
\hline Distúrbio & Equação Paramétrica & Parâmetros \\
\hline Interrupção & $x(t)=A\left(1-\alpha\left(u\left(t-t_{1}\right)-u\left(t-t_{2}\right)\right)\right) \sin (\omega t)$ & $\begin{array}{l}0,91 \leq \alpha \leq 1,0 \\
T \leq t_{2}-t_{1} \leq 7 T\end{array}$ \\
\hline Afundamento & $t_{1}<t_{2} \quad u(t)=\left\{\begin{array}{lll}1 & \text { se } & t \geq 0 \\
0 & \text { se } & t<0\end{array}\right.$ & $\begin{array}{l}0,08 \leq \alpha \leq 0,9 \\
T \leq t_{2}-t_{1} \leq 7 T\end{array}$ \\
\hline Elevação & $\begin{array}{c}x(t)=A\left(1+\alpha\left(u\left(t-t_{1}\right)-u\left(t-t_{2}\right)\right)\right) \sin (\omega t) \\
t_{1}<t_{2} \quad u(t)=\left\{\begin{array}{l}1 \text { se } t \geq 0 \\
0 \text { se } t<0\end{array}\right.\end{array}$ & $\begin{array}{l}0,08 \leq \alpha \leq 0,8 \\
T \leq t_{2}-t_{1} \leq 7 T\end{array}$ \\
\hline Transitórios oscilatórios & $x(t)=A\left(\sin (\omega t)+\alpha e^{-\gamma\left(t-t_{1}\right)} \sin \left(\omega_{T r} t-t_{1}\right)\right)$ & $\begin{array}{l}0,2 \leq \alpha \leq 2 \\
200 \leq \gamma \leq 1000 \\
500 \leq f_{T r} \leq 3000\end{array}$ \\
\hline Harmônicos & $\begin{array}{c}x(t)=A\left(\alpha_{1} \sin (\omega t)+\alpha_{3} \sin (3 \omega t)+\alpha_{5} \sin (5 \omega t)+\right. \\
\left.\alpha_{7} \sin (7 \omega t)+\alpha_{9} \sin (9 \omega t)\right)\end{array}$ & $\begin{array}{l}\alpha_{1}=1,0 \\
0 \leq \alpha_{3} \leq 0,30 \\
0 \leq \alpha_{5}, \alpha_{7} \leq 0,20 \\
0 \leq \alpha_{9} \leq 0,10\end{array}$ \\
\hline Notch & $x(t)=A\left(\sin (\omega t)+\alpha e^{-\gamma\left(t-t_{1}\right)} \sin \left(\omega_{T r} t-t_{1}\right)\right)$ & $\begin{array}{l}-0,6 \leq \alpha \leq-0,2 \\
1000 \leq \gamma \leq 5000 \\
2000 \leq f_{T r} \leq 3000\end{array}$ \\
\hline
\end{tabular}

Uma vez obtidos os sinais dos distúrbios individuais, cada um por separado, a obtenção de sinais com distúrbios múltiplos se faz evidente, sendo gerados pela soma de distúrbios simples de acordo com (5.1). 0 total de eventos simulados é de 3800, sendo 280 sinais para cada um dos tipos que incluam distúrbio "harmônico" e 200 sinais para cada um dos outros tipos a serem estudados.

\subsection{Transformada S e Wavelet - Análise gráfica em tempo e frequência.}

No decorrer do texto, tem-se exposto a importância e as vantagens de ferramentas que extraem características próprias de um evento dentro de um sinal baseado na análise em tempo e frequência, como também, tem-se mostrado de forma geral algumas aplicações do seu uso em conjunto com outras técnicas na classificação de ditos eventos. Nesta seção pretende-se enxergar, um pouco mais de perto, a abrangência do uso das transformadas S e wavelet na análise de QEE. Para isto, são analisados de 
forma gráfica alguns eventos que contem um ou vários distúrbios, gerados com parâmetros conhecidos seguindo o método paramétrico mostrado na seção anterior.

Com respeito à transformada wavelet, os sinais são decompostos em cinco níveis de resolução (Tabela 5.3), utilizando como wavelet mãe a família daubechies de oito coeficientes $D b$-8. A escolha desta wavelet mãe se deve a ser a wavelet de suporte compacto mais utilizada em aplicações de qualidade de energia (JANIK e LOBOS, 2006; REAZ et al., 2007; POZZEBON et al., 2010)

Tabela 5.3. Faixas de frequências de cada nível decomposto pela TWD.

\begin{tabular}{|c|c|c|}
\hline Nível & Parâmetro & $\begin{array}{c}\text { Faixa de Frequência } \\
\mathrm{Hz}\end{array}$ \\
\hline 1 & Detalhe 1 [D1] & $1920 \sim 3840$ \\
\hline 2 & Detalhe 2 [D2] & $960 \sim 1920$ \\
\hline 3 & Detalhe 3 [D3] & $480 \sim 960$ \\
\hline 4 & Detalhe 4 [D4] & $240 \sim 480$ \\
\hline 5 & Detalhe 5 [D5] & $120 \sim 240$ \\
\hline 5 & Aproximação 5 [A5] & $0 \sim 120$ \\
\hline
\end{tabular}

Por outra parte, e lembrando que a saída da transformada S é uma matriz complexa, onde os vetores fila indicam as frequências e as colunas são os vetores de tempo, é possível determinar componentes no espectro da frequência, tanto como variações do sinal no tempo. Conforme com isto, da matriz complexa da TS é abstraído três tipos de informações, mostrados em forma de gráficos facilitando a interpretação e fazendo mais claro a informação a se transmitir. Primeiro, um gráfico que mostra os valores absolutos das três dimensões da matriz - frequência, tempo, amplitude -, partindo deste e fazendo uso de (5.2) é obtido o gráfico das freqüências que permite visualizar/identificar componentes como a freqüência fundamental e variações no espectro como harmônicos e transitórios, sendo MF (Máximos das Frequências) o vetor que contêm os valores absolutos máximos da relação amplitude - frequência, e por ultimo, é obtido o gráfico que permita ver a relação tempo - amplitude, em aquelas frequências específicas que seja imperioso, isto, por meio do vetor AT (Amplitude no Tempo) fazendo uso de (5.3).

$$
M F=\max \left|S\left[j T, \frac{n}{N T}\right]^{T}\right|
$$




$$
A T=\left|S\left[j T, \frac{n}{N T}\right]\right| \quad \text { para cada } n \text { requerido }
$$

Para começar com a análise, na Figura 5.2 mostra-se um sinal com $40 \%$ de afundamento de tensão de seis ciclos de duração. No primeiro passo, será vista a informação dada pela TS e depois a TWD.

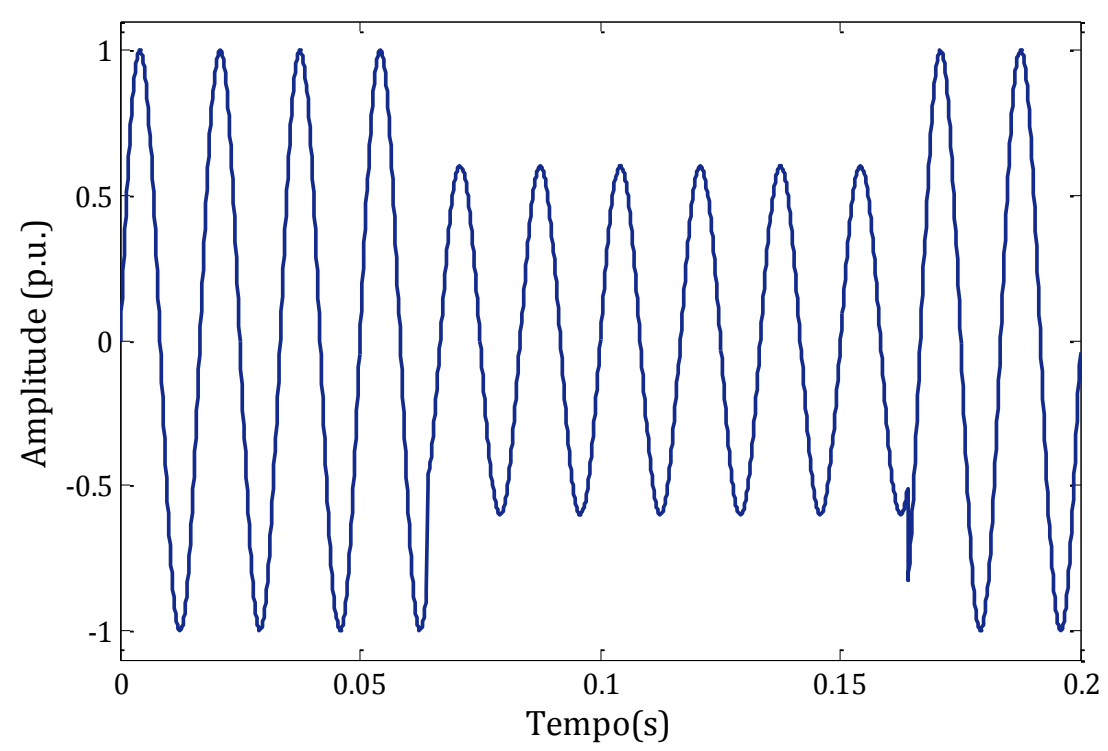

Figura 5.2. Afundamento de tensão

A Figura 5.3 apresenta em (a) o gráfico de três dimensões que permite enxergar a TS como um todo, neste caso, o gráfico em três dimensões mostra uma diminuição na amplitude equivalente ao parâmetro de afundamento estipulado, como também uma variação de frequência nos pontos aonde acontece o inicio e o fim do evento, vistos como uma prolongação de um valor constante, em ambos os casos, ao longo do eixo da frequência.

Com o objetivo de ver um pouco mais de perto as variações tanto na amplitude como na frequência são apresentados em (b) o vetor que contêm os valores absolutos máximos em relação à frequência vs. amplitude, de modo que é possível observar um pico de magnitude importante que faz referencia à frequência fundamental $(60 \mathrm{~Hz})$. Em (c) são mostradas as frequências "ativas" ou picos achados em (b), os quais são aqueles que apresentam uma magnitude significativa que caracteriza uma frequência específica, para este caso é mostrado a frequência fundamental, representando o grau de 
afundamento no eixo do tempo, e a modo de complemento os componentes na maior frequência, sendo possível identificar esses componentes em frequência produzido pela diminuição na amplitude, agora em função do tempo conseguindo determinar, de certo modo, a duração do evento. Seguindo com o anterior, o fato de obter (b) e (c) faz com que sejam encontrados os valores máximos - que determinam as frequências ativas - e determinar o seu comportamento no tempo, permitindo realizar uma análise em tempo e frequência de forma simultânea.

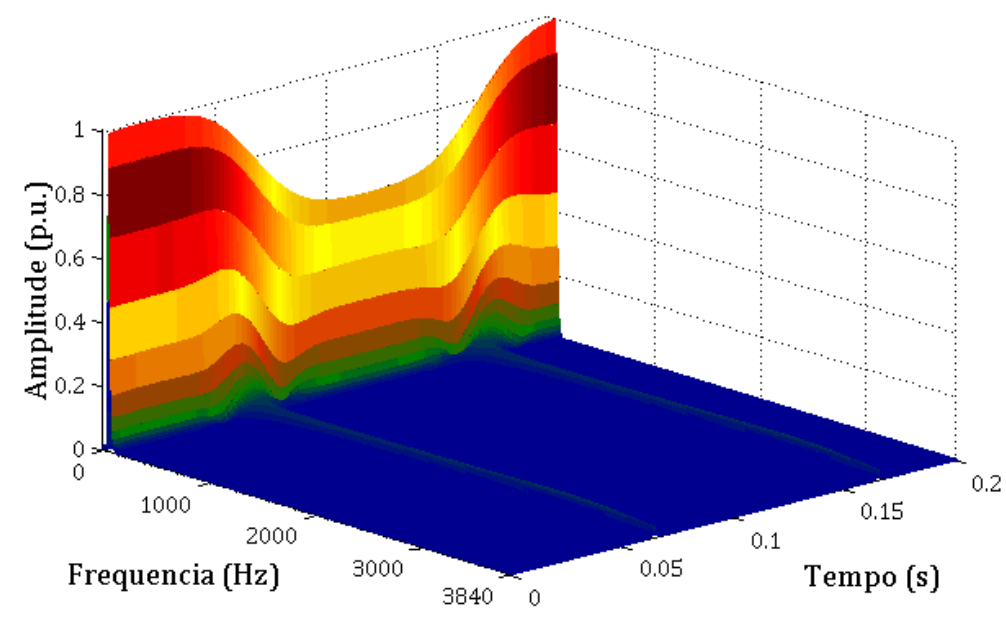

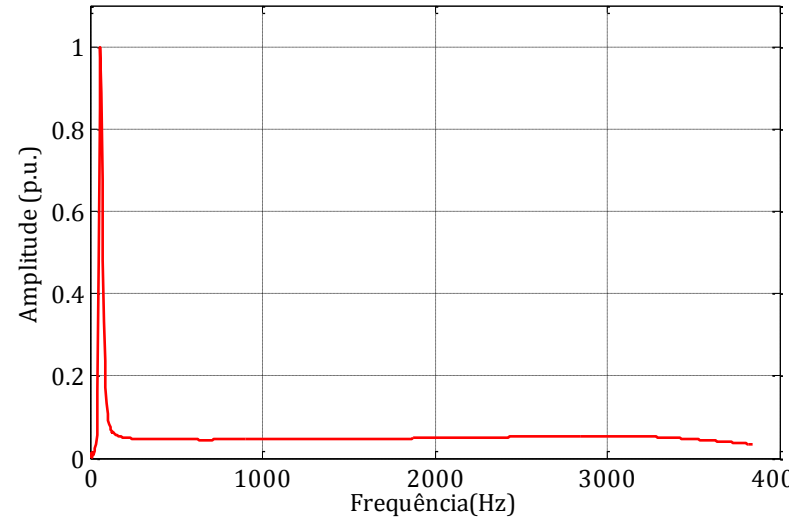

(b)

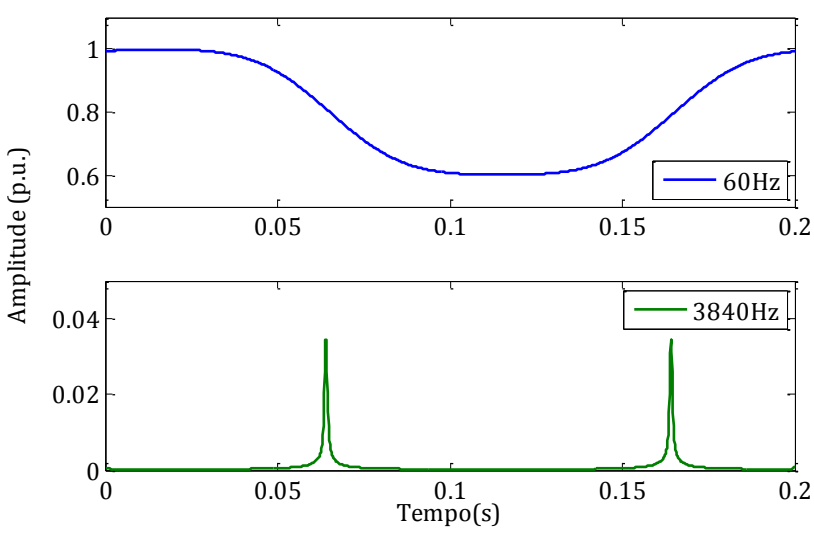

(c)

Figura 5.3. Transformada $S$ aplicada em afundamento de tensão.

Em complemento, a Figura 5.4 apresenta o resultado da TWD nos seus diferentes detalhes (D1-D5) e aproximação (A5). Sendo o afundamento de tensão o evento em análise, é preciso observar a variação em baixas frequências, assim se pode observar em A5 uma diminuição na amplitude, no entanto é importante ver que da mesma forma que 
na TS, nas altas frequências, D1-D4, se observa os componentes correspondentes às variações que marcam o inicio e fim do evento de valor quase constante.

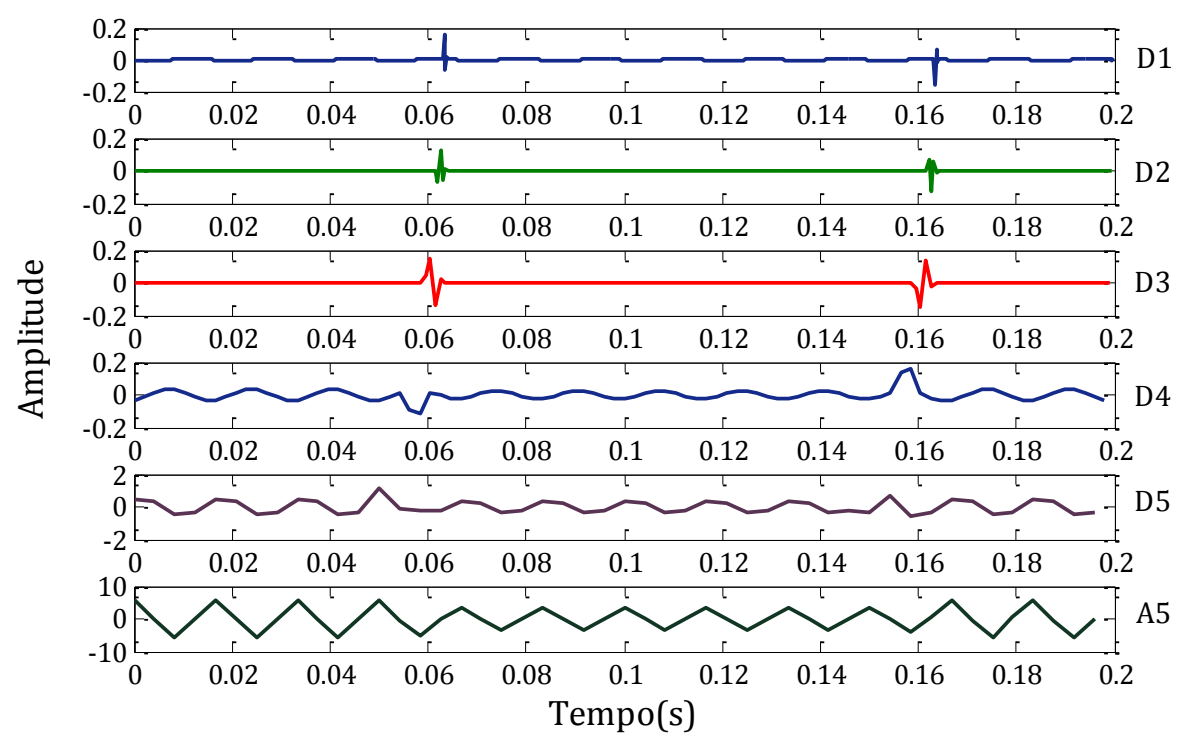

Figura 5.4. Transformada wavelet discreta aplicada em afundamento de tensão.

A continuação se mostra na Figura 5.5 um sinal com uma súbita alteração no regime da tensão com componentes em altas frequências correspondendo a um evento transitório oscilatório. Como parâmetros estabelecidos para este evento são considerados uma amplitude de 0,4 p.u., e uma frequência de $2460 \mathrm{~Hz}$.

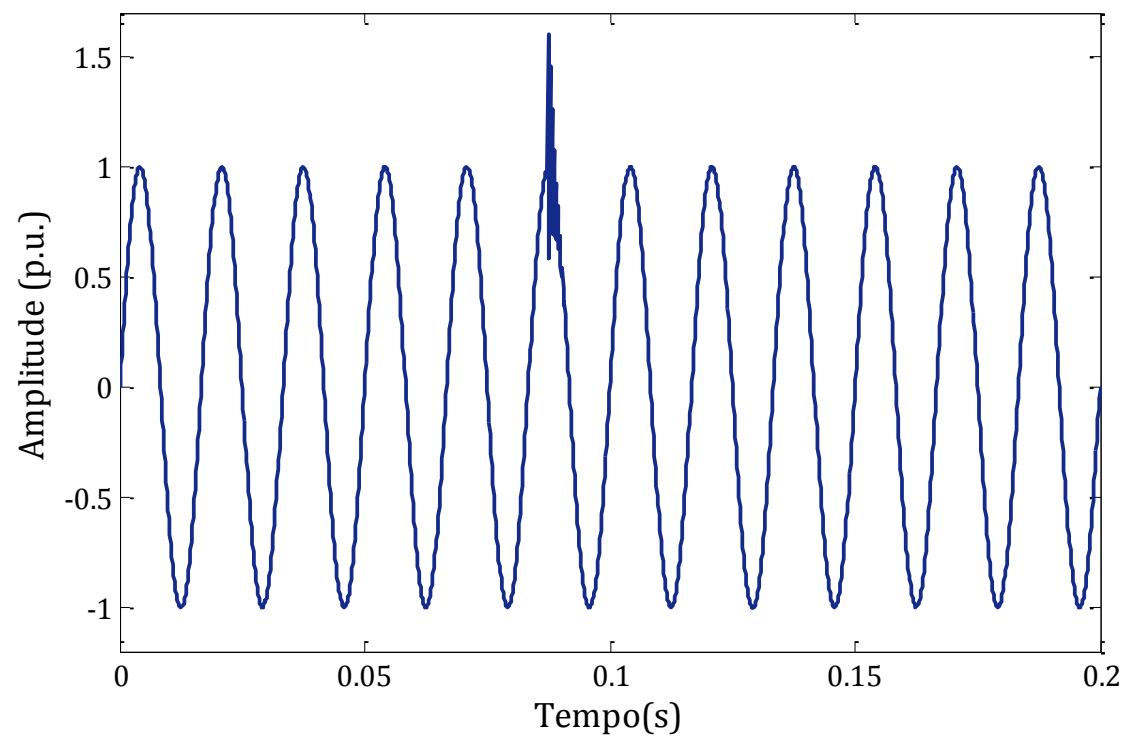

Figura 5.5. Transitório oscilatório. 


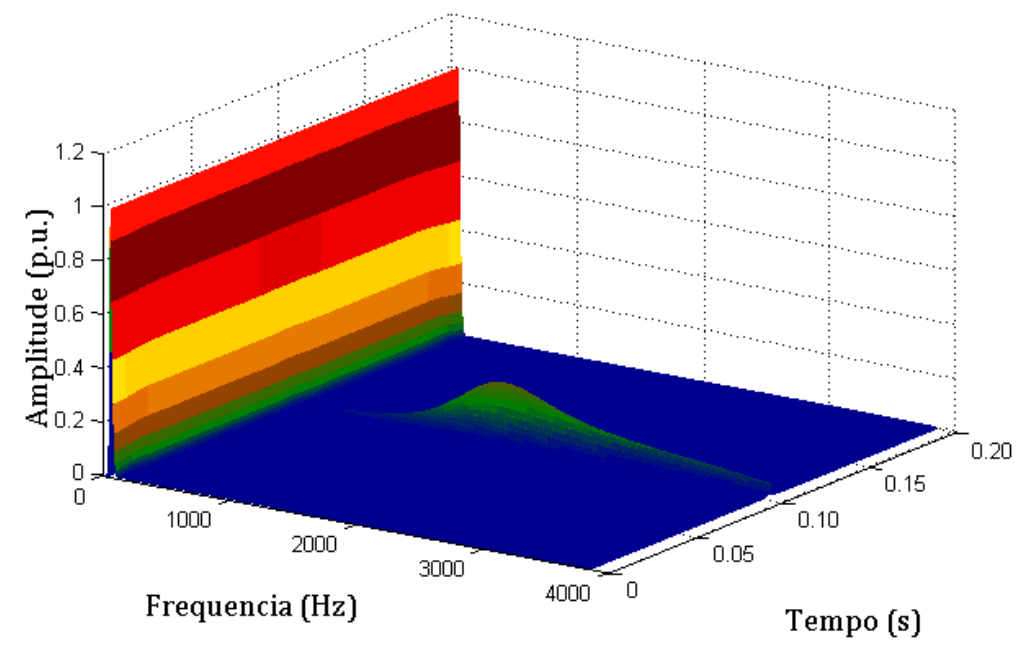

(a)

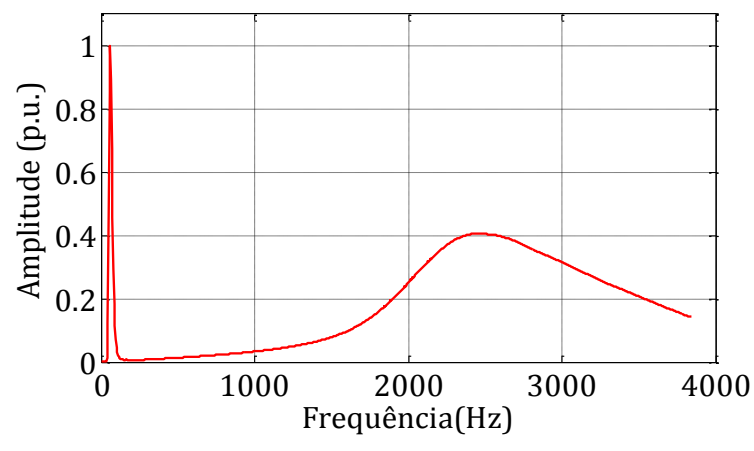

(b)

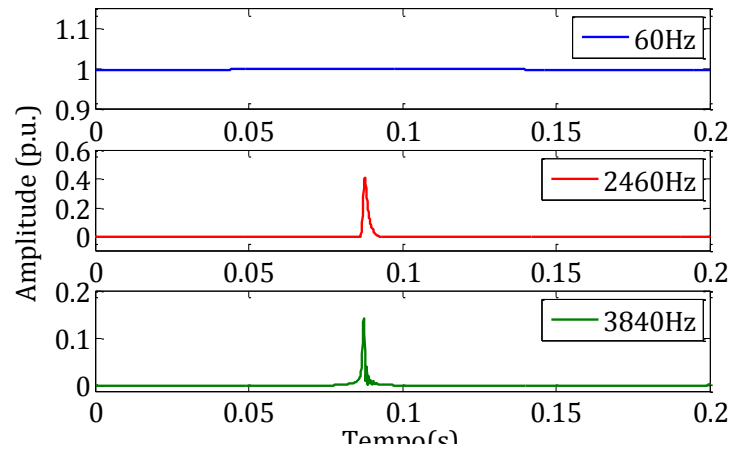

(c)

Figura 5.6. Transformada $S$ aplicada em um sinal com transitório oscilatório.

Assim, uma vez aplicada a TS, a Figura 5.6 exibe a capacidade da transformada em identificar, separar e quantizar o evento, fazendo com que seja fácil determinar tanto a frequência do evento (b) como a sua amplitude e duração (c). Além do anterior é importante observar que a variação súbita característica do transitório não afeta a frequência fundamental.

Da mesma forma que a TS, a TWD presente na Figura 5.7 consegue identificar o evento nos detalhes D1-D3, mostrando a máxima amplitude em D1, estabelecendo assim que o evento apresenta uma maior notoriedade na faixa de frequências correspondente a 1920 3840 Hz acorde aos parâmetros determinados previamente, no entanto os valores dos coeficientes wavelet não refletem a magnitude do evento. 


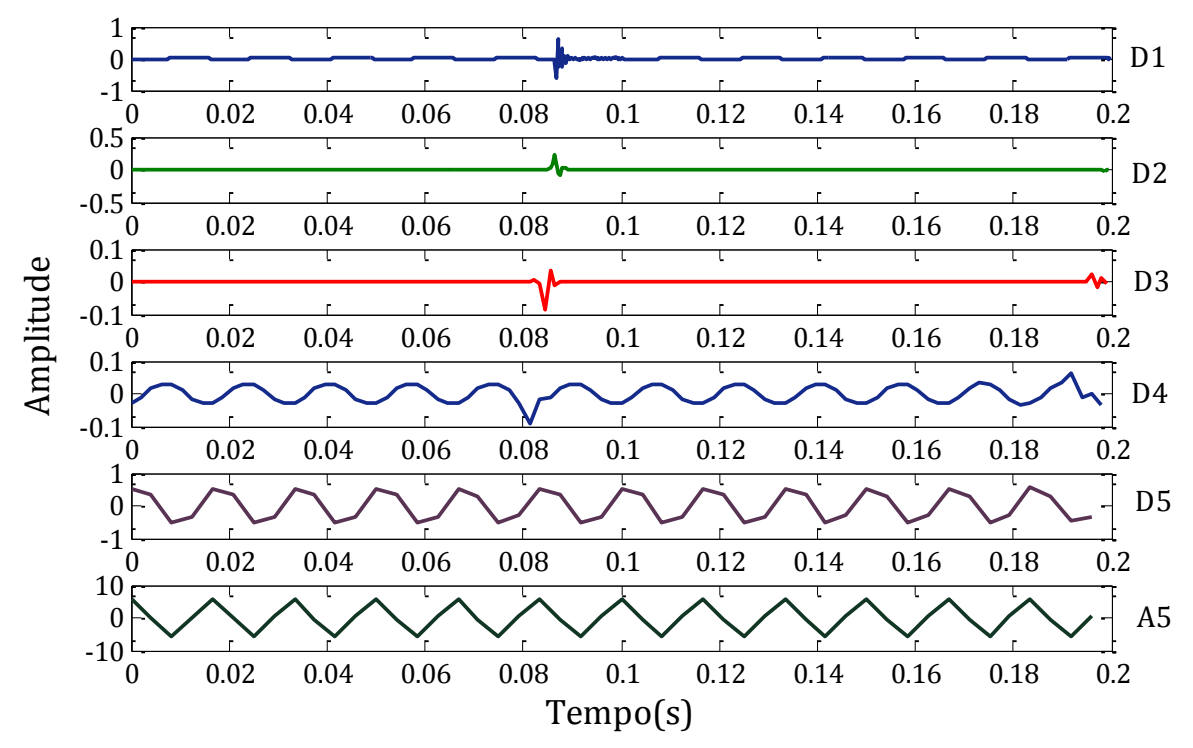

Figura 5.7. Transformada wavelet discreta de transitório oscilatório.

A Figura 5.8 apresenta um sinal com distorção harmônica. Já que as harmônicas são senoides de frequências múltiplas da frequência fundamental, neste caso, foram inseridos componentes harmônicos de 3 a $(180 \mathrm{~Hz})$ e 9 a $(540 \mathrm{~Hz})$ sendo de $20 \%$ e de $8 \%$ do valor nominal da forma da onda seniodal respectivamente.

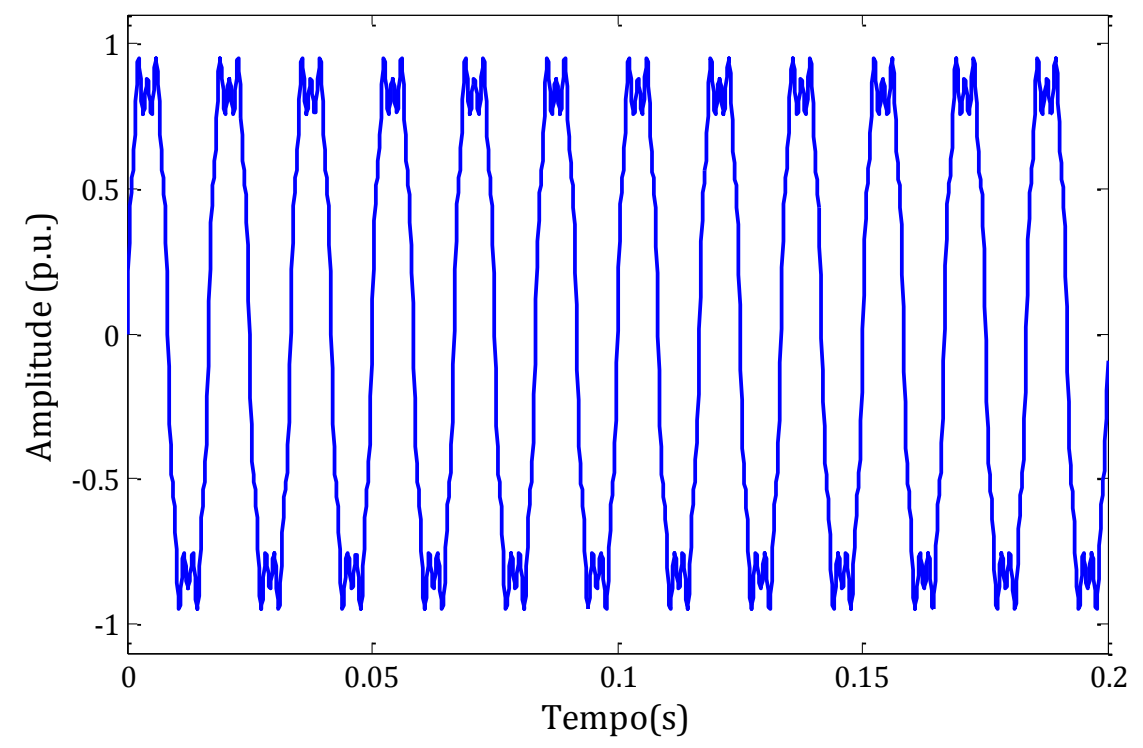

Figura 5.8. Sinal com harmônicos: $3^{\mathrm{a}}$ e $\mathbf{9}^{\mathrm{a}}$. 
Quando a TS é aplicada neste sinal cabe fazer algumas observações, para isto a Figura 5.9 é de grande ajuda. Em (a) consegue-se observar três componentes em frequências especificas que conservam um valor constante ao longo do eixo do tempo. Como visto nos casos anteriores, essa primeira componente faz referencia a componente da frequência fundamental, da mesma forma as duas seguintes apresentam o mesmo comportamento, mas de amplitudes menores, comportando-se como replicas da anterior em freqüências maiores. Seguindo com o mesmo pensamento e sabendo que os harmônicos são senoides de frequências múltiplas á fundamental, é possível afirmar que sinais contínuos inseridos num sinal senoidal puro, na TS, mostrarão um comportamento constante relacionado a sua amplitude. Assim, em (c) são mostrados os valores específicos das frequências ativas e as suas magnitudes,

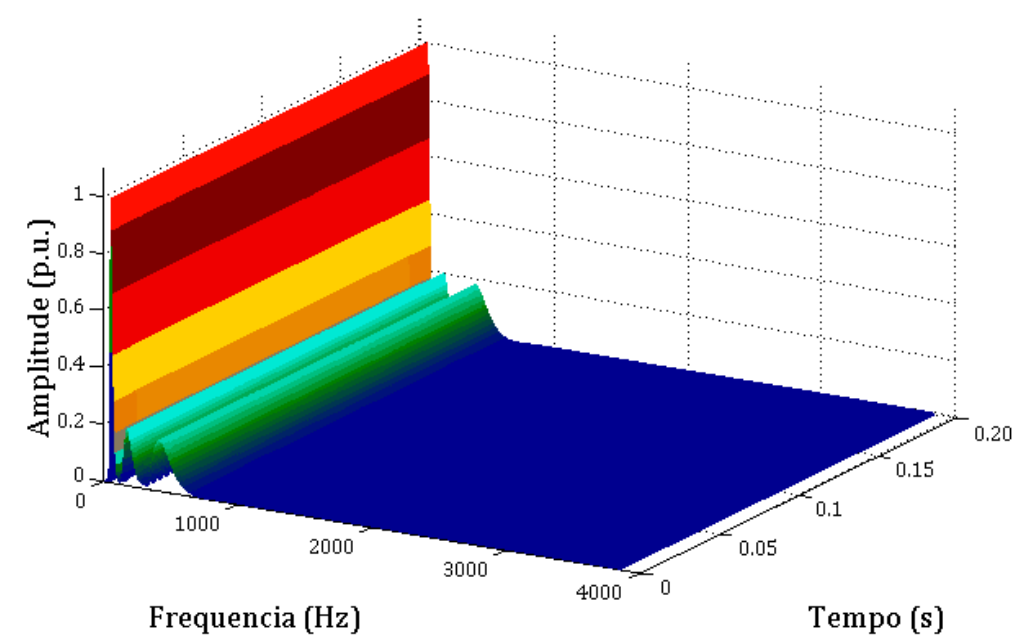

(a)

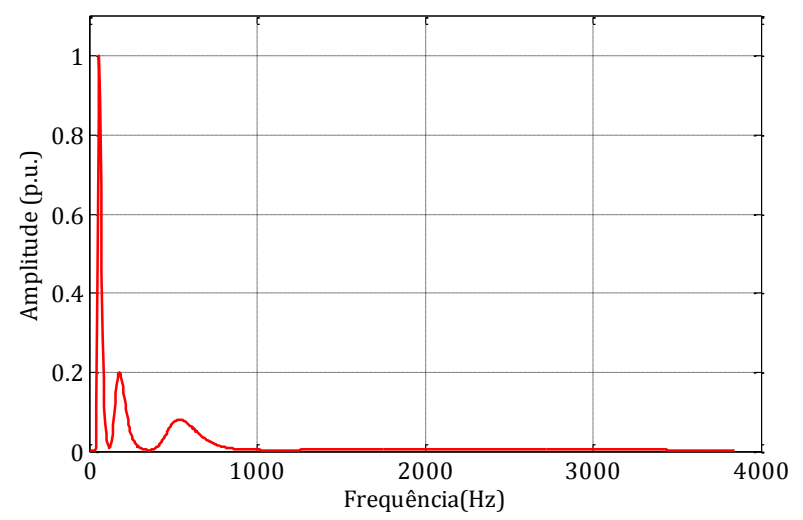

(b)

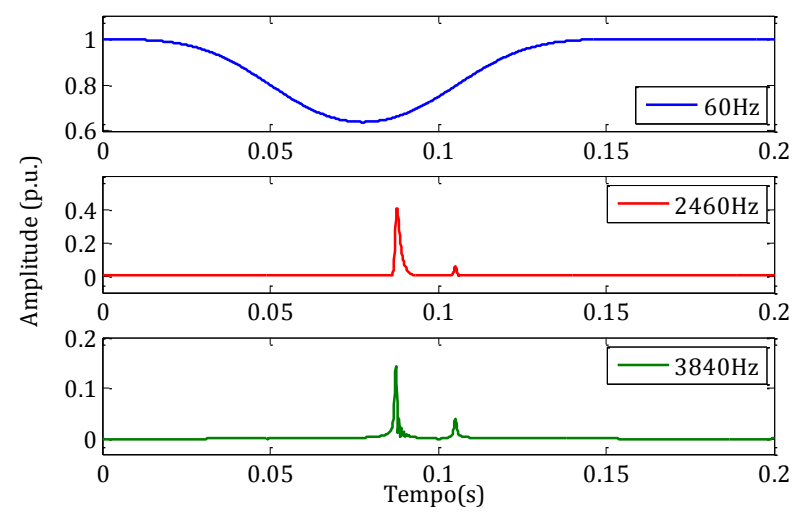

(c)

Figura 5.9. Transformada $S$ aplicada em um sinal com conteúdo harmônico. 
A TWD para o caso de sinais com harmônicos é apresentada na Figura 5.10. Considerando que os harmônicos inseridos são de frequências 180 e $540 \mathrm{~Hz}$ seria de se esperar encontrar-lhos concentrados nos detalhes D5 e D3 respectivamente, porém é observável que nos detalhes D2 a D4 existe a presença de variações que permitiriam identificar o distúrbio, mas as informações do evento em si, seriam insuficientes.

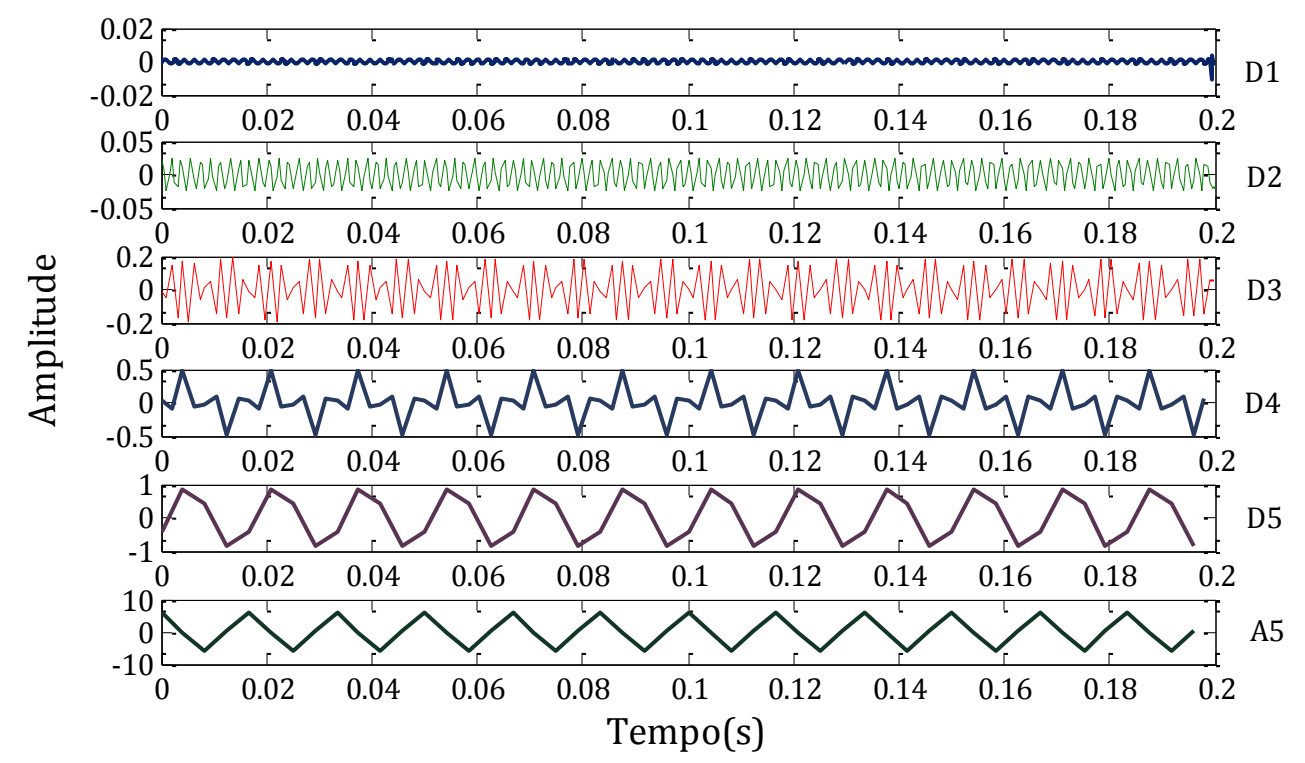

Figura 5.10. Transformada wavelet discreta aplicada em sinal com harmônicos.

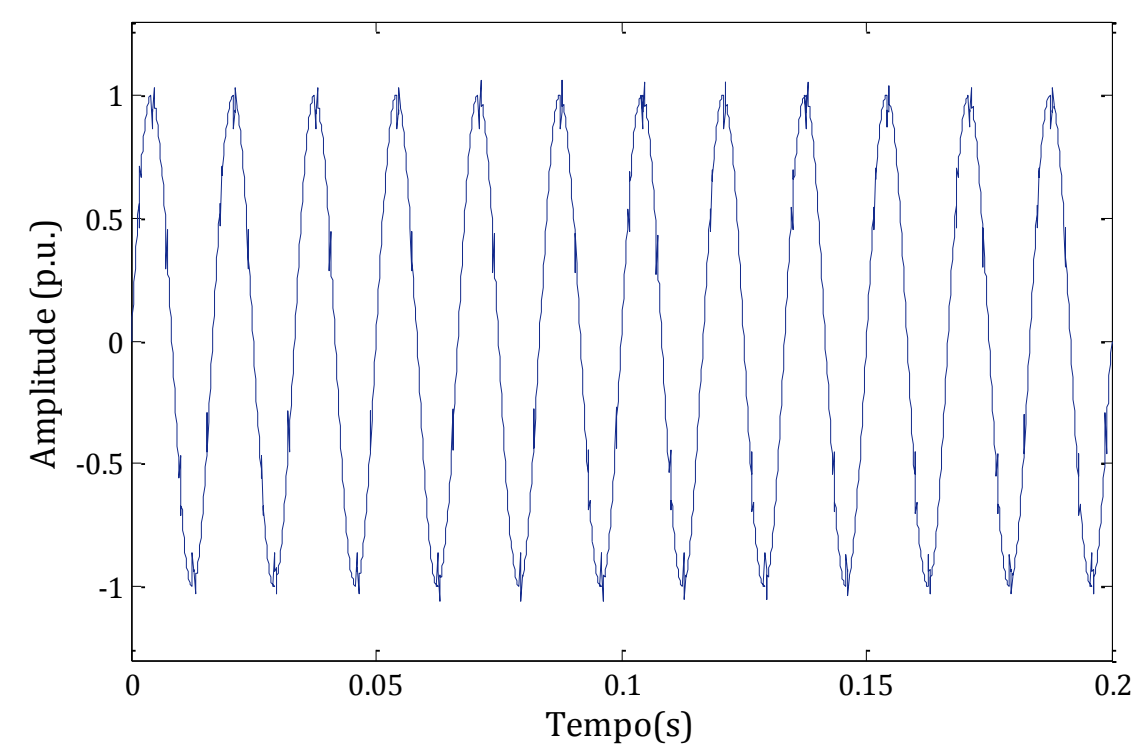

Figura 5.11. Sinal com notch. 
Continuando com os diferentes eventos, na Figura 5.11 é apresentado um sinal com presença periódica de notch. Na análise feita pela TS ilustrada na Figura 5.12 permite observar em (a) que variações rápidas no sinal de tensão são refletidas ao longo do eixo das frequências, mostrando-se como pequenos picos no eixo do tempo. Em relação ás frequências, (b) identifica a frequência fundamental e um leve incremento ao longo do eixo. Entretanto em (c) é observado que, para a frequência fundamental, o notch gera uma pequena diminuição na amplitude e na máxima frequência são mostrados os picos que farão possível diferenciar o notch dos outros distúrbios.

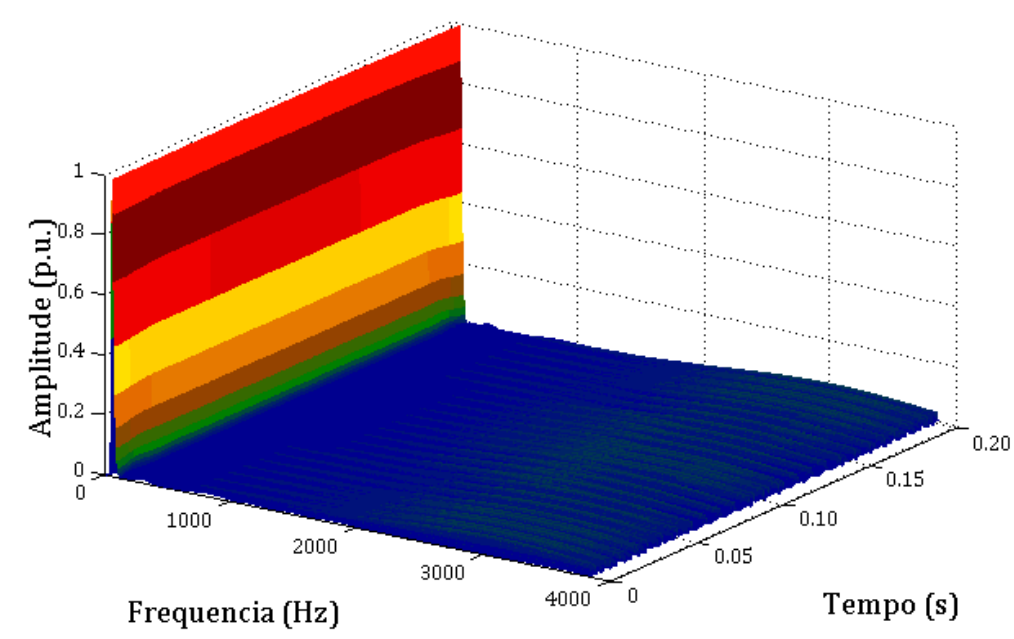

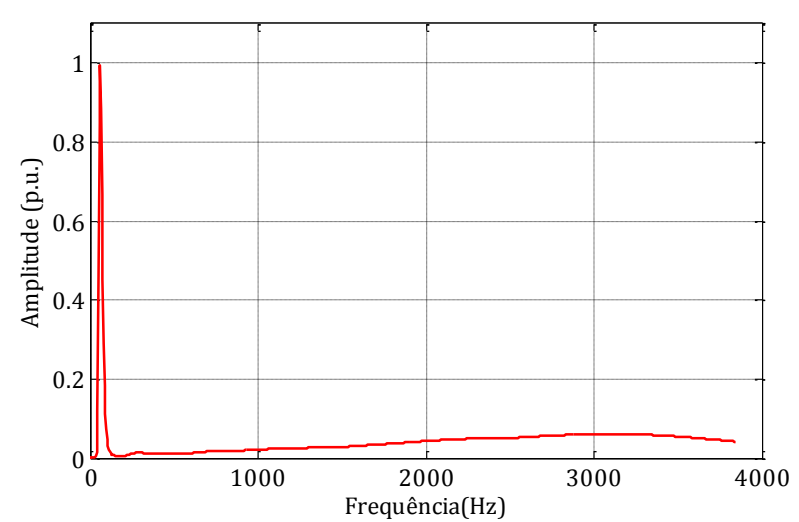

(b)

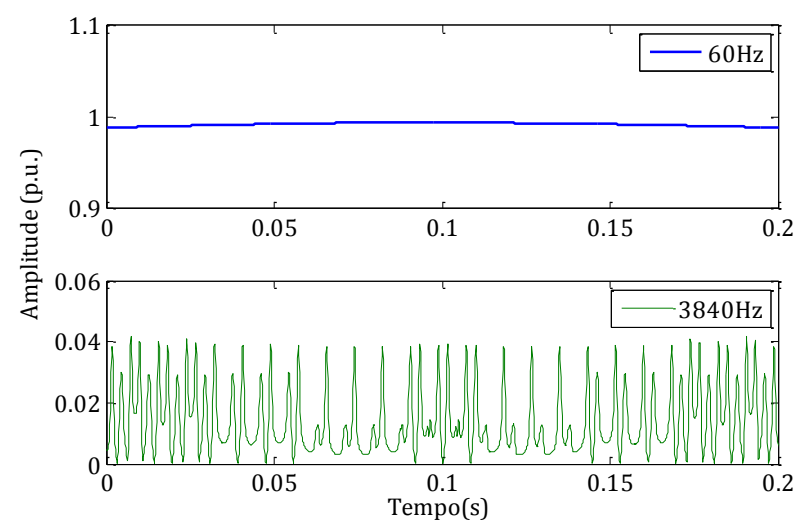

(c)

Figura 5.12. Transformada $S$ aplicada em um sinal com notch.

A Figura 5.13 apresenta os níveis decompostos pela TWD quando o evento notch é avaliado. Os detalhes D1-D4 detectam componentes em frequência derivados do notch. 
Igual que na TS, é perceptível que o notch afeta uma faixa ampla de frequências com amplitudes pequenas e consecutivas.

Já vistos os distúrbios de forma individual, prossegue-se com alguns distúrbios múltiplos, isto permitirá ver o comportamento quando acontecem de forma simultânea abrindo o campo de visão e analise no desenvolvimento deste trabalho. Como primeiro caso de distúrbios mistos a Figura 5.14 ilustra um sinal com afundamento de tensão e transitório oscilatório.

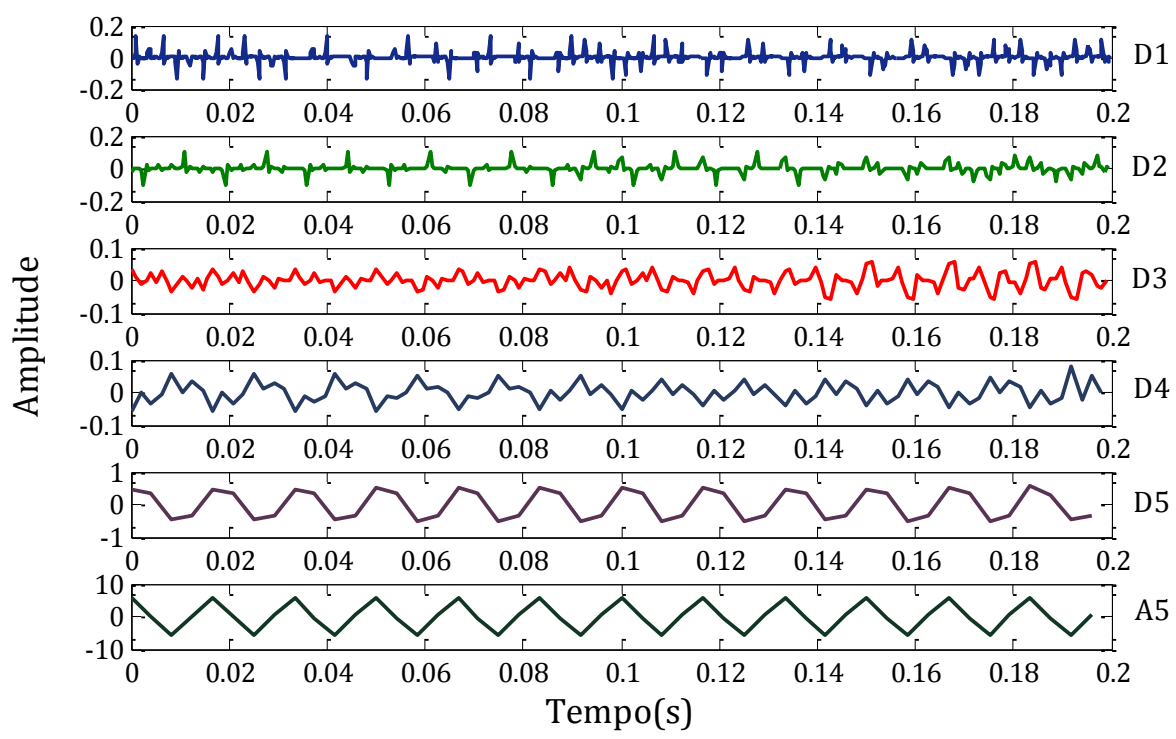

Figura 5.13. Transformada wavelet discreta aplicada em um sinal com notch.

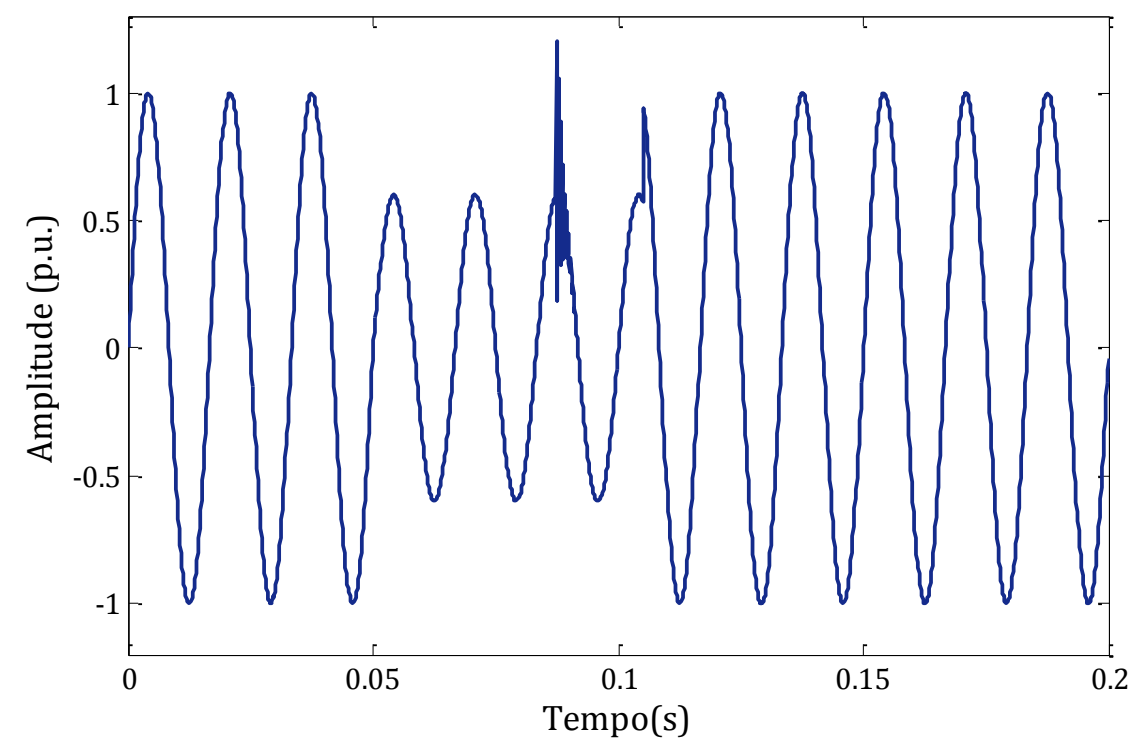

Figura 5.14. Sinal com afundamento de tensão e transitório oscilatório. 
Na Figura 5.15 (a), se diferenciam os dois distúrbios contidos no sinal, a diminuição da amplitude na frequência fundamental indica a presença de afundamento de tensão e o aumento da amplitude nas altas frequências indica a presença de um evento transitório. Em (b) é possível ver os dois picos correspondentes as frequências ativas, tanto a fundamental como a frequência que caracteriza o transitório. Com a finalidade de encontrar um maior numero de características é apresentado em (c) o comportamento destas frequências ativas ao longo do tempo, permitindo conhecer a magnitude do afundamento tanto como a amplitude do transitório além de mostrar na frequência máxima os dois picos representativos do transitório, no primeiro lugar, e um outro que poderia se considerar como o fim do afundamento.

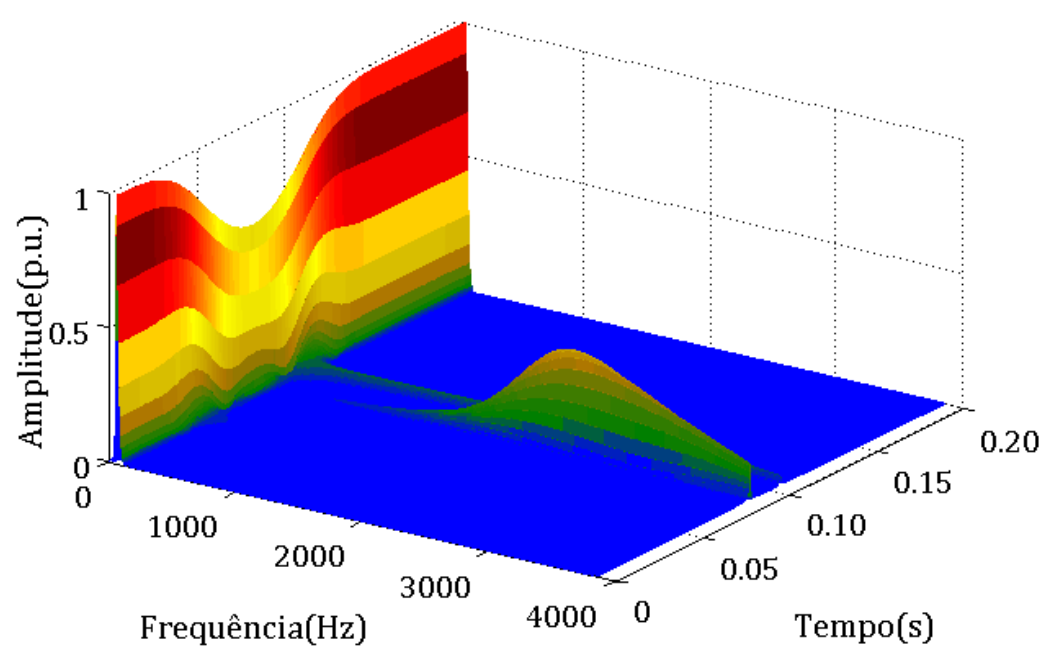

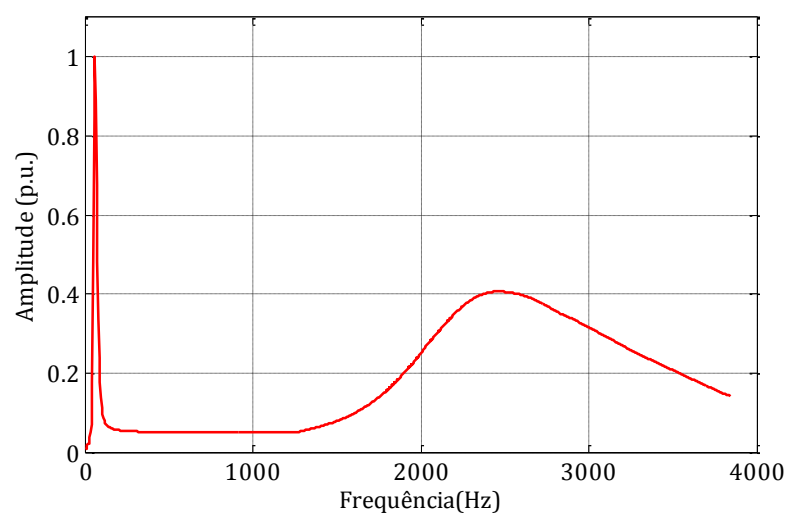

(b)

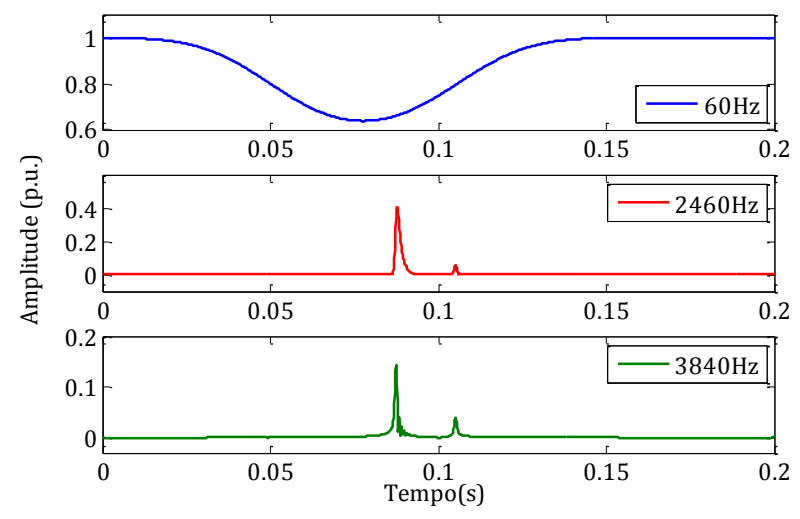

(c)

Figura 5.15. Transformada $S$ aplicada em um sinal com afundamento e transitório oscilatório. 
Por outro lado, quando a TWD é aplicada no sinal, pode-se ver nos detalhes D1 a D4 diferentes picos, destacando em D1 uma variação súbita de amplitude considerável. Além do anterior, em D5 e A5 se encontra uma diminuição na amplitude entre 0,04s e 0,1s indicando um afundamento de tensão. Entanto, as informações estando presentes nos diferentes níveis decompostos tornam-se um pouco confusas na identificação visual dos distúrbios.

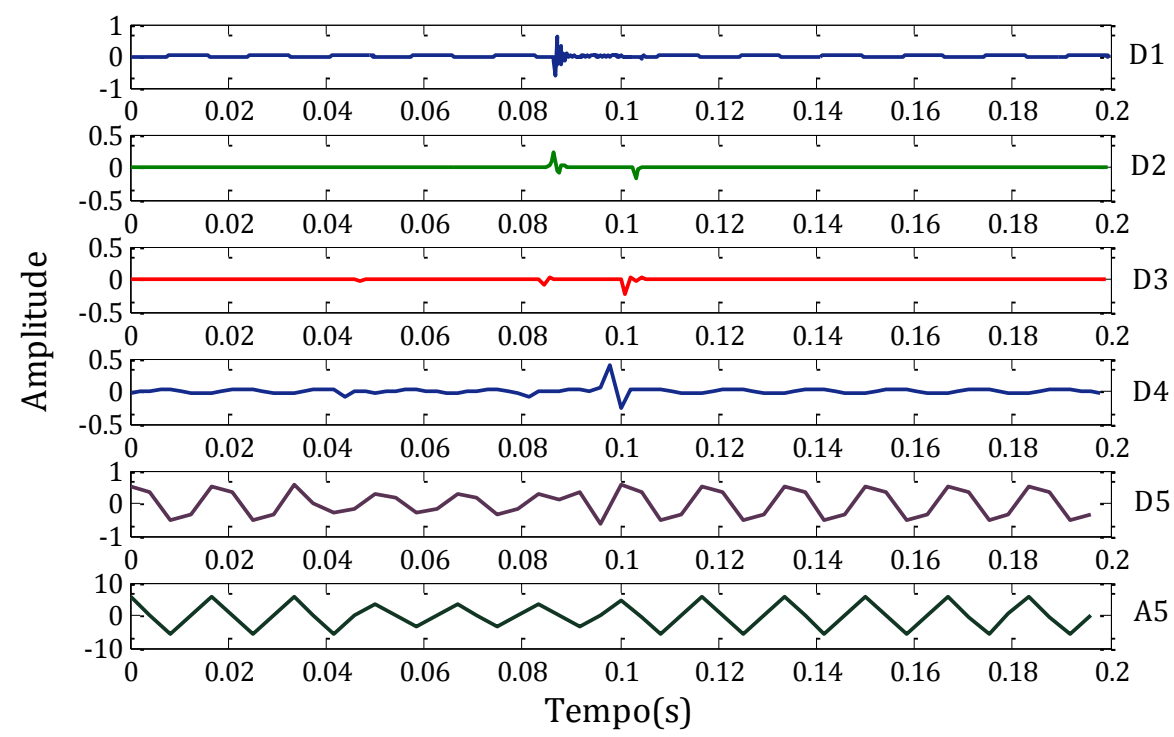

Figura 5.16. Transformada wavelet discreta aplicada em um sinal com afundamento de tensão e transitório oscilatório.

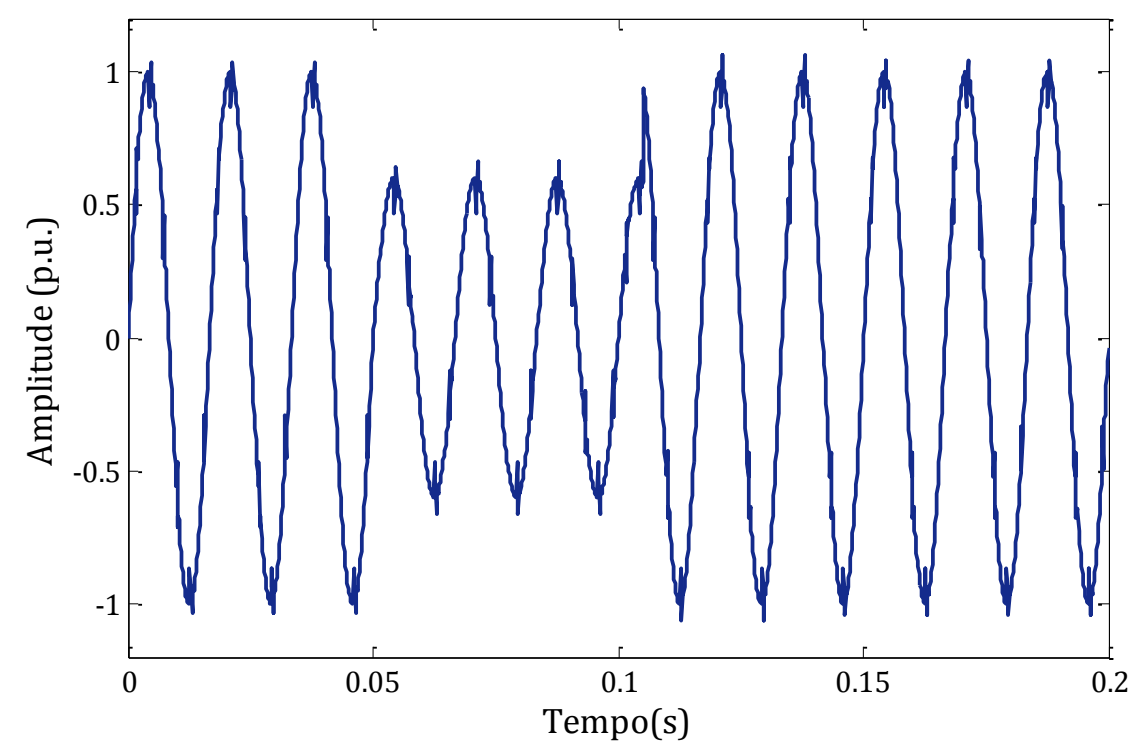

Figura 5.17. Sinal com afundamento de tensão e notch. 
Outro caso de distúrbios mistos é apresentado na Figura 5.17, sendo um sinal composto por afundamento de tensão e notch. Uma vez aplicada a TS neste caso, as características advindas da transformada são exibidas na Figura 5.18. A visão suprida em (a) permite ver a separação dos distúrbios, cada um deles cumprindo o seu papel independentemente como quando apresentados de forma individual. Em (b) e (c) encontram-se a magnitude do afundamento assim como, o gráfico característico do notch.

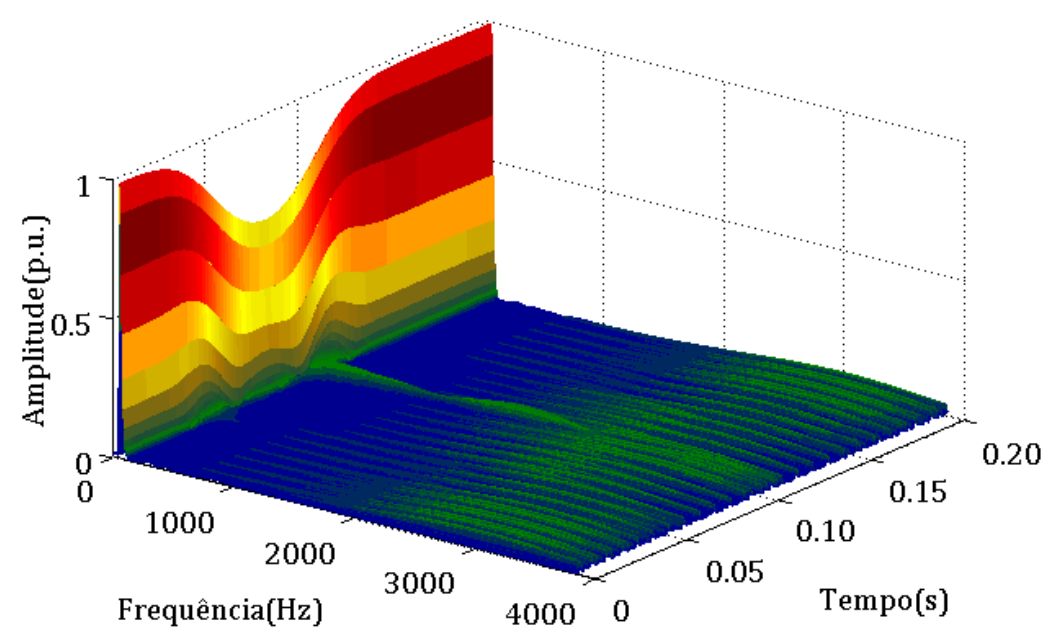

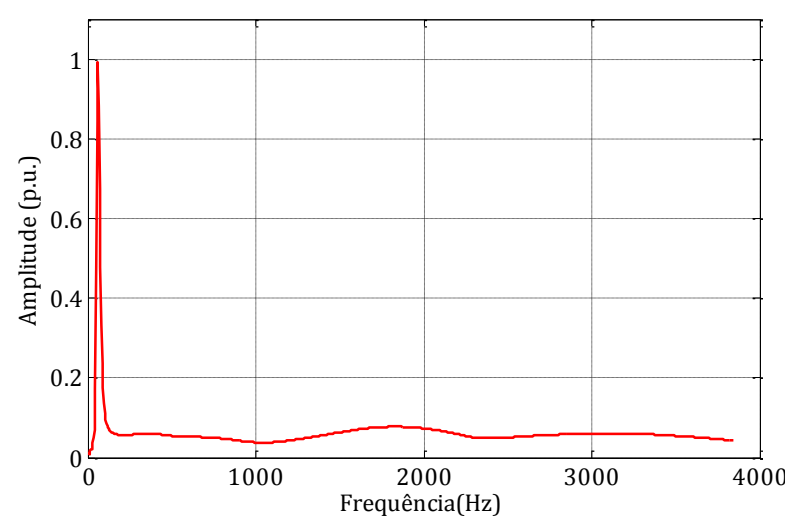

(b)

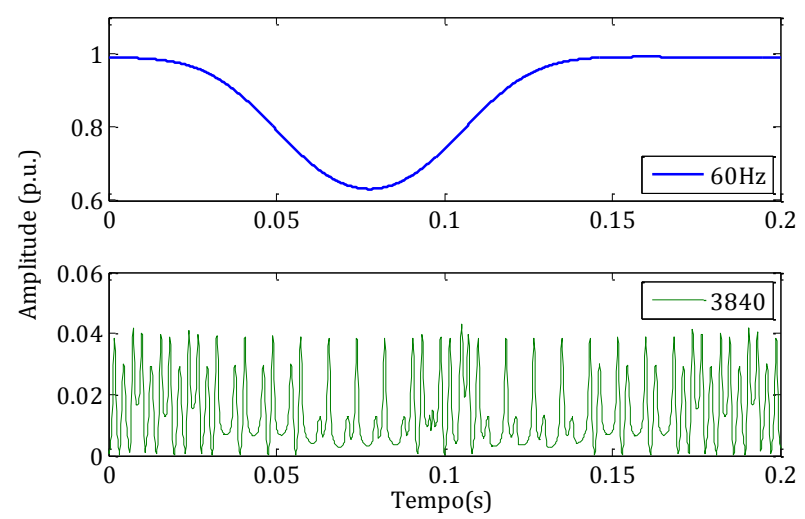

(c)

Figura 5.18.Transformada $S$ aplicada em um sinal com afundamento de tensão e notch.

Através da TWD para o caso afundamento - notch mostrado na Figura 5.19, atendendo só a os extremos das frequências, pode-se observar o comportamento dos distúrbios analisados por separado, de forma que em A5 nota-se uma diminuição na 
amplitude e em D1 se observa o comportamento do notch (picos periódicos). Contudo quando se observa os detalhes D2 a D4, os coeficientes wavelet também mantêm um formato semelhante ao encontrado na análise do evento notch individual.

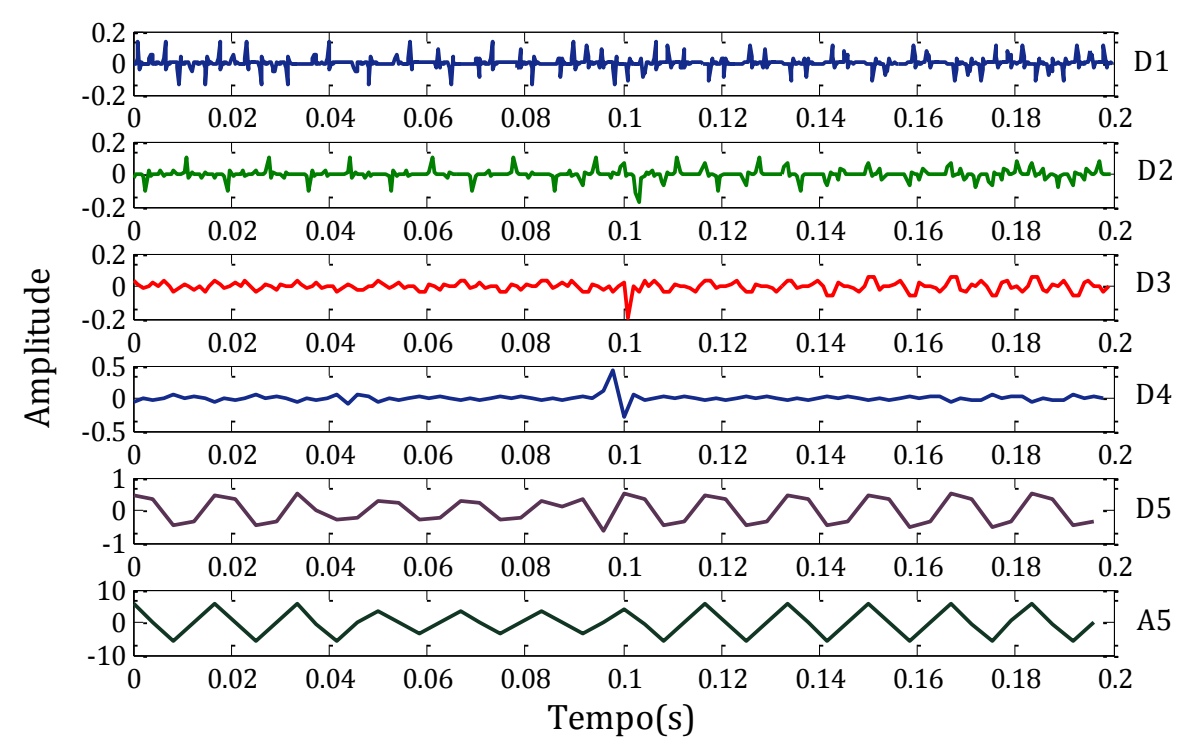

Figura 5.19. Transformada wavelet discreta aplicada em um sinal com afundamento de tensão e notch.

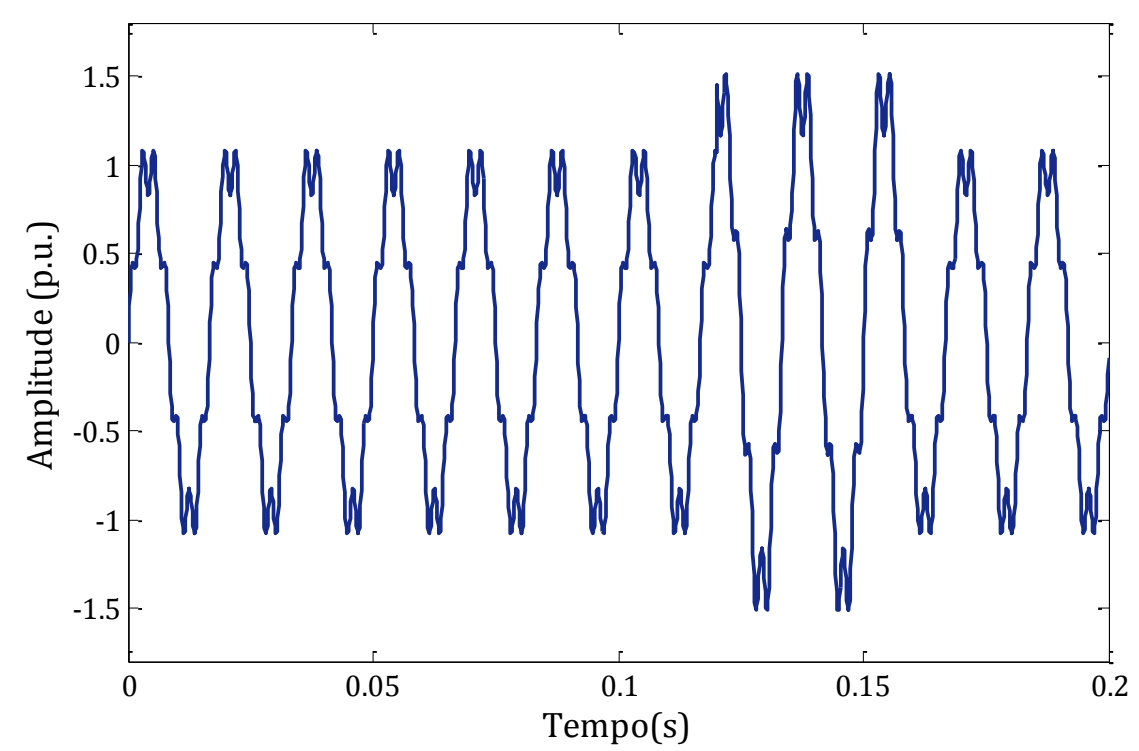

Figura 5.20. Sinal com conteúdo harmônico e elevação de tensão.

A Figura 5.20 apresenta um sinal misto, composto de $7^{\text {a }}$ harmônica e elevação de tensão. Como em casos anteriores que incluem eventos que afetam a componente da frequência fundamental, a TS apresenta a saída desejada representando de forma clara o 
evento (Figura 5.21(a)). Como mencionado anteriormente na análise de harmônicos (Figura 5.9), seniodes de frequências múltiplas á fundamental apresentam o mesmo comportamento ao longo do tempo por serem replicas que possuem uma frequência maior e uma amplitude própria. Deste modo, variações na amplitude na componente da frequência fundamental serão refletidas nas freqüências múltiplas subseqüentes como mostrado em (c), sendo estas as frequências ativas localizadas em (b).

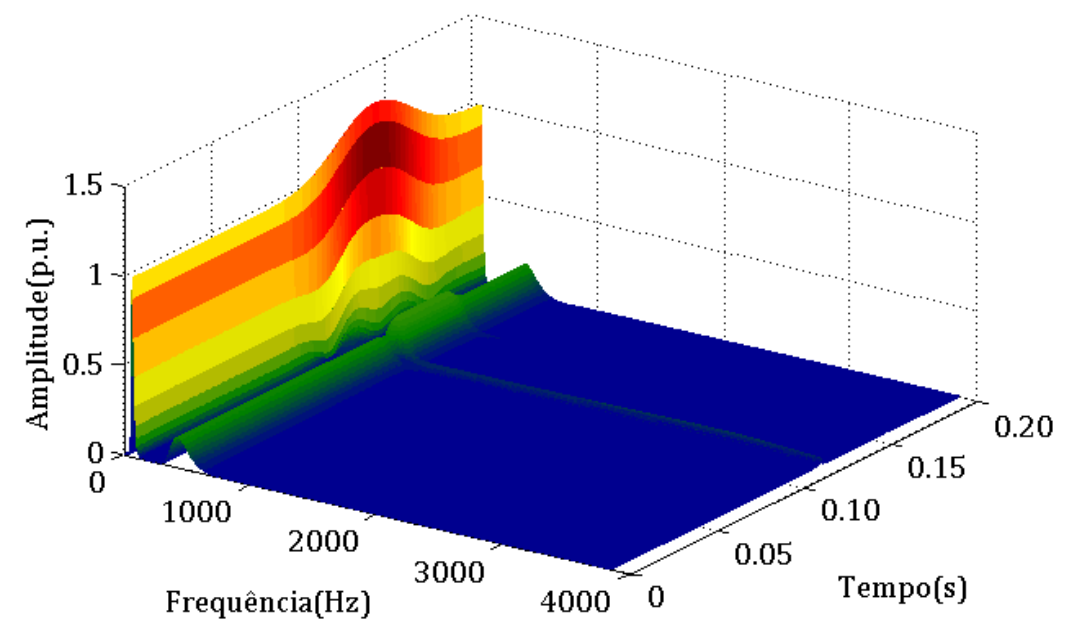

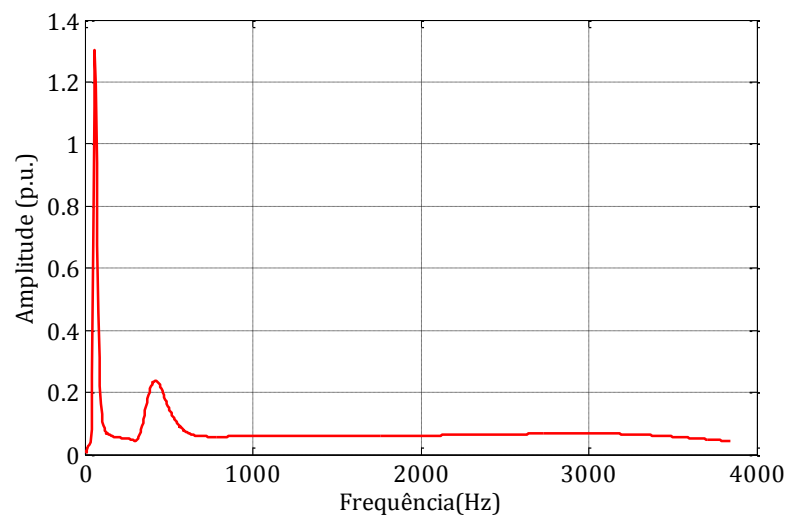

(b)

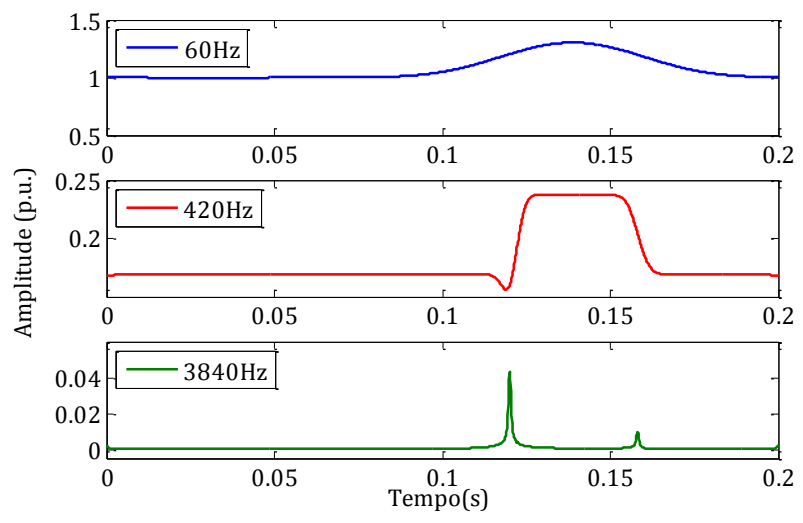

(c)

Figura 5.21. Transformada $S$ aplicada em um sinal com harmônicos e elevação de tensão.

Por sua parte a TWD (Figura 5.22) apresenta uma elevação na amplitude na aproximação A5 e amplitudes consideráveis referentes ao conteúdo harmônico em D4 e D5 abrangendo uma faixa de frequência de 120 a $480 \mathrm{~Hz}$, sem somar os componentes no detalhe D3. 


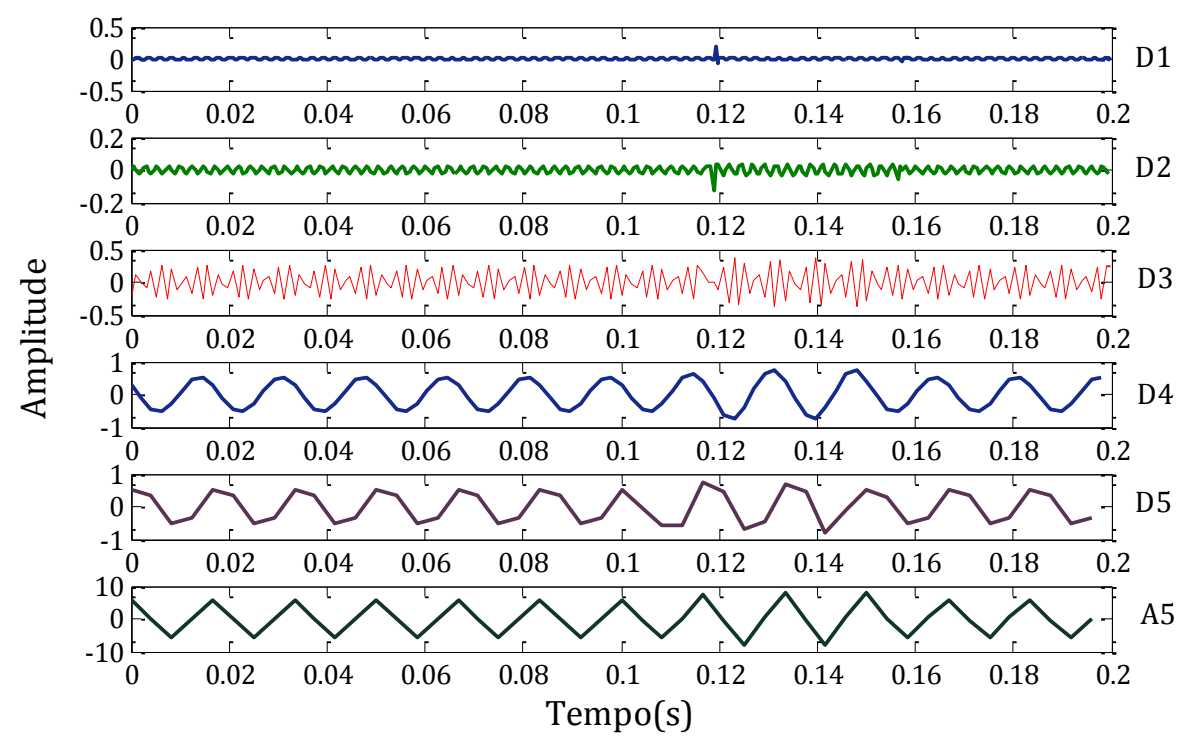

Figura 5.22. Transformada wavelet aplicada em sinal com harmônicos e elevação de tensão.

A continuação é apresentada na Figura 5.23 um sinal com elevação de tensão atingindo os 1,8 p.u. de amplitude, em combinação com um evento transitório oscilatório de frequência $1750 \mathrm{~Hz}$ e amplitude de 0,2 p.u.

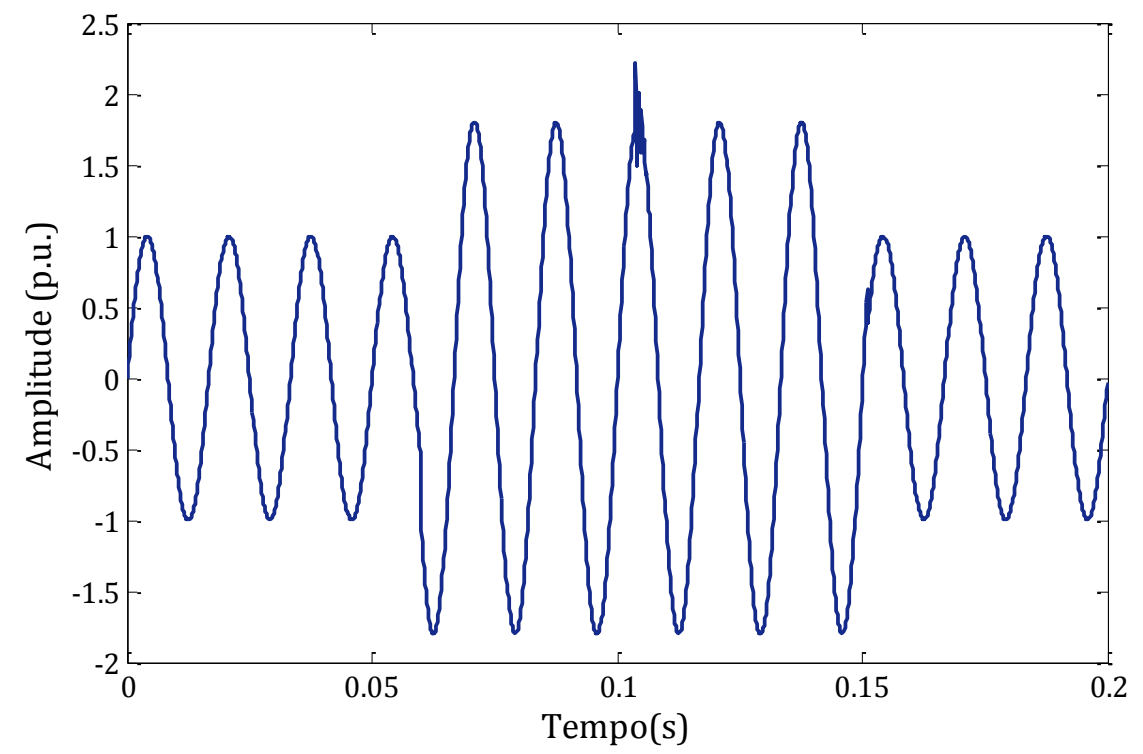

Figura 5.23. Sinal com elevação de tensão e transitório oscilatório.

Aplicando a TS são captadas características que diferenciam um distúrbio do outro, na Figura 5.24(a) se aprecia cada um dos distúrbios em localizações especificas no tempo e 
na frequência; em (b) são mostrados os picos que determinam as frequências ativas para em (c) serem apresentados em função do tempo, adicionando a estas a frequência máxima, aonde são mostrados três picos de pequena amplitude os quais determinam o transitório e as variações na amplitude da frequência fundamental e que são propagadas ao longo das frequências da mesma forma que no afundamento. A TS consegue determinar frequências especifica e magnitudes de cada distúrbio.

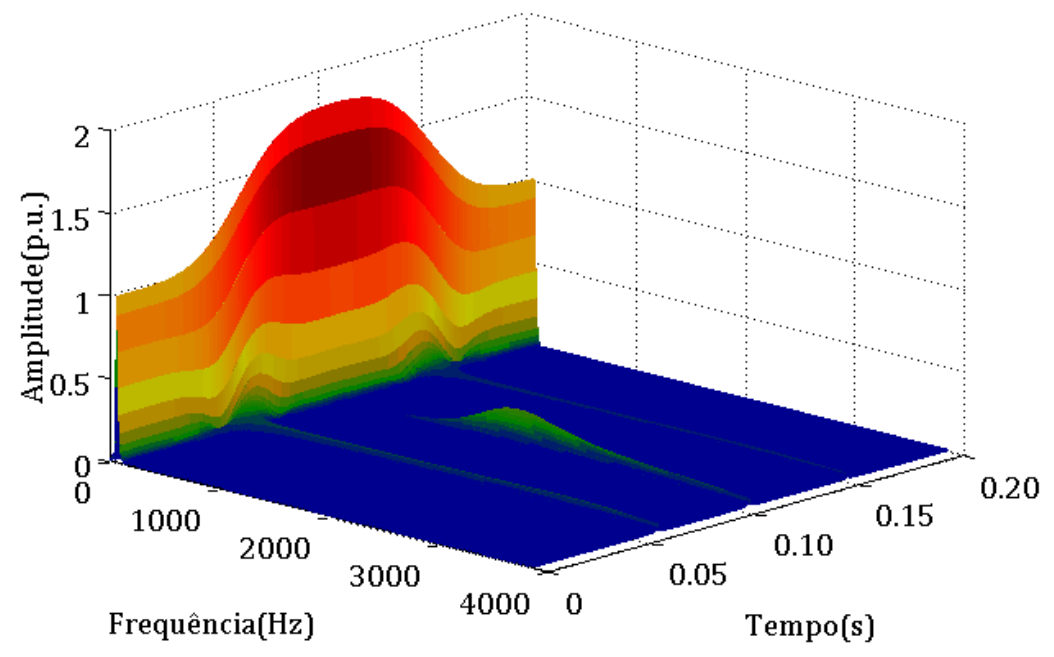

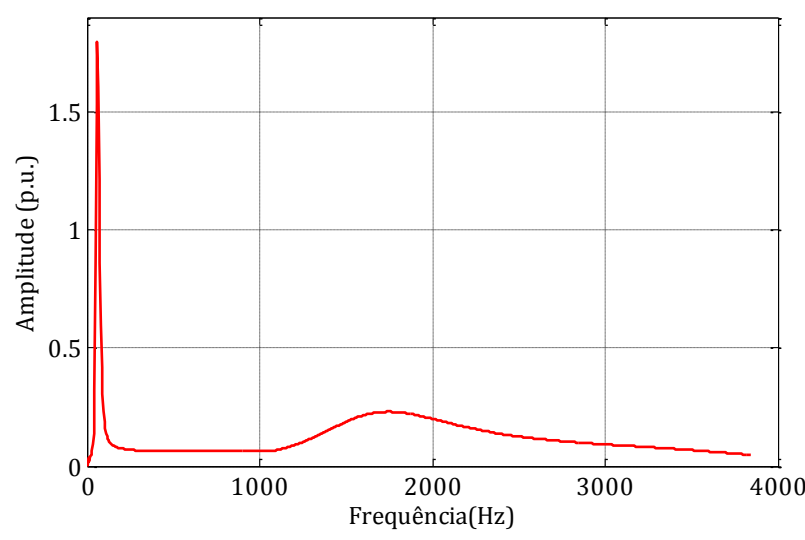

(b)

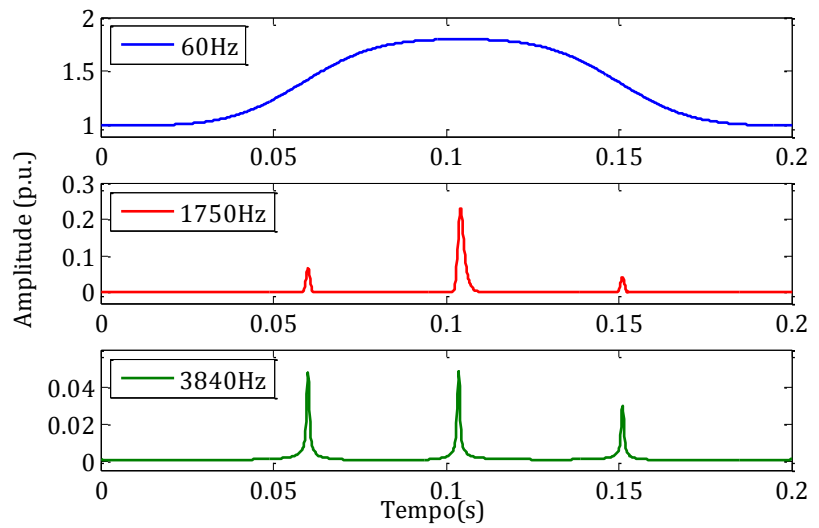

(c)

Figura 5.24. Transformada $S$ aplicada em um sinal com elevação de tensao e transitório oscilatório.

Para o caso da transformada wavelet a Figura 5.25 apresenta o comportamento do sinal nos diferentes detalhes e aproximação. Observando os detalhes D1 e D2 é localizado o 
transitório oscilatório com igual magnitude $(0,28)$; já na aproximação se nota uma elevação na amplitude determinando o evento.

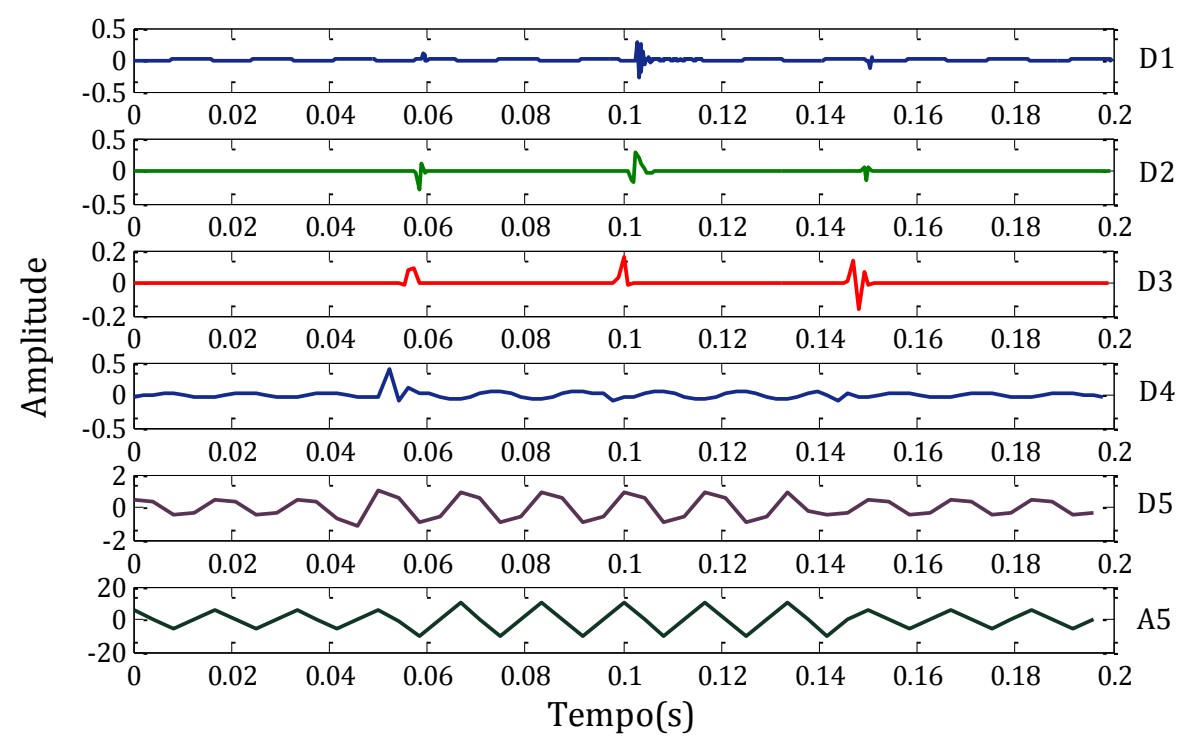

Figura 5.25. Transformada wavelet aplicada em um sinal com elevação de tensão e transitório oscilatório.

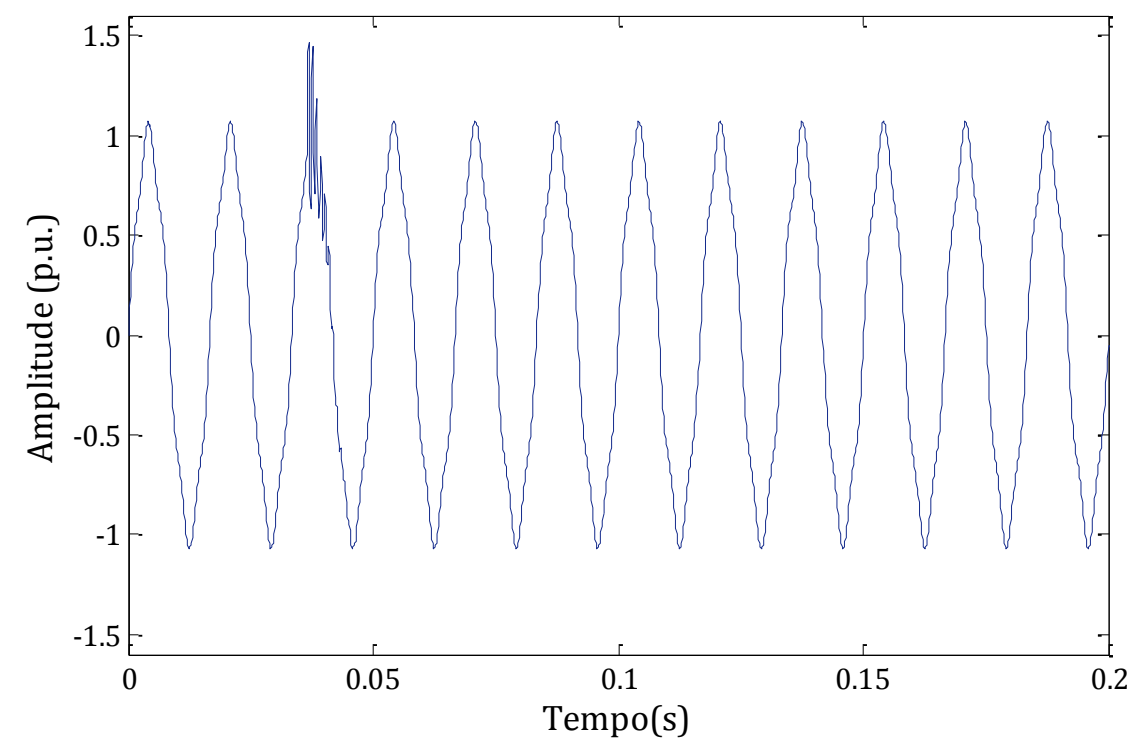

Figura 5.26. Sinal com presencia de harmônicos e transitório oscilatório.

O ultimo caso a ser apresentado corresponde a um sinal com 7\% da $5^{\text {a }}$ componente harmônica e com presença de transitório oscilatório, mostrado na Figura 5.26. 0 resultado da TS é apresentado na Figura 5.27. No gráfico 3D são facilmente reconhecidos 
os distúrbios atuantes, contudo, em (b) são mostradas as freqüências ativas: a componente da frequência fundamental, a $5^{\underline{a}}$ harmônica e a freqüência do transitório, e em (c) são observadas as variações da amplitude e as magnitudes.

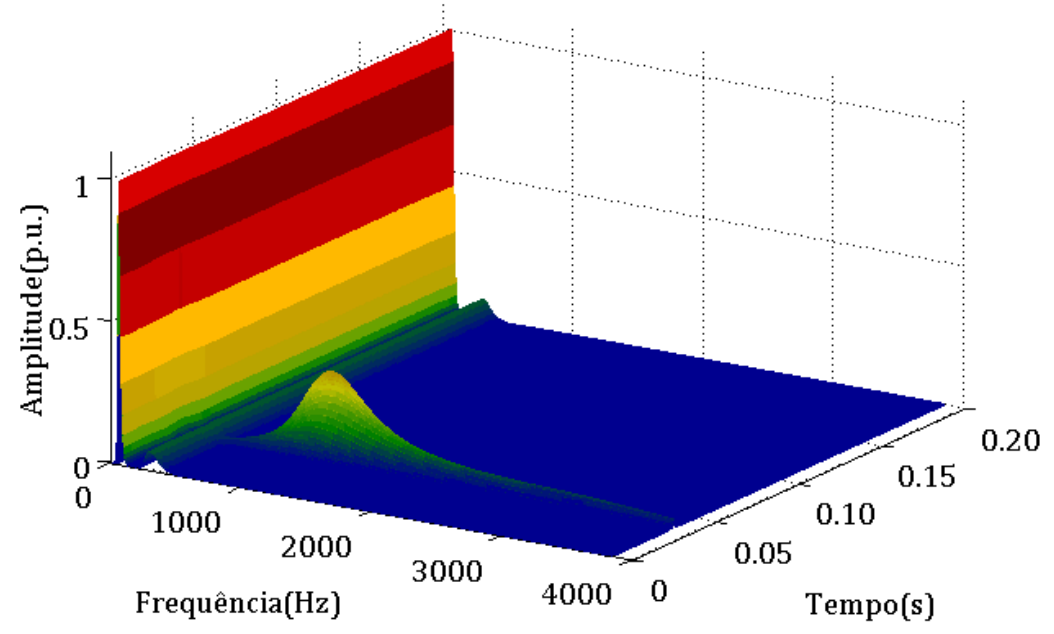

(a)

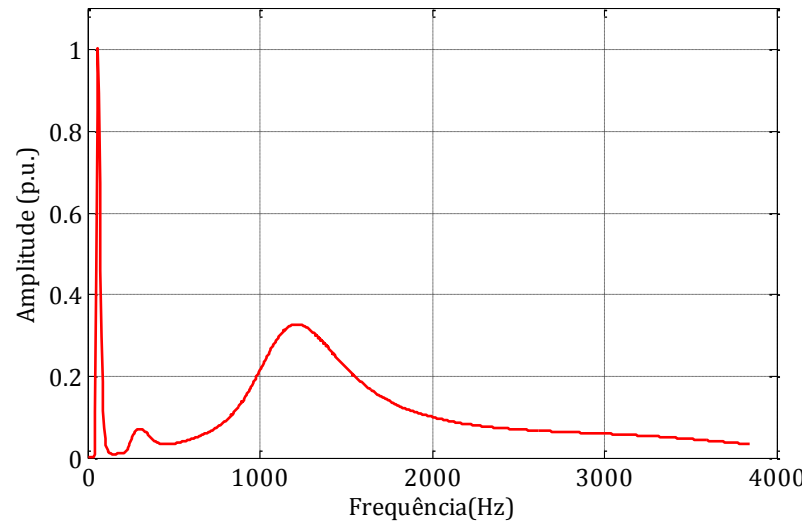

(b)

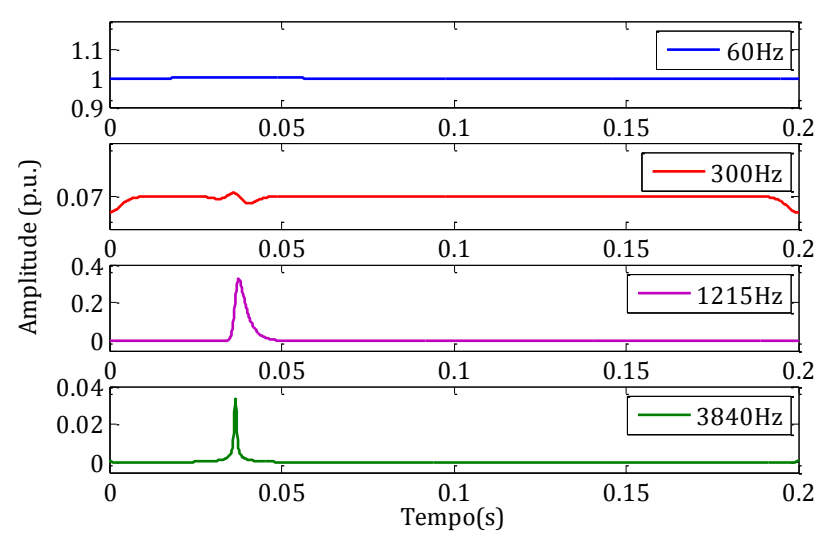

(c)

Figura 5.27. Transformada $S$ aplicada em um sinal com harmônicos e transitório oscilatório.

Por sua parte a TWD localiza o transitório oscilatório nos detalhes D1, D2 e D3 encontrando uma maior amplitude em D2 (960 1920 Hz). É importante observar que os valores referentes aos harmônicos estão distribuídos nos detalhes D4 e D5, com predomínio no detalhe D5 com faixa de frequência de 120 a $240 \mathrm{~Hz}$. Sabendo a magnitude do componente harmônico previamente, pode-se assegurar que, neste caso, a 
transformada wavelet "indicaria" a presencia de um evento, sem conseguir discriminá-lo em razão de sua capacidade.

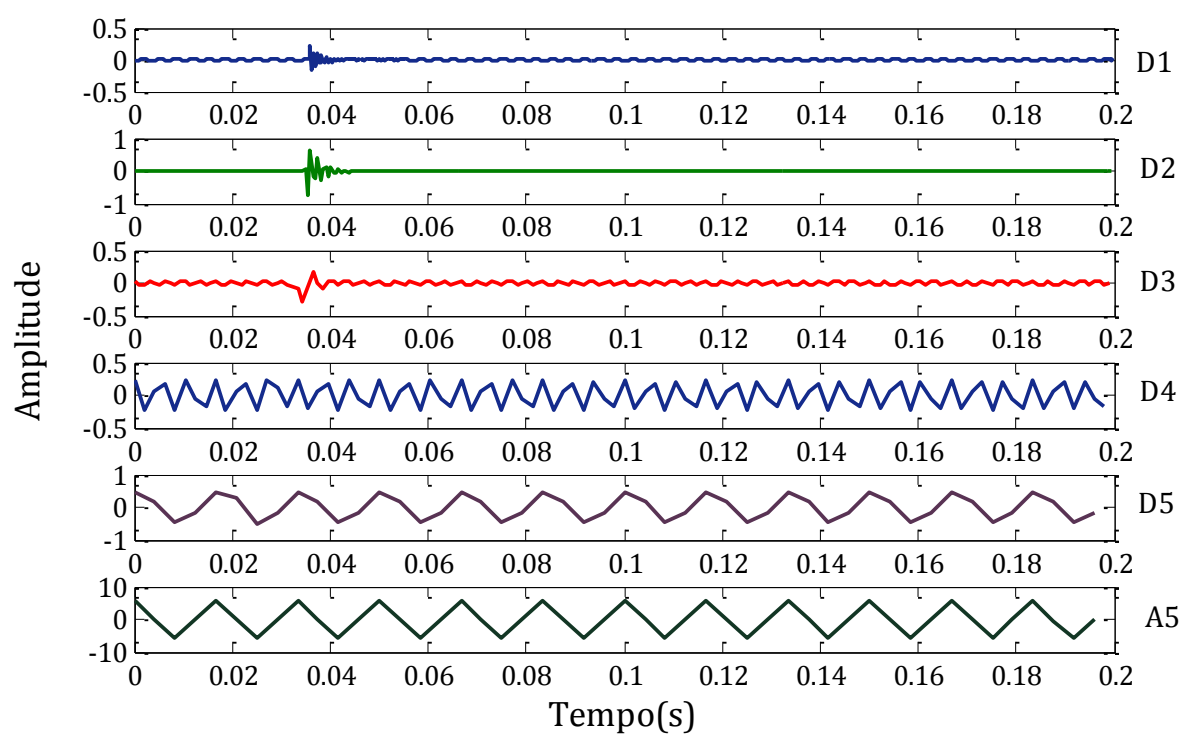

Figura 5.28. Transformada wavelet aplicada em um sinal com harmônico e transitório oscilatório.

Dos sinais analisados anteriormente é possível abstrair algumas diferencias importantes em ralação as transformadas. Mesmo que as duas consigam localizar e identificar eventos de qualidade de energia, como observado nos casos prévios, observase a vantagem da transformada S. O analise de frequências independentes fornece informações locais diferenciáveis ao longo do espectro, com sinais melhor comportadas, sem variações abruptas que permitem uma melhor discriminação e quantificação do evento, proporcionando informação importante como magnitude, frequência e localização temporal. Neste sentido, os coeficientes da TWD respondem a um conjunto de frequências, pelo qual dificulta a quantização tanto da frequências especificas como das amplitudes, isto leva a obter características extraindo informação dos coeficientes como energia ou fazendo uso de métodos estatísticos. 


\subsection{Sistema Classificador}

O sistema classificador de distúrbios de qualidade de energia compreende a etapa final do trabalho. Para definir o classificador a se usar, partiu-se da análise das transformadas $S$ e wavelet em relação às informações que estas foram capazes de fornecer, com o intuito de gerar um sistema de classificação simples, com alto desempenho e de fácil expansão ou escalabilidade. Como definido na seção anterior, a transformada $S$ mostrou um melhor comportamento na separação dos atributos que diferenciam cada distúrbio, portanto foi escolhida como ferramenta para extração das características a serem levadas na toma de decisão do classificador.

Uma vez observada a capacidade da transformada $\mathrm{S}$ em decompor um sinal em função do tempo e da frequência, é projetado um algoritmo classificador que mapeia a matriz de saída da transformada, convertendo essas características em dados pontuais que definirão os parâmetros quantizáveis para a toma de decisão definindo a existência de determinado distúrbio e localizando-o na sua respectiva classe.. Para isto, o mapeamento da matriz pode ser resumida em zonas, a primeira zona definida pelos distúrbios que estão inteiramente ligados a variações na componente fundamental (afundamento, elevação e interrupção) separando-os dos distúrbios cujas características estão ligadas ao espectro de frequências (transitórios oscilatórios e harmônicos) os quais serão abrangidos na segunda zona, por último, a zona três corresponde á maior frequência, encarregada de determinar a presencia de notch, devido a que a presença deste tipo de evento é diferençável mais facilmente nessa frequência como visto na seção anterior. Para cada zona é estabelecido um marcador que será acionado quando seja identificada a presença de um distúrbio. A identificação e ativação de vários destes marcadores independentes indicarão a presença de múltiplos distúrbios no sinal sob análise. Para uma melhor visualização do processo de classificação, na Figura 5.29 é mostrado um fluxograma que define cada um dos passos levados em consideração e os valores limites considerados como limiares para a classificação dos distúrbios, sendo A a amplitude, $\overline{\mathbf{A}}$ a media das amplitudes do vetor no tempo e $\boldsymbol{\sigma}$ o desvio padrão do vetor no tempo na máxima frequência.

0 algoritmo consta das seguintes etapas: 
Etapa1: uma vez a transformada S é aplicada no sinal com distúrbio, fazendo uso de (5.2) são encontrados o número de componentes em frequência mediante um algoritmo identificador de picos, onde cada pico representa uma frequência específica dominante, portanto cada valor e posição do pico e armazenada para se tratar na segunda etapa. É assim como se pode encontrar o pico que determina a frequência fundamental, em todos os casos, e picos que determinam harmônicos e/ou transitórios, dependendo da sua existência. Cabe ressaltar que algoritmo identificador de picos projetou-se baseado no conceito da derivada. Neste contexto, distúrbios como afundamentos, elevações e interrupções que são característicos da componente fundamental, o numero de picos é um. No caso de harmônicos e transitórios oscilatórios, o numero de picos será maior do que um.

Etapa 2: conhecendo os parâmetros de posição e amplitude de cada um dos picos obtidos na etapa 1 , nesta etapa, será observado seu comportamento ao longo do eixo do tempo fazendo uso de (5.3) determinando variações na amplitude. Estas variações positivas ou negativas na amplitude da componente fundamental definirão a presença de afundamentos, elevações ou interrupções. Nos picos subseqüentes ao fundamental, dado que é conhecendo o valor máximo da amplitude nessa frequência especifica, é analisado se o valor dessa magnitude se mantém constante ao longo do tempo, como é característico no caso de harmônicos, ou apresenta variações rápidas como acontece no caso de transitórios.

Etapa 3: notches devem ser analisados como um caso aparte dos anteriores. Os notches são identificados na frequência mais alta fazendo uso de (5.3),

Assim, quando definidas as três etapas anteriores, deve-se levar em conta que a identificação de um distúrbio dado, ativa um marcador representativo de cada zona de análise. São definidos quatro marcadores diferentes assim:

Marcador 1: se ativa quando há presencia de distúrbios na componente fundamental. No caso de interrupção o marcador $1=1$, para afundamento o marcador $1=2$ e para elevação o marcador1=3, caso não houver distúrbio marcador1=0.

Marcador 2: este marcador será definido exclusivamente para harmônicos. Dado o caso da existência de harmônicos o marcador2 será igual a um (marcador2=1), caso contrario será zero. 


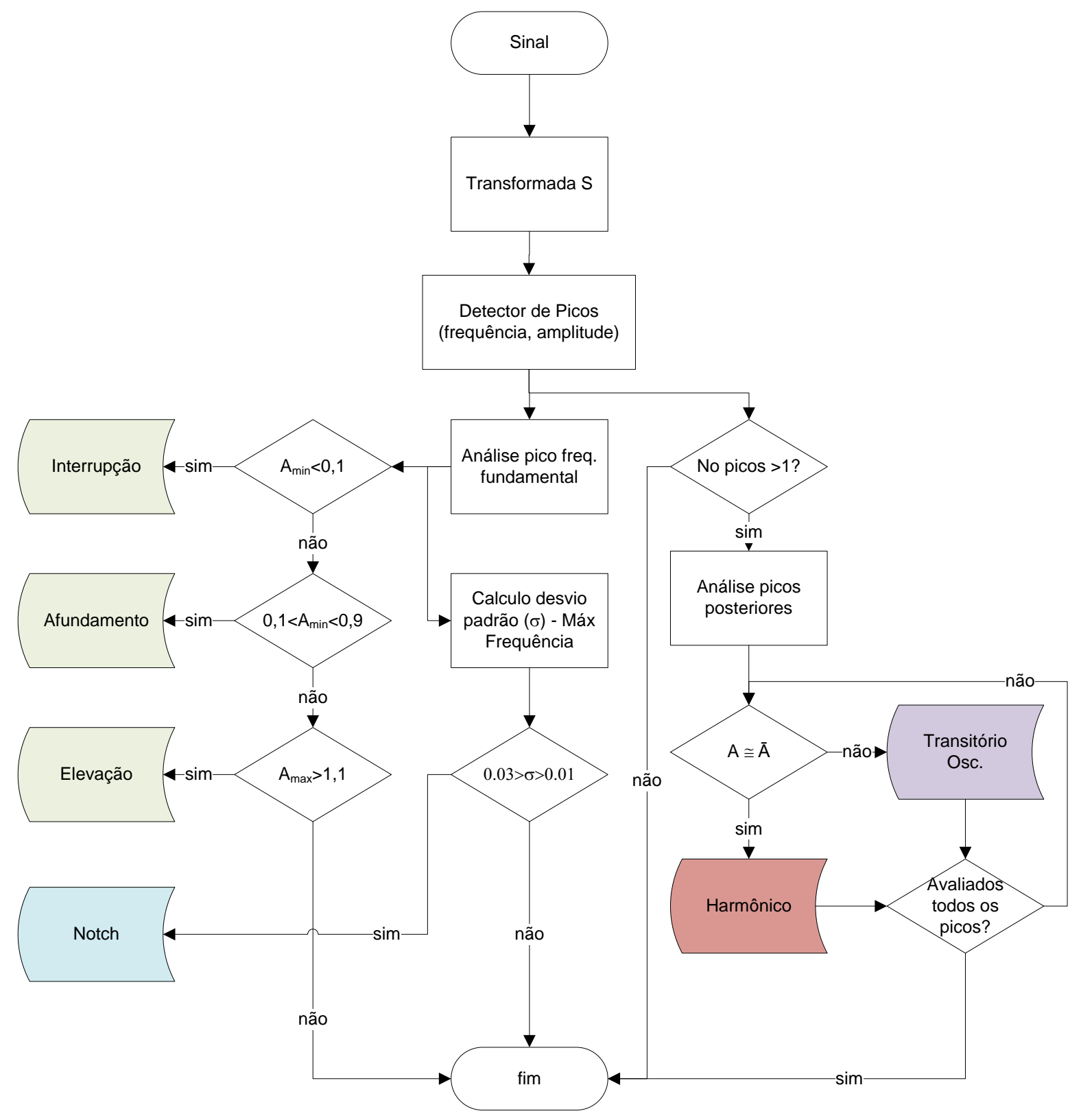

Figura 5.29. Fluxograma do sistema classificador.

Marcador 3: este marcador irá definir a existência de transitórios oscilatórios, sendo que sua ativação fará com que marcador3=1 no caso de houver, e marcador3=0 caso contrario.

Os marcadores 2 e 3 pertencem a zona 2, no entanto são separados devido á possibilidade de ambos distúrbios se encontrar no sinal. 
Marcador 4: utilizado para definir a presença de notch e esta diretamente relacionado ao valor do desvio padrão na máxima freqüência como se observa no fluxograma do classificador (Figura 5.29)

Devido à individualidade dos marcadores, a ativação de mais de um deles determinará a existência de vários distúrbios no sinal, por exemplo, se o marcador1=2 e marcador2=1 então, é possível determinar que o sinal apresente afundamento com conteúdo harmônico. Agora, como mencionado na etapa 1, os valores de amplitude e frequência armazenados fornecem informação adicional da localização específica do evento dado o caso de houver mais de um componente harmônico.

Para validação do método foram apresentados ao classificador 280 casos para cada uma das cinco classes que envolvem harmônicos e 200 casos para as outras dez classes analisando um total de 3400 sinais. Os resultados obtidos são mostrados na Figura 5.4, indicando na primeira coluna o numero total de distúrbios para cada classe, nas colunas seguintes são expressados o numero de acertos e desacertos, identificando também o distúrbio pelo que foi erroneamente classificado, na última coluna é mostrada a taxa de acerto obtida.

A pesar de o classificador ter mostrado taxas de acerto elevadas, no caso de interrupção a taxa de acerto foi baixa, isto devido a que para tempos de duração curtos (menor a dois ciclos) a TS não consegue chegar ao umbral especificado determinando dito evento como afundamento.

Como ponto importante, deve-se destacar que o classificador, sendo simples, em combinação com a TS conseguiu uma taxa de acerto elevada mostrando que não é necessário o uso de classificadores complexos e, que além de ser simples, apresenta características como fácil expansão (escalabilidade) para tratar novos distúrbios por meio da adição de novas regras, e uma grande capacidade de quantificar distúrbios. 


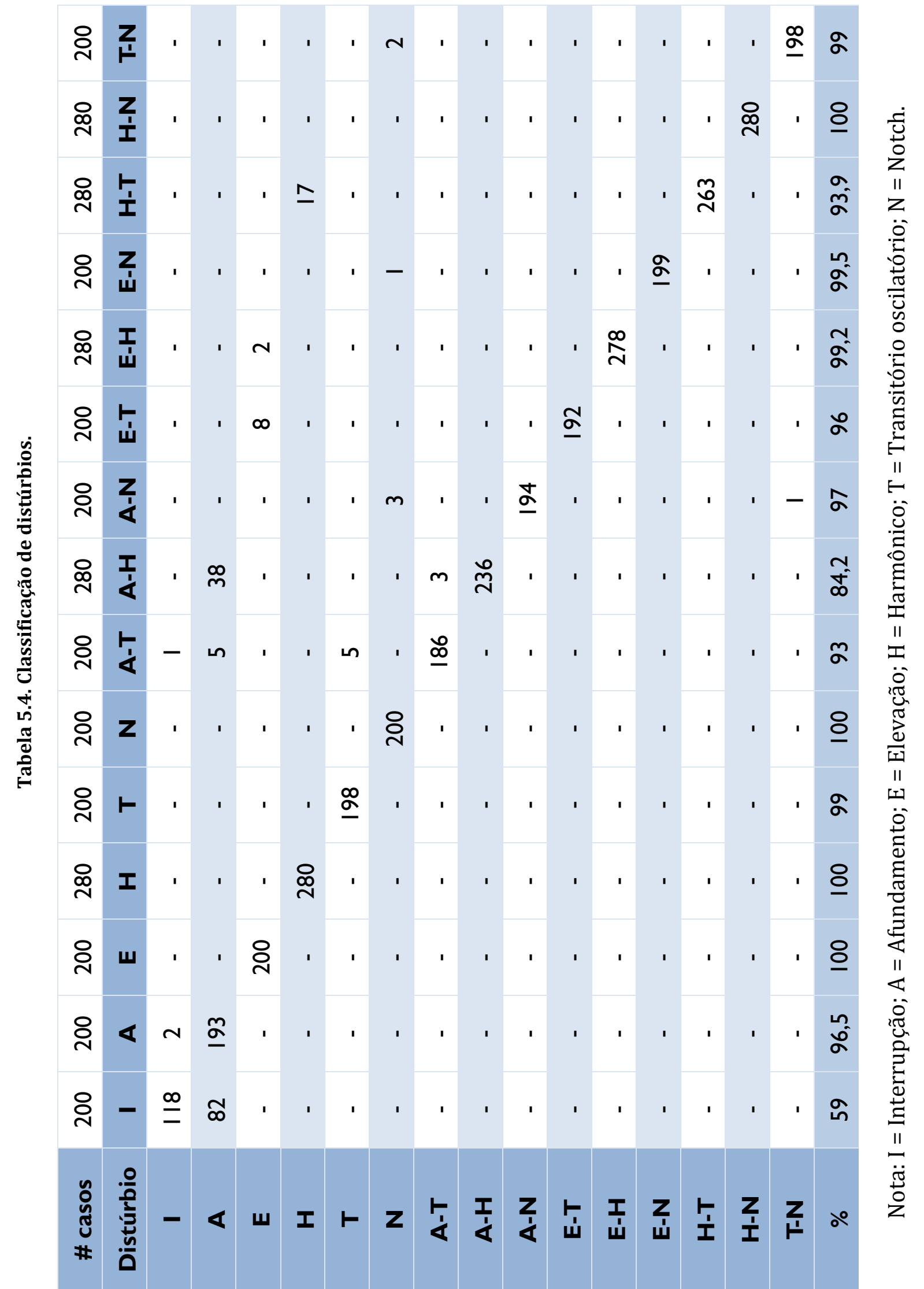




\subsection{Considerações finais}

No decorrer deste capitulo, foi visto o método utilizado para a geração de distúrbios através de equações paramétricas. Após a geração dos distúrbios utilizou-se as ferramentas de análise transformada wavelet e S. desta forma observou-se que as transformadas fornecem informações e características distintas para cada sinal. Por fim, mostrou-se o sistema classificador de distúrbios por meio de regras de decisão. 


\section{Capitulo 6}

\section{Conclusões}

O presente trabalho apresentou uma comparação de duas técnicas para a análise tempo - frequência projetado a QEE para sinais de tensão que contem um o mais distúrbios. 0 objetivo é encontrar uma ferramenta completa que forneça características e parâmetros chaves para a localização, identificação e classificação de distúrbios. As ferramentas utilizadas foram à transformada wavelet discreta e a transformada-S discreta, as quais foram testadas com diferentes tipos de distúrbios individuais e múltiplos para estudar seu desempenho. Os diferentes distúrbios foram obtidos através de equações paramétricas que permitem gerar sinais de QEE de forma controlada, mediante variação de parâmetros como amplitude, tempo de duração e frequência, obtendo quinze tipos de distúrbios, dos quais correspondem a seis tipos de distúrbios individuais: afundamentos, elevação e interrupção de tensão, transitórios oscilatórios, harmônicos e notches e combinações entre estes como afundamentos com notch, elevação com harmônicos etc.

Como resultados obtidos, as duas ferramentas, tanto a TWD como a TS apresentaram resultados satisfatórios na identificação e localização dos eventos, tanto na analise individual de cada distúrbio, como quando vários distúrbios interagem na mesma janela sob analise. No entanto ressaltam diferenças significativas entre as duas transformadas. 
A TWD proporciona detalhes que oferecem informação valiosa na localização temporal, no entanto a informação é insuficiente para determinar frequências especificas e magnitudes particulares ou característicos dos sinais, sem dizer, que não seja uma ferramenta útil na maioria das aplicações focadas a QEE, esta precisa do acompanhamento de outras técnicas para conseguir obter um desempenho satisfatório. Por outra parte a TS apresenta um melhor desempenho do que a TW, sendo que fornece um número maior de parâmetros tais como a amplitude do distúrbio, localização temporal, espectro de frequência e em si uma melhor caracterização de sinais.

Como sistema classificador se escolheu um sistema simples baseado em regras de decisão que aproveita a grande quantidade de informação suprida pela transformada S para classificar um total de quinze tipos de distúrbios diferentes, tanto individuais como compostos.

Algumas sugestões para trabalhos futuros são:

- Estudar e aplicar diferentes classificadores com o intuito de obter maiores percentuais de acerto na classificação.

- Aplicar os métodos utilizados neste trabalho usando banco de dados reais.

- Desenvolver um software para análise de QEE utilizando os métodos desenvolvidos no trabalho. 


\section{Referências Bibliográficas}

ABDEL-GALIL, T. K.; EL-SAADANY, E. F.; YOUSSEF, A. M.; SALAMA, M. M. A. Disturbance classification using Hidden Markov Models and vector quantization. IEEE Transactions on Power Delivery, v.20, n.3, p.2129-2135. 2005.

ADDISON, P. S. The Illustrated Wavelet Transform Handbook: Introductory theory and applications in science, engineering, medicine and finance. London: Institute of Physics Publishing Bristol and Philadelphia. 2002. 353 p.

ADDISON, P. S.; WALKER, J.; GUIDO, R. C. Time-frequency analysis of biosignals. IEEE Engineering in Medicine and Biology Magazine, v.28, n.5, p.14-29. 2009.

ANEEL. Procedimentos de Distribuição de Energia Elétrica no Sistema Elétrico Nacional. PRODIST. Modulo 8 - Qualidade de Energia Elétrica 2009.

BEHERA, H. S.; DASH, P. K.; BISWAL, B. Power quality time series data mining using Stransform and fuzzy expert system. Applied Soft Computing, v.10, n.3, p.945-955. 2009.

BHENDE, C. N.; MISHRA, S.; PANIGRAHI, B. K. Detection and classification of power quality disturbances using S-transform and modular neural network. Electric Power Systems Research, v.78, n.1, p.122-128. 2008.

BROSLN, A. Monitoring power quality beyond EN 50160 and IEC 61000-4-30. 9th International Conference on Electrical Power Quality and Utilisation, EPQU 2007. . 9-11 Oct. 2007, 2007. 1-6 p.

CHILUKURI, M. V.; DASH, P. K. Multiresolution S-transform-based fuzzy recognition system for power quality events. IEEE Transactions on Power Delivery, v.19, n.1, p.323-330. 2004.

CHUI, C. K. An Introduction to Wavelets. Boston: Academic Press. 1992. 264 p.

DASH, P. K.; PANIGRAHI, B. K.; PANDA, G. Power quality analysis using S-transform. IEEE Transactions on Power Delivery v.18, n.2, p.406-411. 2003.

DEBANATH, L. Wavelet Transform and Their Applications. Boston: Birkhäuser. 2002. $575 \mathrm{p}$. 
DUGAN, R. C.; MC GRANAGHAM, M. F.; SANTOSO, S.; BEATY, H. W. Electrical Power Systems Quality. New York: Mc Graw - Hill. 2002. 521 p.

DUQUE, C. A.; RIBEIRO, M. V.; RAMOS, F. R.; SZCZUPAK, J. Power quality event detection based on the divide and conquer principle and innovation concept. IEEE Transactions on Power Delivery, v.20, n.4, p.2361-2369. 2005.

FENGZHAN, Z.; RENGANG, Y. Power quality disturbance recognition using S-transform. IEEE Transactions on Power Delivery v.22, n.2, p.944-950. 2007.

GARGOOM, A. M.; ERTUGRUL, N.; SOONG, W. L. Automatic classification and characterization of power quality events. IEEE Transactions on Power Delivery v.23, n.4, p.2417-2425. 2008.

GRANADOS, L. D.; ROMERO, R. J.; OSORNIO, R. A.; GARCIA, P. A.; CABAL, Y. E. Techniques and methodologies for power quality analysis and disturbances classification in power systems: a review. IET Generation, Transmission \& Distribution, v.5, n.4, p.519-529. 2011.

IEEE Recommended Practice for Monitoring Electric Power Quality. IEEE Std 11591995: i p. 1995.

IEEE Recommended Practice for Monitoring Electric Power Quality. IEEE Std 11592009 (Revision of IEEE Std 1159-1995): c1-81 p. 2009.

IEEE Recommended Practices and Requirements for Harmonic Control in Electrical Power Systems. IEEE Std 519-1992: 0_1 p. 1993.

JANIK, P.; LOBOS, T. Automated classification of power-quality disturbances using SVM and RBF networks. IEEE Transactions on Power Delivery, v.21, n.3, p.1663-1669. 2006.

JENSEN, A.; LA COUR-HARBO, A. Ripples in mathematics: the discrete wavelet transform: Springer-Verlang Berlin Heidelberg. 2001. 246 p.

MASOUM, M. A. S.; JAMALI, S.; GHAFFARZADEH, N. Detection and classification of power quality disturbances using discrete wavelet transform and wavelet networks. IET Science, Measurement \& Technology, v.4, n.4, p.193-205. 2010.

OLESKOVICZ, M.; COURY, D. V.; FELHO, O. D.; USIDA, W. F.; CARNEIRO, A. A. F. M.; PIRES, L. R. S. Power quality analysis applying a hybrid methodology with wavelet transforms and neural networks. International Journal of Electrical Power and Energy Systems, v.31, n.5, p.206-212. 2009.

PANIGRAHI, B. K.; PANDI, V. R. Optimal feature selection for classification of power quality disturbances using wavelet packet-based fuzzy k-nearest neighbour algorithm. IET Generation, Transmission \& Distribution, v.3, n.3, p.296-306. 2009. 
POZZEBON, G. G.; PEÑA, G. G.; GONÇALVES, A. F. Q.; MACHADO, R. Q. Neural classification of power quality disturbances: An application of the wavelet transform and principal component analysis. 9th IEEE/IAS International Conference on Industry Applications (INDUSCON). 8-10 Nov., 2010. 1-6 p.

REAZ, M. B. I.; CHOONG, F.; SULAIMAN, M. S.; MOHD-YASIN, F.; KAMADA, M. Expert system for power quality disturbance classifier. IEEE Transactions on Power Delivery, v.22, n.3, p.1979-1988. 2007.

RIBEIRO, P. F. Wavelet Transform: an advanced tool for analyzing non-stationary harmonic distortion in power systems. IEEE International Conference on Harmonics in Power Systems, ICHPS IV. Bologna, Italy. september 21-23, 1994. 365-369 p.

ROBERTSON, D. C.; CAMPS, O. I.; MAYER, J. S.; GISH, W. B. Wavelets and electromagnetic power system transients. IEEE Transactions on Power Delivery, v.11, n.2, p.10501058. 1996.

SANTOSO, S.; POWERS, E. J.; GRADY, W. M.; HOFMANN, P. Power quality assessment via wavelet transform analysis. IEEE Transactions on Power Delivery v.11, n.2, p.924930. 1996.

SANTOSO, S.; POWERS, E. J.; GRADY, W. M.; PARSONS, A. C. Power quality disturbance waveform recognition using wavelet-based neural classifier. I. Theoretical foundation. IEEE Transactions on Power Delivery, v.15, n.1, p.222-228. 2000a.

Power quality disturbance waveform recognition using wavelet-based neural classifier. II. Application. IEEE Transactions on Power Delivery, v.15, n.1, p.229-235. 2000b.

STOCKWELL, R. G. S-Transform Analysis of Gravity Wave Activity From a Small Scale Network of Airlog Imagers. Physics, University of Western Ontario, Ontario, London, 1999. 366 p.

STOCKWELL, R. G.; MANSINHA, L.; LOWE, R. P. Localization of the complex spectrum: the S transform. IEEE Transactions on Signal Processing, v.44, n.4, p.998-1001. 1996.

VENTOSA, S.; SIMON, C.; SCHIMMEL, M.; DANOBEITIA, J. J.; MANUEL, A. The Stransform from a wavelet point of view. IEEE Transactions on Signal Processing, v.56, n.7, p.2771-2780. 2008.

VETTERLI, M.; HERLEY, C. Wavelets and filter banks: theory and design. IEEE Transactions on Signal Processing, v.40, n.9, p.2207-2232. 1992. 